\title{
L'UTILISATION DE LA POMME DE TERRE POUR L'ALIMENTATION DES ANIMAUX DOMESTIQUES
}

PAR

\author{
A. M. LEROY, S. ZELTER et R. FEVRIER
}

Laboratoire de Zootechnie de l'Institut national agronomique et Station expérimentale de Bois-Corbon

\section{PLAN DU MÉMOIRE}

\section{Introduction}

Généralités, par A. M. LEROY et S. ZEL'TER

Étude chimique de la Pomme de Terre.

Digestibilité et valeur nutritive.

Recherches sur la conservation, par A. M. LEROY et S. ZEITER

Influence du traitement sur la qualité de l'ensilage.

Conservation comparée d'ensilages.

Recherches sur l'emploi de la pomme de terre comme aliment du bétail

Expériences sur porcins, par A.-M. LEROY, S. ZELTER et R. FÉvrIER.

Expériences sur ovins i par A.-M. LEROY

Expériences sur bovins $($ et S. ZeLTER

Conclusions

(vaches laitières)

\section{Bibliographie}

\section{INTRODUCTION}

La récolte annuelle de pommes de terre représente actuellement en France près de I 800 ooo tonnes. L'utilisation d'une masse aussi élevée de produits pose des problèmes de solution délicate. D'où l'importance particulière que revêt, pour notre Economie agricole, l'emploi massif de la pomme de terre pour l'alimentation animale. 
La généralisation d'une telle pratique pourrait entraîner :

I Une résorption facile des stocks excédentaires qui contribuent à l'alourdissement du marché de ce tubercule ;

$2^{\circ}$ une réduction de nos besoins en aliments du bétail d'importation, qui allègerait ainsi notre balance commerciale ;

$3^{\circ}$ un abaissement sensible du côtt de nos productions animales et une meilleure valorisation de la pomme de terre ainsi transformée.

Le problème, on le conçoit, est d'envergure et l'on comprend aisément la raison pour laquelle nous avons entrepris de lui trouver des solutions appropriées.

\section{I. - GÉNÉRALITÉS}

\section{Par A. M. LEROY et S. ZELTER}

\section{Etude chimique de la pomme de terre}

Le tubercule de pomme de terre est essentiellement constitué par une masse parenchymateuse dont les cellules sont gorgées de grains d'un amidon désigné sous le nom de fécule. Sa composition chimique moyenne oscille dans des limites très étroites, comme le démontrent les données de nombreux auteurs.

Composition centésimale de la pomme de terre d'après :

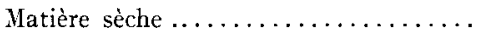

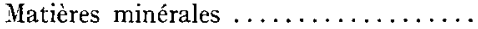

Matières cellulosiques .............

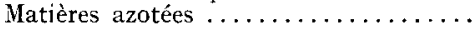

Matières grasses..................

Extractifs non azotés...............

$\begin{array}{rcc}\text { Pott (I) } & \text { Schermann (2) } & \text { Randoin (3) } \\ 25,0 & - & - \\ 0,9 & 2 \mathrm{I}-25 & 23,0 \\ 0,8 & 1,0 & 1,0 \\ 2,1 & 1,0 & 1,0 \\ 0,2 & 2-2,5 & 2,0 \\ 2 \text { I, } & -18-2 & 0,1 \\ & 10,0 & 20\end{array}$

D'une variété à l'autre, cependant, les différences sont notables (Gours (4)) et portent essentiellement sur la richesse en fécule et en matières azotées Selon Potr ( I), les teneurs en fécule peuvent osciller entre I 6 et $29 \%$. Les déchets de triage des variétés utilisées lors de certaines de nos expériences, et provenant de la récolte de 1948 , montrent également des variations importantes dans leurs teneurs en matière sèche et en fécule :

\begin{tabular}{|c|c|c|c|}
\hline Variété & Bintje & Flava & Ackersegen \\
\hline tière sèche $\% \ldots \ldots \ldots \ldots \ldots \ldots$ & 21,45 & 26,65 & 24,12 \\
\hline$\ldots \ldots \ldots \ldots \ldots$ & I 5,55 & 20,36 & I 7,87 \\
\hline
\end{tabular}

I ${ }^{\circ}$ Les matières azotées. - L'azote amidé prédomine dans la pomme de terre (RITHAUSEn et Osborne (5)) ; il se rencontre essentiellement sous forme d'asparagine (Schulze (6)). La Tubérine, protéine caractéristique du tubercule, renferme quelques acides aminés essentiels. Son taux varierait de 43,9 à $58,3 \%$ selon KELLNER (7) et de 43,2 à $64,6 \%$ d'après Morgen (8). JACQUOT (9) constate des variations allant de 29 à $5 \mathrm{I} \%$.

JACQUOT et ARMAND (IO) trouvent que dans la tubérine, l'azote aminé représente $75,8 \%$ de son azote total et se répartit comme voici : 
$\mathrm{N}$ des acides aminés dont :

Tryptophane, tyrosine, leucine, proline, etc............

$\mathrm{N}$ des acides diaminés dont :

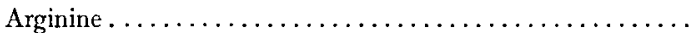

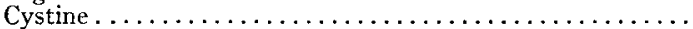

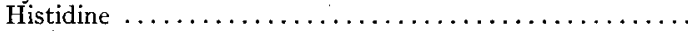

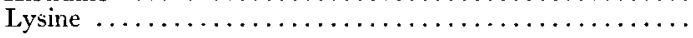

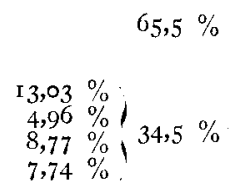
$65,5 \%$

Pour roo g de tubérine, on trouve, selon ces auteurs : 5,2 d'arginine, 5,4 de cystine, 4,I d'histidine et 4,7 de lysine. On relève un léger désaccord entre ces données et celles avancées par JoNES et NÉLSON (II).

Malgré son taux relativement faible, l'azote protéique de la pomme de terre possède une valeur biologique élevée et présente un grand intérêt alimentaire. En effet, de nombreux auteurs cités par TERROINE (I2) reconnaissent une grande efficacité biologique à ces matières protéiques, principalement pour l'entretien. Pour 'Tномas (I3), cette efficacité s'apparente plutôt à celle des protéines animales qu'à celle des protéines végétales et se classe immédiatement après celle de la caséine. JACQUOT et ARMAND (Io) concluent, eux aussi, que l'azote protéique de la pomme de terre possède, pour la croissance et l'entretien du rat, une utilisation digestive et une efficacité rappelant celles de la caséine.

$2^{\circ}$ Les matières grasses. - La pomme de terre contient des quantités négligeables de matières grasses de peu de valeur nutritive. L'extrait éthéré ne contient, selon StelwaAG (I4), que I6,33\% de lipides vrais, dont 56,92\% sont des acides gras et 3,07 \% des lécithines.

$3^{\circ}$ Les extractifs non azotés. - Ils sont essentiellement constitués par de l'amidon, dont la saccharification par les diastases, la ptyaline et la pancréatine est plus facile que celle des amidons des céréales (WInTHROP et EsTONE (I5)). D'après GRIMm (I6), le pouvoir de gonflement de cet amidon dépasserait nettement ceux du manioc et des céréales.

A côté de l'amidon, on rencontre également de petites quantités de sucres $(2,2 \%)$ et de pentosanes $(0,67 \%)$ selon Forfang (I 7$)$. MunTz (I8) signale également la présence de pectines $(0,6 \%)$, de gommes $(0,8 \%)$; tanđis que d'autres auteurs ont trouvé des acides oxalique, lactique et citrique.

$4^{\circ}$ Les éléments minéraux. - La pomme de terre est caractérisée par des teneurs très élevées en $\mathrm{P}$ et surtout en $\mathrm{K}$, et faibles en Ca. Selon RaNdoin, IE Gali IC et Causerér (3), on trouve : 4,5\% de $\mathrm{K}$ contre $0,20 \%$ de $\mathrm{Na}$ seulement, et $0,60 \%$ de $\mathrm{P}$ contre $0,15 \%$ de $\mathrm{Ca}$. Nos propres dosages ont également montré la pauvreté du tubercule en ces éléments, dont les proportions relatives sont considérées généralement comme défectueuses.

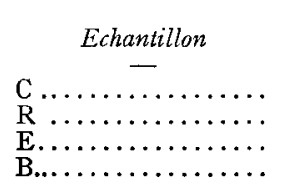

$\begin{array}{cc}\begin{array}{c}\text { Phosphore } \\ \text { Matière } \\ \text { brute }\end{array} & \begin{array}{c}\text { Matière } \\ \text { sèche }\end{array} \\ \overline{0} & - \\ 0,67 & 2,95 \\ 0,85 & 3,39 \\ 0,76 & 2,98 \\ 0,55 & 2,44\end{array}$

\begin{tabular}{|c|c|}
\hline Calcium & $g r \%$ \\
\hline $\begin{array}{c}\text { Matière } \\
\text { brute }\end{array}$ & $\begin{array}{c}\text { Matière } \\
\text { sèche }\end{array}$ \\
\hline - & - \\
\hline 0,31 & 1,38 \\
\hline 0,39 & $r, 56$ \\
\hline 0,57 & 2,22 \\
\hline $0,3 \mathbf{I}$ & $\mathrm{I}, 4 \mathrm{I}$ \\
\hline
\end{tabular}

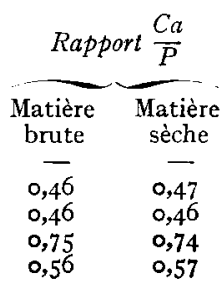


Parmi les oligo-éléments, on peut noter la présence de fer (Io mg par $\mathrm{kg}$ ) ainsi que des traces de manganèse et d'iode.

$5^{\circ}$ Les vitamines. - Très riche en vitamine C (I40 $\mathrm{mg}$ par $\mathrm{kg}$ ) contenant un peu de PP (25 mg), la pomme de terre est totalement privée de carotène et ne possède que des traces de $B_{1}$ et de $B_{2}$. La cuisson détruit ces vitamines à l'exception de la vitamine $\mathrm{C}$, qui ne disparaît que dans la proportion de $50 \%$. (RANdoin, LE Galitic et Causeret (3)).

$6^{\circ}$ Les principes toxiques. - En I82I, DESFOSSES a découvert dans la pomme de terre, un glucoside - la solanine - à laquelle HILGER a attribué la formule $\mathrm{C}_{43} \mathrm{H}_{71} \mathrm{NO}_{16}$. Sa répartition dans la masse est inégale ; on en trouve $0,36 \%$ dans les épluchures et $0,24 \%$ dans la masse charnue, d'après HaNT et Huzemann (I9). Selon Maxer (20) cependant, le taux de cette substance est bien plus élevé dans le germe, où il peut atteindre $0,5 \%$.

Les troubles provoqués chez l'animal par l'ingestion de solanine sont très graves et peuvent entraîner des accidents mortels. Le dégermage et la cuisson prolongée permettent d'éliminer la majeure partie de la solanine, particulièrement abondante dans les tubercules germés ou insuffisamment mûrs.

\section{Digestibilité et valeur nutritive de la pomme de terre}

De nombreuses recherches ont porté sur la digestibilité des éléments nutritifs de la pomme de terre. WOLF (2I) a déterminé les coefficients de digestibilité suivants :

Coefficients de digestibilité \%:

\begin{tabular}{|c|c|c|c|}
\hline & $\begin{array}{l}\text { Matières } \\
\text { azotées }\end{array}$ & $\begin{array}{c}\text { Graisses } \\
\text { brutes }\end{array}$ & $\begin{array}{l}\text { Extractifs } \\
\text { non azotés }\end{array}$ \\
\hline & - & - & - \\
\hline 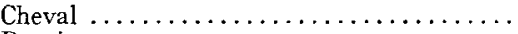 & 88 & $\ldots$ & 99,4 \\
\hline 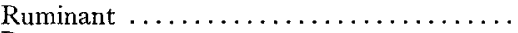 & $6 \mathrm{I}$ & - & 90 \\
\hline 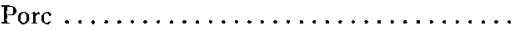 & 77 & 29,8 & 98,5 \\
\hline
\end{tabular}

VorTz et DIETrich (22), en comparant la digestibilité des tubercules crus et cuits, obtiennent avec des moutons, les résultats suivants :

\begin{tabular}{|c|c|c|c|}
\hline & $\begin{array}{c}\text { Matières } \\
\text { organiques }\end{array}$ & $\begin{array}{l}\text { Matières } \\
\text { azotées } \\
\text { - }\end{array}$ & $\begin{array}{c}\text { Extractifs } \\
\text { non azotés } \\
\end{array}$ \\
\hline & 84 & 44 & 95 \\
\hline & 80 & 59 & 96. \\
\hline $\begin{array}{l}\text { Pommes de terre crues } \ldots \ldots \ldots \ldots \ldots \ldots \ldots \\
\text { Pommes de terre cuites } \ldots \ldots \ldots \ldots \ldots \ldots\end{array}$ & $88, \mathbf{r}$ & 67,8 & 94,2 \\
\hline
\end{tabular}

WATson et MorTon (23), chez la même espèce, obtiennent, avec des tubercules cuits, des valeurs un peu différentes $88,1,67,8,94,2$.

Les travaux de BolimanN (24) offrent un intérêt particulier parce qu'ils portent à la fois sur des pommes de terre crues, des pommes de terre cuites, et des pommes de terre ensilées après cuisson : Ils ont été effectués sur porcs, sur vaches et sur bœufs. Les résultats obtenus sont les suivants : 


\begin{tabular}{|c|c|c|c|c|c|c|c|c|c|}
\hline & \multicolumn{3}{|c|}{ Pommes de terre crues } & \multicolumn{3}{|c|}{ Pommes de terre cuites } & \multicolumn{3}{|c|}{$\begin{array}{l}\text { Pommes de terre } \\
\text { ensilées après cuisson }\end{array}$} \\
\hline & $\begin{array}{l}\text { Mat. } \\
\text { org. }\end{array}$ & $\begin{array}{l}\text { Mat. } \\
\text { azotées }\end{array}$ & $\begin{array}{c}\text { Extra } \\
\text { non } \\
\text { azotés }\end{array}$ & $\begin{array}{l}\text { Mat. } \\
\text { org. }\end{array}$ & $\begin{array}{l}\text { Mat. } \\
\text { azotées }\end{array}$ & $\begin{array}{l}\text { Extra } \\
\text { non } \\
\text { azotés }\end{array}$ & $\begin{array}{l}\text { Mat. } \\
\text { org. }\end{array}$ & $\begin{array}{c}\text { Mat. } \\
\text { azotćes }\end{array}$ & $\begin{array}{c}\text { Extra } \\
\text { non } \\
\text { azotés }\end{array}$ \\
\hline $\begin{array}{l}\text { Porc } \ldots \ldots \ldots \ldots \\
\text { Mouton } \\
\text { Varhe laitière } \ldots \\
\text { Boeuf } \quad \ldots \ldots \ldots \ldots\end{array}$ & $\begin{array}{l}93,2 \\
79,2 \\
70,0 \\
7 \mathrm{I}, 7\end{array}$ & $\begin{array}{r}37, \mathrm{I} \\
22,2 \\
34,0 \\
7,9\end{array}$ & $\begin{array}{l}98,2 \\
85,4 \\
74,5 \\
78,5\end{array}$ & $\begin{array}{l}98,6 \\
80,6 \\
76,2 \\
66,5\end{array}$ & $\begin{array}{r}72,7 \\
-31,9 \\
-10,0 \\
-24,6\end{array}$ & $\begin{array}{c}\text { Ioo } \\
87,5 \\
86,3 \\
76,9\end{array}$ & $\begin{array}{l}95,4 \\
85,3 \\
74,2 \\
73,7\end{array}$ & $\begin{array}{r}67,0 \\
35,2 \\
2,9 \\
-22,1\end{array}$ & $\begin{array}{l}97 ; 5 \\
9 \mathrm{I}, 5 \\
83,7 \\
82,7\end{array}$ \\
\hline
\end{tabular}

D'après ces travaux, il semble que la digestibilité des extractifs non azotés de la pomme de terre soit particulièrement élevée. Les résultats concernant les matières azotées sont d'interprétation plus délicate. La cuisson améliorerait la digestibilité pour toutes les espèces animales, et le porc parait être le meilleur utilisateur. L'interprétation des résultats observés au cours d'expériences avec ruminants est délicate, car il s'agit d'un aliment que ces animaux ne peuvent consommer isolément, de telle sorte que les données publiées ont toujours été obtenues par la méthode par différence.

Le calcul de la valeur énergétique de la pomme de terre, à partir de sa composition chimique et de la digestibilité de ses constituants, est relativement aisé. Les tables d'alimentation humaine évaluent l'énergie brute du $\mathrm{kg}$ de pommes de terre à 820-89o calories.

Pour l'alimentation animale, l'on indique que la valeur fourragère de I $\mathrm{kg}$ est comprise entre 0,20 et $0,25 \mathrm{U}$. F.

Les effets constatés lors de l'emploi de ce tubercule sont néanmoins extrêmement variés. Les déficiences azotées, minérales, vitaminiques appellent l'emploi d'aliment complémentaire dont l'absence ou l'insuffisance se traduit par une très mauvaise utilisation des éléments qui leur sont associés.

L'emploi de la pomme dej̣ terre pour l'alimentation du bétail pose le problème de la conservation. C'est celui qui, tout d'abord a retenu notre attention.

\section{II. - RECHERCHES SUR LA CONSERVATION}

Par A. M. LEROY et S. ZELTER

On sait que la conservation des pommes de terre à l'état cru pose un problème délicat : les maladies cryptogamiques, la respiration cellulaire et la germination - source de solanine - provoquent des pertes importantes de substances et rendent très difficile une utilisation alimentaire prolongée au-delà du printemps. 
La cuisson journalière améliore 1'utilisation digestive, mais elle est onéreuse et ne résoud pas, pour autant, le problème de la conservation. Par contre, la cuisson suivie d'ensilage constitue une solution heureuse $\left.{ }^{(}{ }^{1}\right)$. Elle permet, en effet, une conservation très prolongée et une utilisation alimentaire continue. Cette technique ne supprime cependant pas entièrement les pertes, et le séjour en silo expose la masse de tubercules à des fermentations plus ou moins désirables. Son efficacité doit, par conséquent, être étudiée sous un aspect à la fois quantitatif et qualitatif. L'impossibilité matérielle dans laquelle nous nous sommes trouvés, pendant nos expériences, de chiffrer les pertes qu'entraîne cette technique, nous a amenés à n'envisager que l'étude de l'aspect qualitatif du problème de la conservation des pommes de terre conservées par ensilage après étuvage.

Nous avons adopté le dispositif expérimental suivant : les pommes de terre étaient cuites à la fin de l'automne, toujours avec le même matériel. La masse cuite, refroidie aux environs de $40^{\circ} \mathrm{C}$, était emmagasinée dans des silos rustiques (cases de porcherie désaffectées ou tranchées en terre), qui étaient aussitôt fermés hermétiquement par une couche de terre d'environ $20 \mathrm{~cm}$. Ils étaient ouverts 2 mois après, pour permettre l'alimentation des animaux. La durée de 1'utilisation s'échelonnait sur 4 mois environ (février à mai). Tous les I5 jours, on prélevait un échantillon d'ensilage destiné à un examen physico-chimique. Celui-ci comportait la détermination de la matière sèche, la mesure du $\mathrm{pH}$ et le dosage des acidités volatile et lactique à l'aide de la méthode de LEPPERT. Les données expérimentales que nous rapportons plus loin constituent des moyennes pondérées établies d'après les résultats observés sur 6 à 8 prélèvements consécutifs par silo.

\section{EXPERIENCE No I}

\section{INFLUENCE DU TRAITEMENT SUR LA QUALITE DE L'ENSILAGE DE POMMES DE TERRE ETUVEES}

Comme pour les autres ensilages, il était logique d'examiner l'utilité de traitements appropriés destinés à réduire les pertes, ainsi que l'influence de ces traitements sur la nature des fermentations et la qualité finale de l'aliment. Cette expérience a eu pour objet de comparer les effets du tassement, accompagnés ou non d'un traitement à l'acide formique ou d'un ensemencement lactique.

(1) Voir " La cuisson et l'ensilage de pommes de terre fourragères " publié en I950 par le Comité d'Études techniques de la pomme de terre. 
Résultats

TableaU I

Influences du traitement sur les fermentations

\begin{tabular}{|c|c|c|c|c|c|c|c|c|}
\hline \multirow{3}{*}{$\begin{array}{l}\text { Nature du } \\
\text { traitement } \\
\end{array}$} & \multirow{3}{*}{$\begin{array}{l}\text { No du } \\
\text { silo } \\
-\end{array}$} & \multirow{3}{*}{$\underline{\mathrm{pH}}$} & \multicolumn{4}{|c|}{$\begin{array}{l}\text { Acidité exprimée } \\
\text { en milliéquivalents \% }\end{array}$} & \multicolumn{2}{|c|}{$\begin{array}{l}\text { Acide } \\
\text { lactique } \\
\% \text { de Rapport }\end{array}$} \\
\hline & & & $\begin{array}{l}\text { Acide } \\
\text { acétique }\end{array}$ & $\begin{array}{l}\text { Acide } \\
\text { buty- } \\
\text { rique }\end{array}$ & $\begin{array}{l}\text { Acide } \\
\text { lactique }\end{array}$ & $\begin{array}{c}\text { Acidité } \\
\text { orga- } \\
\text { nique } \\
\text { totale }\end{array}$ & $\begin{array}{c}\text { l'acidité } \\
\text { orga- } \\
\text { nique } \\
\text { totale }\end{array}$ & $\begin{array}{c}\text { é acide } \\
\text { lactique } \\
\text { acides } \\
\text { volatils }\end{array}$ \\
\hline & & & - & - & $\overline{-1}$ & - & $\overrightarrow{-0}$ & - \\
\hline $\begin{array}{l}\text { Tassement ............ } \\
\text { Tassement ........ }\end{array}$ & $\begin{array}{l}\mathrm{I} \\
\mathbf{2}\end{array}$ & $\begin{array}{l}4,0 \\
4,0\end{array}$ & $\begin{array}{l}7,00 \\
5,83\end{array}$ & $\begin{array}{l}0,45 \\
0,68\end{array}$ & $\begin{array}{l}27,32 \\
20,77\end{array}$ & $\begin{array}{l}34,77 \\
27,28\end{array}$ & $\begin{array}{l}78 \\
76\end{array}$ & $\begin{array}{r}3,64 \\
3,19\end{array}$ \\
\hline Tassement ......... & 3 & 4,2 & 8,16 & 0,45 & $22,3^{2}$ & 30,93 & $7^{2}$ & 2,59 \\
\hline $\begin{array}{l}\text { Moyenne } \ldots \ldots \ldots \ldots \ldots \ldots \ldots \\
\text { Acide formique en solution à }\end{array}$ & & 4,1 & 7,00 & 0,53 & 23,47 & 30,99 & 75 & 3,14 \\
\hline $5 \% \ldots \ldots \ldots \ldots \ldots \ldots$ & I & 3,4 & 8,33 & $I, 82$ & 26,32 & 36,47 & 72 & 2,63 \\
\hline Moyenne...$\ldots \ldots$ & & $\begin{array}{l}3,0 \\
3,5\end{array}$ & $\begin{array}{l}2,00 \\
5,16\end{array}$ & $\begin{array}{l}0,34 \\
1,08\end{array}$ & $\begin{array}{l}10,77 \\
22,54\end{array}$ & $\begin{array}{l}21,11 \\
28,79\end{array}$ & $\begin{array}{l}89 \\
80\end{array}$ & $\begin{array}{l}7 ; 95 \\
5,29\end{array}$ \\
\hline Ferments lactiques.. & & 3,5 & 6,83 & $0,9 \mathrm{I}$ & 22,10 & 29,84 & 74 & 2,90 \\
\hline
\end{tabular}

\section{Interprétation}

Ces résultats montrent que le recours à un procédé physique comportant un tassement énergique de la masse cuite préserve la pomme de terre des fermentations nocives, avec autant d'efficacité que le procédé chimique de l'acidification artificielle ou que le procédé biologique đe l'ensemencement lactique. Ce fait s'explique aisément, car le tubercule de pomme de terre renferme des grosses réserves glucidiques immédiatement fermentescibles, et la température de la masse au moment de son ensilage $\left(40^{\circ} \mathrm{C}\right)$ favorise un déclenchement rapide et intense de la fermentation lactique $\left(^{1}\right.$ ). La formation presque immédiate de fortes quantités d'acide lactique suffit à inhiber presque totalement la fermentation butyrique et à assurer la stabilité de 1'ensilage, même au moment de l'apparition des chaleurs estivales, phase critique de la conservation.

L'exemple suivant (tableau II) met en lumière la stabilité remarquable de l'ensilage :

\section{Tableau II}

Evolution de la qualité de l'ensilage au cours de sa conservation

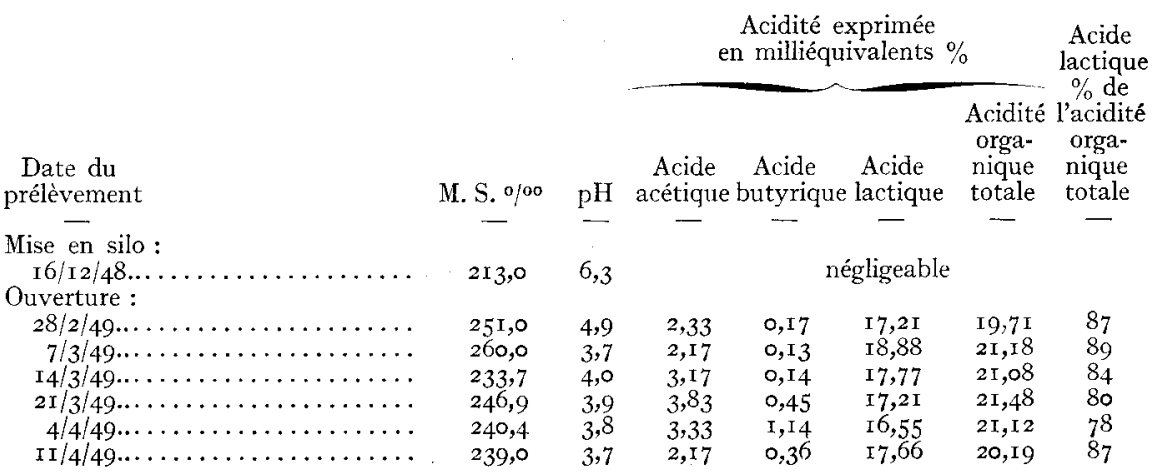

(1) Il faut aussi remarquer que le traitement par cuisson à $100^{\circ}$ détruit de nombreux microbes générateurs de fermentations putrides. 
Ces observations suggèrent 1'hypothèse que la forte fermentation lactique qui caractérise l'ensilage de pommes de terre étuvées pourrait être utilement employée pour la conservation de certains fourrages, notamment les légumineuses, qui est particulièrement difficile en l'absence de conservateurs généralement onéreux. On peut se demander également si un simple broyage préalable du tubercule ne serait pas aussi efficace que la cuisson, pour la conservation par ensilage.

Ces deux hypothèses ont constitué l'objet de l'expérience qui suit.

EXPÉRIENCE No 2

\section{CONSERVATION COMPAREE D'ENSILAGES DE POMMES DE TERRE BROYEES CRUES, DE POMMES DE TERRE ETUVEES, DE POMMES DE TERRE ETUVES EN MELANGE AVEC DES FOURRAGES VERTS SEULS.}

Cette expérience a été conduite pendant les hivers I947-48 et I948-49 de la façon suivante : les tubercules de pommes de terre ont été traités au broyeur à marteau, ou cuits par étuvage. L'ensilage mixte de pommes de terre et de fourrages verts a été obtenu par la technique des couches alternées. Les proportions pondérales des deux matières au moment de la mise en silo ont été de I/3 pour le fourrage vert et de $2 / 3$ pour la pomme de terre étuvée. Les fourrages verts du silo sans pomme de terre ont subi un hachage préalable.

Tous les silos ont été énergiquement tassés ; aucun conservateur n'a été utilisé. Des prélèvements fréquents d'échantillons ont été effectués pendant leur utilisation, à partir du $3^{\mathrm{e}}$ mois ayant suivi la mise en silo.

\section{Résultats}

TABleAU III

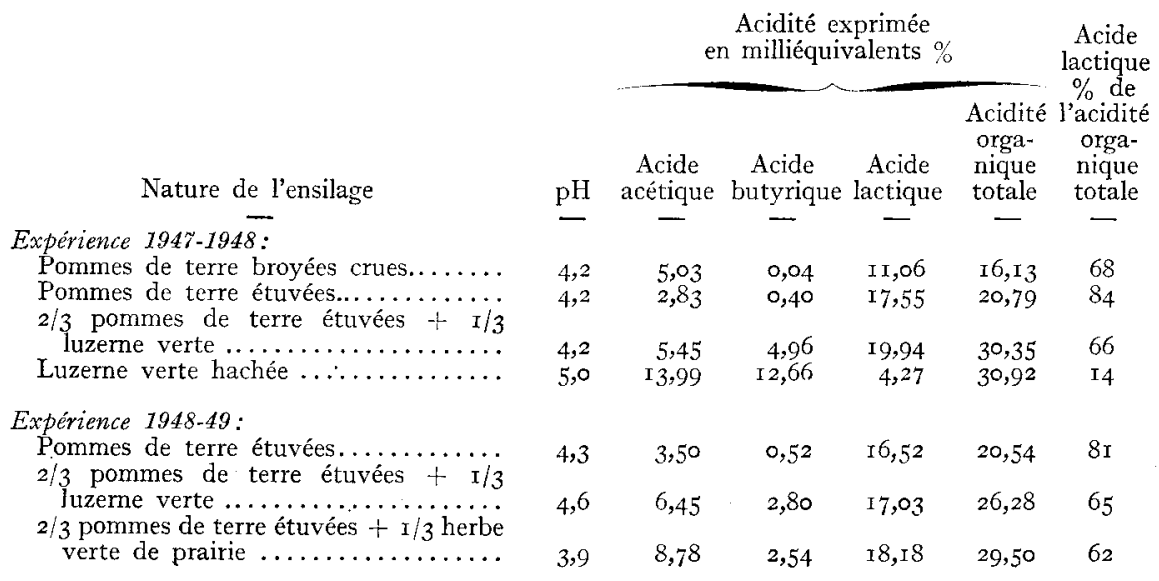




\section{Interprétation}

Ces résultats montrent qu'un broyage préalable permet de conserver les pommes de terre par ensilage dans des conditions relativement satisfaisantes. La cuisson, cependant, améliore la qualité de l'ensilage car elle active la fermentation lactique dans la masse et réduit la fermentation acétique. L'incorporation de fourrages verts dans la masse cuite assure à ceux-ci d'excellentes conditions de conservation que l'on ne retrouve pas dans un ensilage de fourrages verts seuls, en l'absence de conservateurs d'un coût généralement élevé. La technique de l'ensilage mixte avec fourrages verts offre, en outre, l'avantage d'adjoindre aux pommes de terre des substances riches en carotène et en protéines d'une bonne efficacité biologique.

\section{III. - RECHERCHES SUR L'EMPLOI DE LA POMME DE TERRE COMME ALIMENT DU BÉTAIL}

Les recherches concernant l'emploi de la pomme de terre comme aliment du bétail sont peu nombreuses, en dehors de celles précédemment passées en revue, qui concernent la digestibilité de cet aliment.

Nous nous sommes proposés de combler cette lacune, et les études que nous avons entreprises sur les divers animaux domestiques ont pour objet de dégager des règles permettant de tirer le meilleur parti possible de la pomme de terre dans l'alimentation animale.

\section{EXPÉRIENCES SUR PORCINS}

\section{Par A. M. LERoy, S. ZELTER et R. FÉVRIER}

Les premières tentatives de supplémentation de la pomme de terre chez le porc sont dues à HEIDENs (26) qui, en $\mathrm{I} 877$, a essayé d'associer à cet aliment des féculents, des céréales secondaires et des sous-produits de laiterie. Entre I9I4 et I9I8, LEHMANN (27) a imaginé une technique d'engraissement du porc, utilisant très largement la poinme de terre. La supplémentation consistait dans un apport journalier d'une quantité fixe ( $\mathrm{I} \mathrm{kg}$ ) d'tun aliment riche en azote comprenant : remoulage $(35 \%)$, orge $(30 \%)$, farine de poisson $(20 \%)$ tourteau de soja (Io $\%$ ) et farine de luzerne ( $5 \%$ ).

Cet aliment apportait $165 \mathrm{~g}$ de matières protéiques digestibles par $\mathrm{kg}$.

Bolimann (24), puis Kirsch, JANTZON et REISH (28) ont voulu apporter quelques améliorations à la formule recommandée par LEHMANN. Ils préconisaient la suivante : farine de poisson (10 \%), farine de viande $(20 \%)$ et orge $(76 \%)$. Ce mélange apportait environ $200 \mathrm{~g}$ de matières protéiques digestibles. Une légère quantité de phosphate bicalcique et de chlorure de sodium donnée 
en supplément devait remédier à la déficience minérale de la pomme de terre.

Ces deux mélanges nous paraissent trop pauvres en matières protéiques et en matières minérales pour constituer, avec la pomme de terre, des rations adaptées aux besoins des animaux; d'autre part, le problème vitaminique semble avoir été négligé.

Pour nos propres expériences, tout en reprenant l'idée de l'utilisation d'un concentré distribué à dose fixe pendant toute la durée de l'engraissement, nous nous sommes efforcés de constituer un aliment complémentaire mieux équilibré.

L'engraissement du porc à partir de pommes de terre pose un certain nombre de problèmes auxquels nous avons cherché une solution en recourant à l'expérience. Nous avons particulièrement étudié :

$I^{0}$ L'influence du traitement préalable de la pomme de terre sur la croissance et sur l'engraissement.

$2^{\circ}$ L'influence comparée sur l'engraissement d'un régime à base de pommes de terre et d'un régime à base d'orge.

\section{CONDUITE GENERALE DES EXPERIENCES}

\section{I $^{\circ}$ Constitution de groupes d'animaux}

Chaque expérience a toujours été effectuée avec des sujets de même race et provenant d'un même élevage. Elle a parfois été répétée simultanément en plusieurs centres.

Les animaux étaient, selon les Centres, groupés en loges de I, 4,5 ou 7 sujets, qui constituaient des unités. L'effectif des groupes mis en observation comportait au moins deux unités et ro sujets.

A l'exception de l'expérience $n^{0} \mathrm{I}$, toutes les autres comportaient deux périodes distinctes :

a) une "pré-expérience " - période d'observation de $2 \mathrm{I}$ jours, au cours de laquelle les animaux recevaient un aliment standard spécialement étudié, afin de déterminer aussi exactement que possible les particularités des groupes d'animaux étudiés.

Les résultats de cette période étaient utilisés à la constitution des lots de sujets comparables. L'affectation des lots se faisait par un tirage au sort.

b) une "expérience " dont la durée pour chaque Centre variait avec la rapidité de croissance des groupes. D'une façon générale, le moment où les premiers atteignaient le poids vif moyen de $100 \mathrm{~kg}$ par case marquait la fin de l'étude. 


\section{$2^{\circ}$ Comparaison des régimes alimentaires}

Pendant toute la durée de l'expérience, le lot de référence était nourri avec l'aliment standard mis au point par la Station expérimentale du porc (29).

Le régime qui lui était comparé était constitué par un aliment complémentaire, distribué à dose fixe ( I kg par jour) et par de l'ensilage de pommes de terre étuvées, dont la ration quotidienne était fonction de l'appétit des animaux.

Un apport quotidien de $2500 \mathrm{U}$. I. de vitamine A et de $250 \mathrm{U}$. I. de vitamine D (Référence $H$. Clausen (30)) sous forme d'huile de foie de poisson concentrée, était assuré régulièrement à chacun des sujets en observation.

Dans la mesure du possible, pour tous les centres, les aliments utilisés étaient préparés à partir de matières premières de même provenance, à l'exception des pommes de terre dont les variétés différaient d'un Centre à l'autre.

Des prélèvements fréquents d'échantillons permettaient de déterminer la composition chimique des rations. Les résultats de ces analyses figurent dans des tableaux reproduits en annexe de ce mémoire.

Les repas étaient au nombre de 3 par jour, à l'exception du dimanche où ils étaient réduits à 2 . Leur durée était généralement de $\mathrm{I} / 4$ d'heure pour le régime standard et de $\mathrm{I} / 2$ à $3 / 4$ d'heure pour le régime comportant des pommes de terre, par suite du volume plus important des rations. Les quantités d'aliments distribués étaient réglées sur 1'appétit des animaux, de façon à éviter que leur absorption dépasse la durée prescrite.

Il était ajouté environ 3 litres d'eau par $\mathrm{kg}$ de farine et un litre par $\mathrm{kg}$ de pommes de terre.

\section{$3^{\circ}$ Les mesures expérimentales}

Au cours de la croissance, nous avons adopté comme test :

la consommation de nourriture,

le gain de poids vif,

l'indice de consommation.

Les rations étaient pesées à chaque repas ; les animaux étaient pesés individuellement à jeun, le premier jour de chaque semaine. Le rapport de la quantité de nourriture consommée au gain de poids vif donnait "l'indice de consommation $n$.

\section{$4^{0}$ Les méthodes d'interprétation des mesures}

Nous avons effectué :

a) le calcul des moyennes pondérées et l'erreur standard d'après la formule

$$
\text { erreur standard }=\frac{\sqrt{\frac{\sqrt{(x-x)^{2}}}{\mathrm{~N}-\mathrm{I}}}}{\sqrt{\mathrm{N}}}
$$


b) le calcul du test de probabilité à partir de la variance commune aux detux moyennes observées ( $\mathrm{S}\left(x_{1}-x_{2}\right)$ selon les formules :

$$
\begin{aligned}
t & =\frac{\bar{x}_{1}-\bar{x}_{2}}{\mathrm{~S}\left(\bar{x}_{1}-\bar{x}_{2}\right)} \\
\mathrm{S}\left(\bar{x}_{1}-\bar{x}_{2}\right) & =\sqrt{\frac{\Sigma\left(\bar{x}_{1}-x_{1}\right)^{2}}{\mathrm{~N}_{1}\left(\mathrm{~N}_{1}-\mathrm{I}\right)}+\frac{\Sigma\left(x_{2}-x_{2}\right)^{2}}{\mathrm{~N}_{2}\left(\mathrm{~N}_{2}-\mathrm{I}\right)}} .
\end{aligned}
$$

Toute différence dont la valeur $t$ est $>2$ doit être considérée comme signi ficative. On sait que cette valeur correspond au seuil de probabilité limite de $5 \%: P \leqslant 0,05$.

Ce résultat nous permettait d'apprécier la valeur des différences relevées dans les effets comparés des divers régimes.

a) Etude de l'influence du monde de préparation de la pomme de terre sur la croissance et l'engraissement du porc

\section{EXPÉRIENCE N N I}

L'expérience s'est déroulée au Domaine Expérimental de CourcellesChaussy, du I7 mars au 5 mai I948.

Deux groupes de ro porcs de race du Hanovre améliorée, âgés de 5 mois environ, constituaient le matériel animal de l'expérience. La comparaison portait sur des pommes de terre conservées à l'état cru en magasin, et cuites au fur et à mesure des besoins quotidiens, et sur un ensilage de pommes de terre étuvées dont la préparation avait été effectuée en janvier. tion :

Les animatux recevaient, en outre, pour équilibrer leur alimenta$\mathrm{I}^{\mathrm{O}} \mathrm{I} \mathrm{kg}$ par jour du mélange suivant :

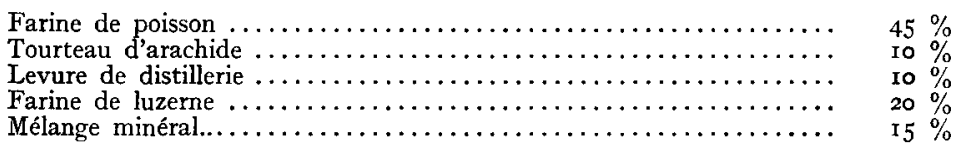

$2^{0} 0,725 \mathrm{~kg}$ de farine de maïs.

\section{Résultats}

Les mesures effectuées lors de cette étude sont rapportées dans le tableau IV ci-dessous. 
TABLEAU IV

Mesures effectuées

Nombre d'animaux $\ldots \ldots \ldots \ldots \ldots \ldots \ldots \ldots$

Régime

Consommation moyenne journalière $(\mathrm{kg})$

Pommes de terre $\ldots \ldots \ldots \ldots \ldots \ldots \ldots \ldots \ldots \ldots \ldots \ldots \ldots \ldots \ldots$
Aliment complémentaire $\ldots \ldots \ldots \ldots \ldots \ldots \ldots \ldots \ldots$

Maïs

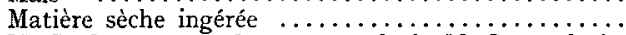

M. S. de pommes de terre $\%$ de la M. S. totale ingérée

Consommation totale $(\mathrm{kg})$

Pommes de terre ${ }^{2}$

Aliment complémentaire $\ldots \ldots \ldots \ldots \ldots \ldots \ldots \ldots \ldots$

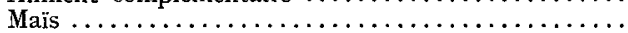

Gain total de poids vif $(\mathrm{kg})$

Indices de consommation :

Pommes de terre.

Aliment complémentaire $\ldots \ldots \ldots \ldots \ldots \ldots \ldots \ldots \ldots \ldots$

Mais

Accroissement de poids

Poids moyen initial $(\mathrm{kg})$

Poids moyen final $(\mathrm{kg})$

Gain moyen journalier $(\mathrm{g})$

\section{Groupe C}

Pommes de terre Ensilage de pommes

Groupe E

fraîchement cuites de terre étuvées.

Il est intéressant de constater non seulement que les résultats globaux sont identiques pour les 2 groupes, mais encore que les courbes de croissance sont superposables (graphique I).

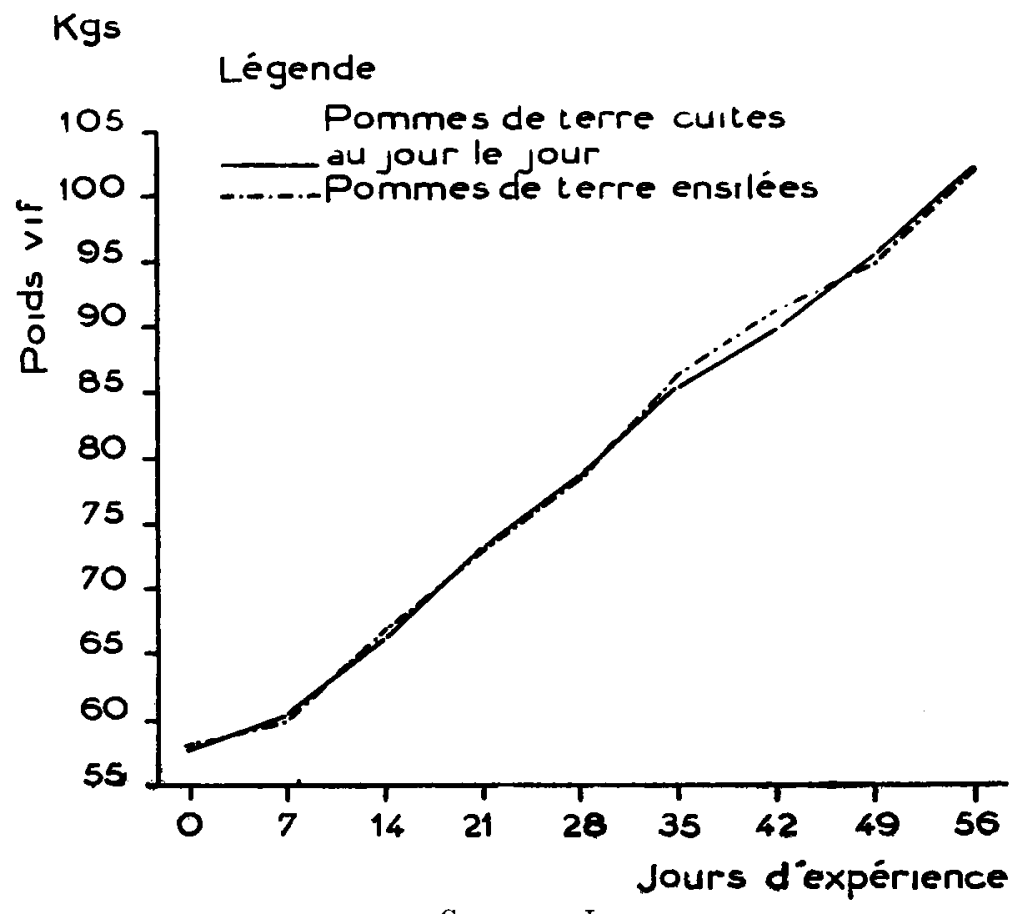

Graphique I 
Les animaux ont été sacrifiés aux abattoirs de la Ville de Metz quelques jours après l'arrêt de l'expérience. Cette opération nous a fourni les éléments permettant une comparaison des viandes provenant de ces deux lots :

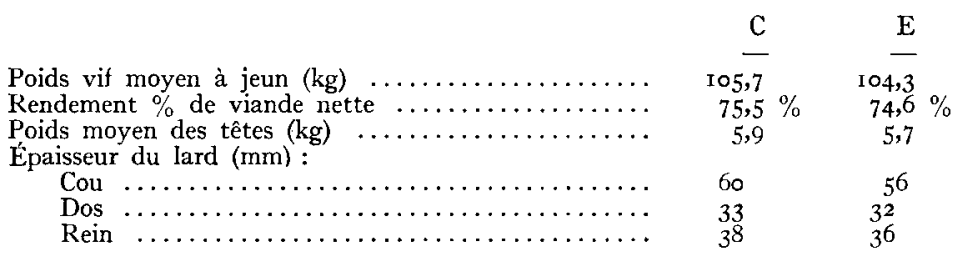

On ne relève donc aucune différence dans l'efficacité nutritive de la pomme de terre préparée selon ces deux méthodes; nos observations sont en parfait accord avec celles faites par JESPERSEN et PLESNER (3I) au cours d'une expérience du même genre.

\section{EXPÉRIENCE $N^{0} 2$}

\section{Ensilage de pommes de terre broyées crues et de pommes de terre étuvées}

Il nous a paru intéressant de vérifier expérimentalement si le broyage suivi d'ensilage améliorait l'utilisation du tubercule cru et s'il le rendait aussi efficace, pour le porc qu'une cuisson suivie d'ensilage. Cette étude a été entreprise dans le même domaine que la première, pendant 1'hiver I949, et a duré 77 jours, dont 2 I de pré-expérience.

28 porcelets de race Large White âgés d'environ 3 mois au début de l'essai, ont été mis en observation. Deux groupes de I4 sujets chacun, parfaitement comparables, ont été constitués. A l'issue de la pré-expérience, le tirage au sort a affecté au groupe $\mathrm{A}$ le régime d'ensilage de pommes de terre crues, et au groupe $B$ celui de l'ensilage de pommes de terre étuvées.

Pendant la pré-expérience, les deux groupes ont consommé uniquement l'aliment standard " croissance " dont voici la formule :

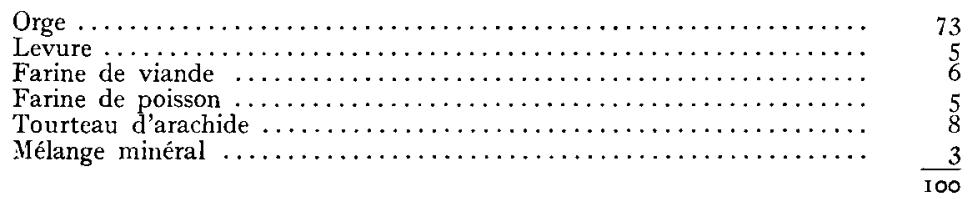

Lors de l'expérience, qui a duré 56 jours, les pommes de terre distribuées à satiété à chacun des sujets ont été complétées par un aliment azoté distribué à la dose de I $\mathrm{kg}$ par jour et ainsi composé :

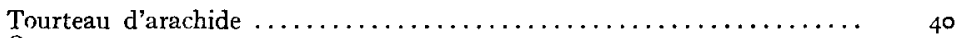

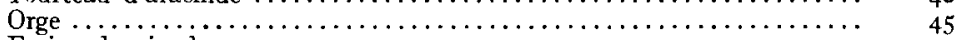

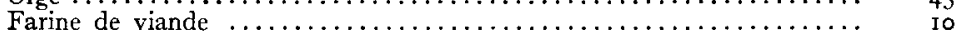

Mélange minéral....................... $\frac{5}{100}$ 
Le mélange minéral employé avait pour formule :

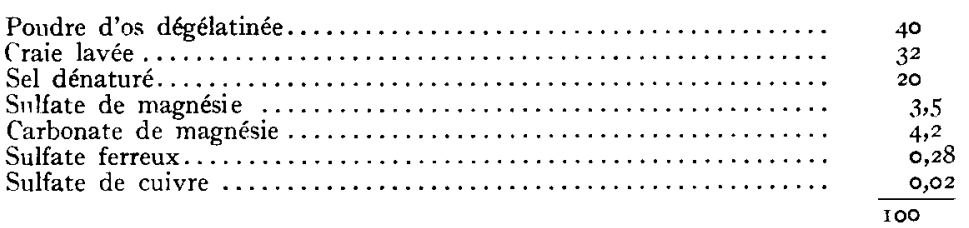

Résultats. - Le tableau $\mathrm{V}$ renferme les données se rapportant à notre expérience.

\section{TaBLEaU V \\ Mesures effectuées}

Nombre de sujets

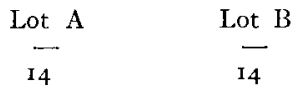

a) Pré-expérience (durée 21 jours) :

Régimes

Consommation moyenne journalière $(\mathrm{kg})$

- totale $(\mathrm{kg}) \ldots \ldots \ldots \ldots \ldots \ldots \ldots \ldots$

Gain total de poids vif $(\mathrm{kg}) \ldots \ldots \ldots \ldots \ldots \ldots \ldots$

Indice de consommation $(\mathrm{kg}) \ldots \ldots \ldots \ldots \ldots \ldots$

Poids vif moyen initial $(\mathrm{kg}) \ldots \ldots \ldots \ldots \ldots \ldots \ldots \ldots$

$-\quad-$ final $(\mathrm{kg}) \ldots \ldots \ldots \ldots \ldots \ldots \ldots \ldots \ldots \ldots \ldots$

Gain moyen journalier (g)

b) Expérience (durée 56 jours) :

Régimes

Consommation moyenne journalière $(\mathrm{kg})$ :

En aliments bruts:

pommes de terre $\ldots \ldots \ldots \ldots \ldots \ldots \ldots \ldots \ldots \ldots \ldots \ldots \ldots \ldots \ldots$
aliment complémentaire $\ldots \ldots \ldots \ldots \ldots \ldots$

En matière sèche :

pomme de terre $\ldots \ldots \ldots \ldots \ldots \ldots \ldots \ldots \ldots$

aliment complémentaire $\ldots \ldots \ldots \ldots \ldots \ldots \ldots \ldots$.

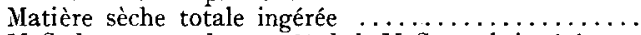

M.S. de pommes de terre $\%$ de la M.S. totale ingérée ...

Consommation totale $(\mathrm{kg})$ :

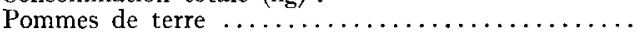

Aliment complémentaire $\ldots \ldots \ldots \ldots \ldots \ldots \ldots \ldots \ldots$

Gain total de poids vif pendant la période $(\mathrm{kg}) \ldots \ldots \ldots$

Indices de consommation:

Pommes de terre:

produit brut $\ldots \ldots \ldots \ldots \ldots \ldots \ldots \ldots \ldots \ldots$

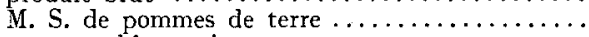

Aliment complémentaire $\ldots \ldots \ldots \ldots \ldots \ldots \ldots \ldots$

Poids vif moyen initial $(\mathrm{kg}) \ldots \ldots \ldots \ldots \ldots \ldots \ldots$

$-\leq-$ final $(\mathrm{kg}) \ldots \ldots \ldots \ldots \ldots \ldots \ldots \ldots \ldots \ldots$

Gain moyen journalier $(\mathrm{g})$

a. standard

"croissance" $\mathbf{I}, 88$

$54 \mathrm{I}, 2$

208,0

2,60

29,72

44,58

$707 \div 24$

ensilage pommes de terre crues

$\begin{array}{cc}3,12 & 4,94 \\ 1,00 & 1,00 \\ & \\ \mathbf{1 , 1 4 4 5} & \mathrm{I}, \mathrm{I} 37 \\ 0,895 & 0,895 \\ 2,040 & 2,032 \\ 56, \mathbf{1} & 56,0 \\ & \\ 2442,2 & 3870,7 \\ 784,0 & 784,0 \\ 345,3 & 486,9 \\ & \\ 7,07 & 7,95 \\ 2,596 & \mathrm{I}, 829 \\ 2,270 & \mathrm{I}, 6 \mathrm{I0} \\ 44,58 & 44,96 \\ 69,24 & 79,74 \\ 440 \pm 23 & 608 \pm 16\end{array}$

\section{Interprétation}

L'utilisation nutritive de l'ensilage de pommes de terre crues se montre donc défectueuse. Les deux groupes, dont le rythme de croissance et la dépense énergétique étaient absolument identiques au départ, accusent pendant l'expérience des différences de croissance significatives. En effet, le gain moyen de poids vif du lot $\mathrm{A}$, nourri avec des pommes de terre crues, est de $28 \%$ inférieur à celui du lot $\mathrm{B}$. Ce ralentissement de la croissance pour le lot A est accompagné, 
malgré une appétence égale, d'une augmentation de la dépense d'aliment par $\mathrm{kg}$ de gain : $30 \%$ pour la matière sèche de la pomme de terre, et $29 \%$ pour l'aliment complémentaire.

Il semble donc incontestable que, pourle porc, l'ensilage de la pomme de terre doit être précédé d'une cuisson.

b) Ensilage de pommes de terre étuvées et d'aliment standard

\section{EXPÉRIENCE N ${ }^{\circ} 3$}

Io7 porcelets provenant du même élevage que ceux de l'essai $n^{0} 2$, ont été répartis dans 4 centres, où l'expérience s'est déroulée simultanément pendant les mois d'hiver I949-I950. Elle a eu pour objet :

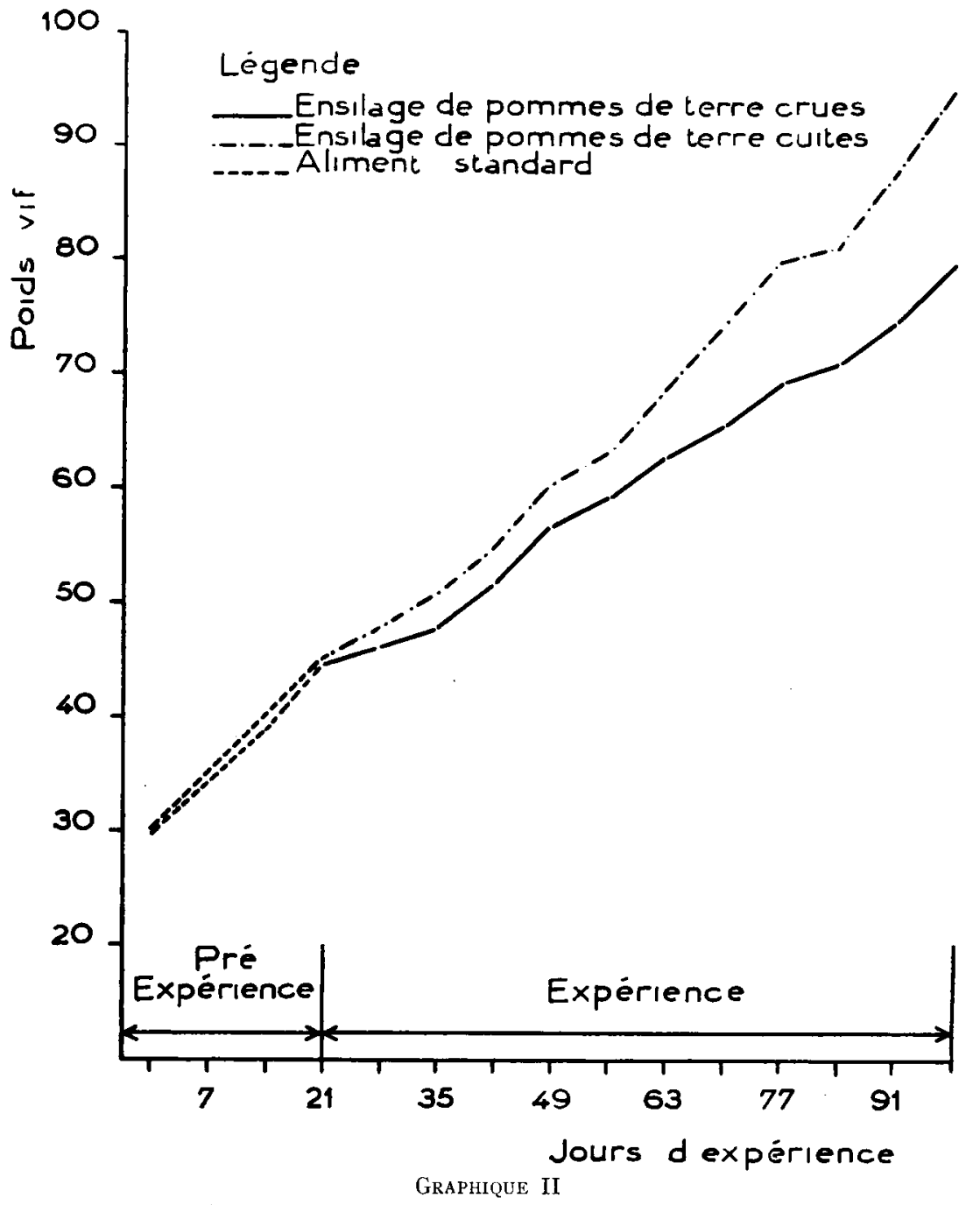


I $^{0}$ d'étudier la possibilité d'utiliser dans 1'alimentation du porc des quantités massives de pommes de terre,

$2^{\circ}$ de déterminer leur valeur nutritive, par référence à un aliment de rendement connu.

Les régimes étaient les mêmes dans tous les Centres. Les pommes de terre étuvées ont été ensilées $2-3$ mois avant leur utilisation. Les variétés différaient d'un Centre à l'autre. L'aliment complémentaire était le même que dans l'expérience 2 .

Dans chaque centre, 2 groupes comparables d'animaux ont été constitués après avoir été soumis au régime témoin de l'aliment "Croissance" pendant la pré-expérience de 2 I jours. Lors de l'expérience, le groupe servant de référence continuait à consommer, jusqu'à un poids moyen d'environ $60 \mathrm{~kg}$, l'aliment standard "croissance ", qui était remplacé ensuite, jusqu'à la fin de l'engraissement, par 1'aliment standard " engraissement ".

\section{TABLEAU VI}

\section{Mesures effectuées}

Effectif

a) Pré-expérience (durée 21 jours) :

Régime

Consommation moyenne journalière $(\mathrm{kg})$

Gain total de poids vif $(\mathrm{kg}) \ldots \ldots \ldots \ldots \ldots \ldots \ldots \ldots \ldots$

Indice de consommation $(\mathrm{kg}) \ldots \ldots \ldots \ldots \ldots \ldots \ldots$

Poids vif moyen initial $(\mathrm{kg}) \ldots \ldots \ldots \ldots \ldots \ldots \ldots$

Gain moyen journalier $(\mathrm{g}) \ldots \ldots \ldots \ldots \ldots \ldots \ldots \ldots \ldots \ldots$

b) Expérience (durée 84 jours) :

Régime

Consommations moyennes journalières ( $\mathrm{kg}$ ) :

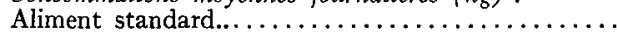

Pommes de terre à $24,9 \%$ de matière sèche .....

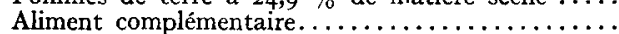

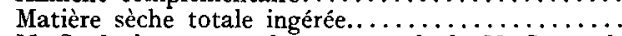
M. S. de la pomme de terre $\%$ de la M. S. totale

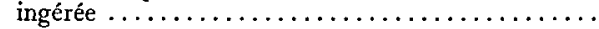

Consommation tolale $(\mathrm{kg})$ :

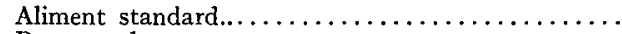

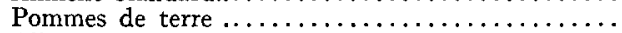

Aliment complémentaire..................

Gain total de poids vif $(\mathrm{kg}) \ldots \ldots \ldots \ldots \ldots \ldots \ldots \ldots$

Indice de consommation :

Aliment standard.

Pommes de terre

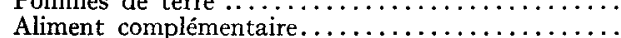

Poids vif initial $(\mathrm{kg}) \ldots \ldots \ldots \ldots \ldots \ldots \ldots \ldots \ldots$

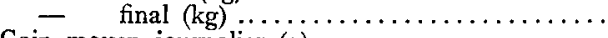

Gain moyen journalier $(\mathrm{g})$

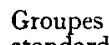

standard

54

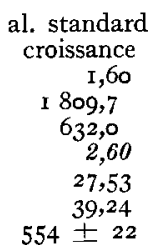

al. standard
Groupes

de terre

53

$$
\begin{gathered}
\text { al. standard } \\
\text { croissance } \\
\mathrm{I}, 6 \mathrm{I} \\
\text { I } 792,2 \\
634,7 \\
2,53 \\
27,52 \\
39,50 \\
570 \pm 23
\end{gathered}
$$

ensilage de pommes de terre étuvées

\begin{tabular}{cr}
$28 \mathrm{I} 7$ & - \\
\hline$\overline{507}$ & 4693 \\
- & 09975 \\
& 2042
\end{tabular}

\begin{tabular}{cr} 
1 $308 \mathrm{I}, 3$ & $\overline{389,4}$ \\
\hline & 2I 389,4 \\
3103,1 & 4443,9 \\
& 2591,4
\end{tabular}

$\begin{array}{cc}4316 & 8254 \\ - & 1705 \\ -19,24 & 39,50 \\ 96,65 & 88,39 \\ 672 \pm 16 & 574 \pm \text { I5 }\end{array}$


Formule de l'aliment standard "engraissement ".

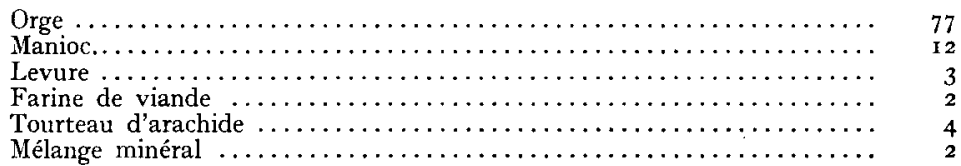

Les animaux du $2^{\mathrm{e}}$ groupe recevaient chacun par jour I $\mathrm{kg}$ de l'aliment complet et des pommes de terre selon leur appétit.

\section{Résultats d'ensemble}

Les résultats pour l'ensemble des Centres figurent dans le tableau VI. (Les effectifs d'expérience n'ayant pas été les mêmes dans chacun des Centres, ces données représentent des moyennes pondérées.)

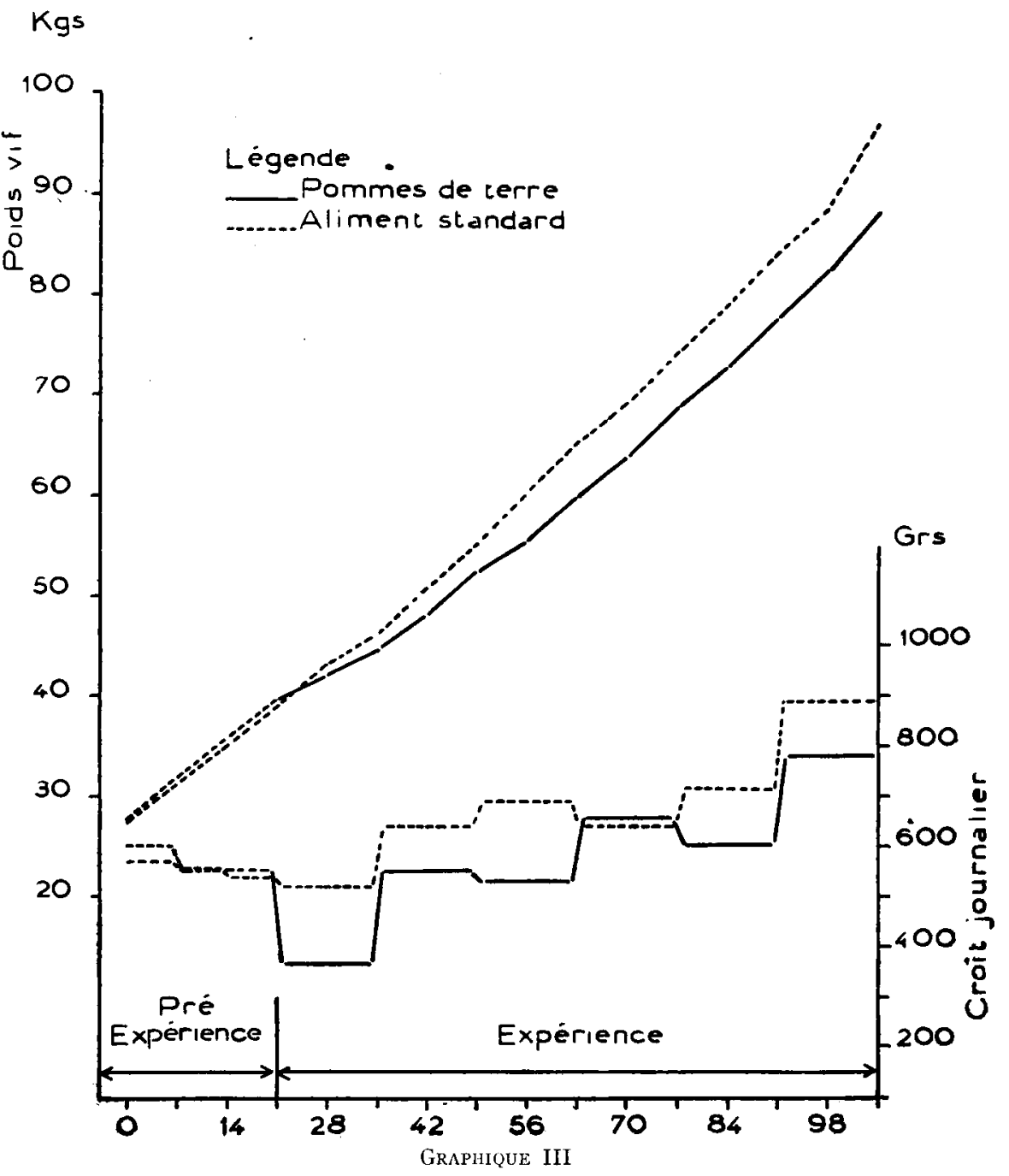




\section{Interprétation}

L'étude statistique des résultats d'ensemble, et de ceux de chaque Centre pris séparément, la comparaison des moyennes et l'analyse de leurs variances communes pour les deux groupes d'animaux soumis à l'expérience, font ressortir que :

I $^{0}$ Les écarts observés lors de la pré-expérience entre les croissances des divers groupes, sont dépourvus de toute signification. En effet, pour l'ensemble des Centres, $t=0,48 \mathrm{I}$ et $\mathrm{P}$ est compris, entre 0,6 et 0,7 . Pour les données séparées des Centres, $t$ est compris entre $0, \mathrm{I} 27$ et $\mathrm{I}, 39$ et les valeurs de $P$ varient de 0,2 à 0,9 (on sait qu'un écart n'est significatif que si $t>2$ et $\mathrm{P} \leqslant 0,05$ ). Par conséquent, les lots formés dans chaque Centre à l'issue de la pré-expérience faisaient bien partie d'une même population et étaient parfaitement comparables entre eux.

$2^{\circ}$ Pendant 1'expérience, la différence entre les croissances des groupes standards et pommes de terre atteint $98 \mathrm{~g}$, soit une différence de - I4,6\% en défaveur de ces derniers. Cet écart est hautement significatif, puisque $t=4,4 \mathrm{r}$ et $\mathrm{P}<\mathrm{O}$ o,oI.

I1 semble donc que l'ensilage de pommes de terre cuites distribuées à satiété, dans un régime bien équilibré par ailleurs, ne permet pas l'engraissement aussi rapide du porc qu'un régime à base d'orge.

Cependant, en procédant à une analyse plus poussée des données portées au tableau VI, on remarque que l'ingestion journalière de matière sèche est nettement plus faible $(8 \mathrm{I}, 4 \%)$ pour les animaux recevant des pommes de terre, ce qui pourrait expliquer cette croissance moindre $(83,4 \%)$.

L'examen de ce très important aspect du problème impose une étude critique détaillée des éléments d'expérience propres à chacun des Centres, afin de vérifier si des facteurs autres que l'influence de la matière sèche n'étaient pas susceptibles d'exercer une action retardatrice sur la croissance du groupe expérimental ayant consommé des pommes de terre.

L'examen détaillé de ce tableau permet de constater que la teneur des deux régimes en protéines a été sensiblement la même et dépassait celle que recommandent les tables d'alimentation. Il en est de même, en ce qui concerne les apports en phosphore et en calcium qui, quoique inférieurs dans le lot expérimental à ceux du lot témoin, sont cependant supérieurs aux minima prévus par les tables. Ces deux facteurs ne semblent pas, par conséquent, avoir pu exercer une influence fâcheuse sur la croissance du groupe " pommes de terre ".

Par contre, une corrélation semble apparaître entre l'accroissement du poids vif et l'ingestion quotidienne de matière sèche, sauf à Courcelles-Chaussy. Le volume relativement important que présentaient les rations comportant des tubercules limitait sensiblement les quantités que les porcs étaient capables d'absorber, et explique l'infériorité du régime expérimental sur ce point. En effet, les quantités maxima de pommes de terre qu'il nous a été possible de 


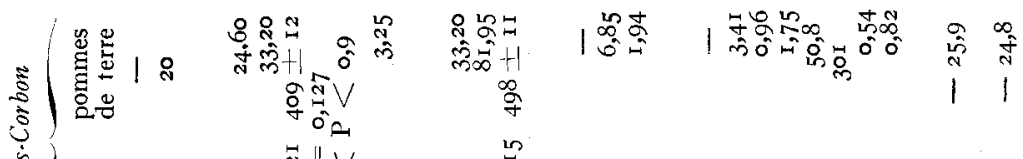

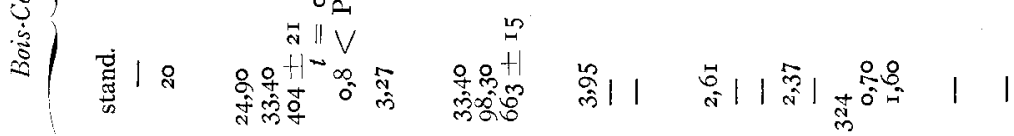

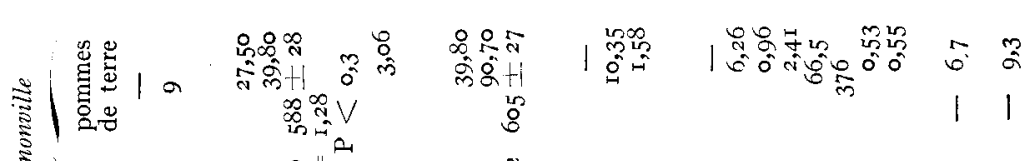

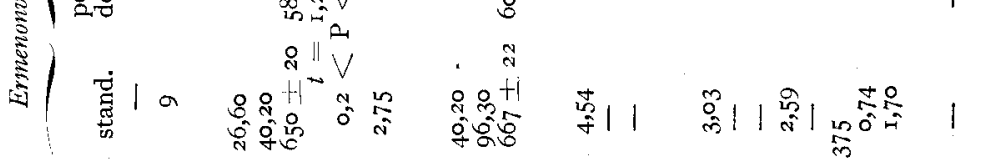

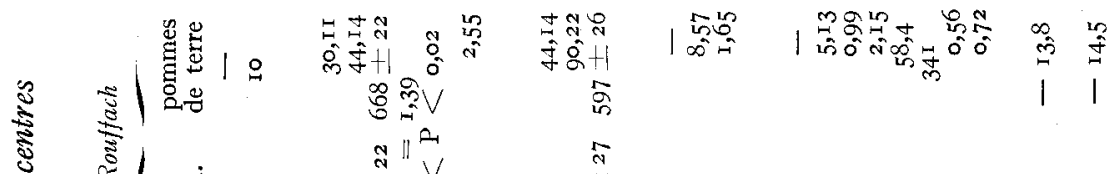

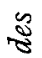

$$
\begin{aligned}
& \text { 焉 } \\
& \text { हैँ }
\end{aligned}
$$

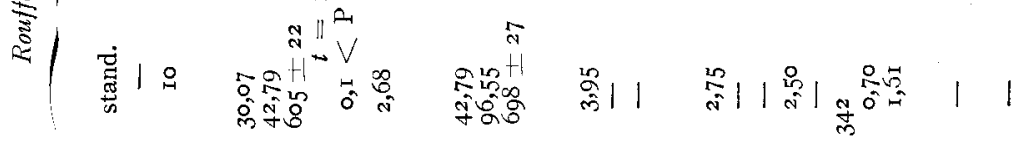

$$
\begin{aligned}
& \text { 劳 } \\
& \text { : }
\end{aligned}
$$

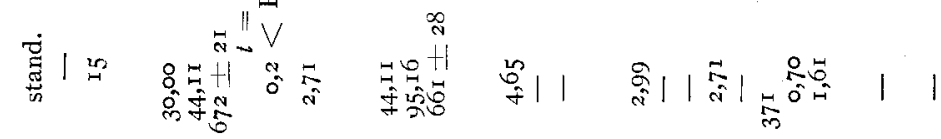

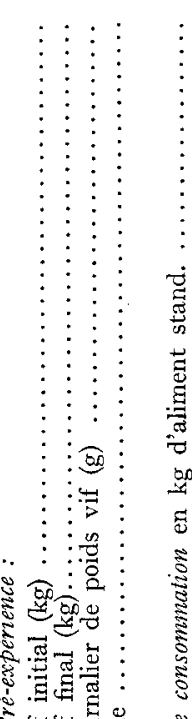

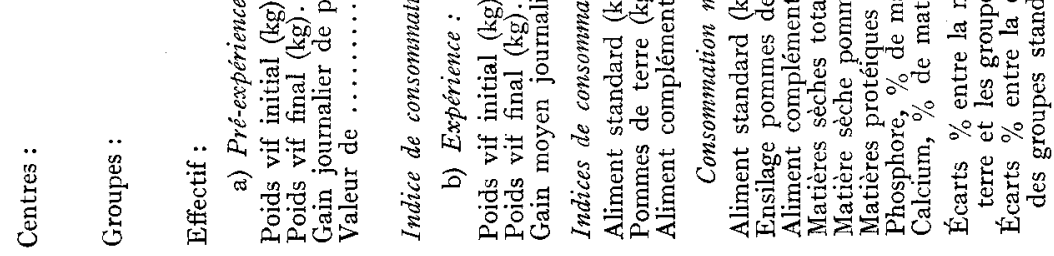


faire ingérer quotidiennement variaient de 700 à $800 \mathrm{~g}$ par ro $\mathrm{kg}$ de poids vif, pour des animaux pesant entre 50 et $60 \mathrm{~kg}$. Elles n'ont jamais dépassé 850 g vers la fin de l'expérience pour des sujets dépassant $80 \mathrm{~kg}$. Cependant, il importe de remarquer qu'à Ermenonville, où les écarts de croissance entre les 2 groupes sont moins prononcés, la déficience du régime expérimental en matière sèche est plus atténuée, car les doses journalières de pommes de terre ingérées atteignaient par moment I $\mathrm{kg}$ par Io $\mathrm{kg}$ de poids vif.

On peut, par conséquent, se demander si l'augmentation de la quantité de matière sèche dans un régime comportant des pommes de terre permettrait d'activer la croissance du porc. L'influence d'autres facteurs n'est cependant pas exclue, et notamment celle de la moins bonne valeur biologique des protéines contenues dans l'aliment complémentaire, dont les composants différaient de ceux des aliments standards qui apportaient en outre, grâce à la présence de levure, des vitamines du groupe $B$.

\section{EXPÉRIENCES No 4 ET 5 (hiver I949-I950)}

Les deux hypothèses émises plus haut nous ont conduits à entreprendre deux expériences parallèles à Guérard et à Bois-Corbon.

Une addition de farine d'orge au régime type pommes de terre, dans le but d'accroître la teneur de ce dernier en matière sèche, devait nous permettre la vérification de notre première hypothèse.

Nous avons modifié la composition de l'aliment complémentaire de façon à y faire figurer les constituants faisant partie de celle de l'aliment standard. La formule utilisée dans ces expériences était la suivante :

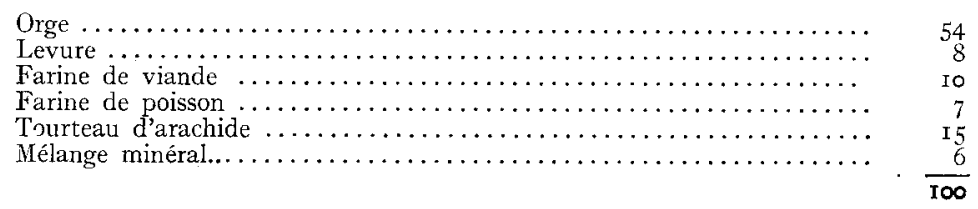

Le dispositif général d'expérience est resté le même.

\section{Expérience $n^{\circ} 4$ de Guerard}

A l'issue d'une pré-expérience de $2 \mathrm{I}$ jours effectuée avec le régime standard, les 62 porcs de race Large White constituant le matériel animal de cette recherche ont été répartis en 3 groupes composés chacun de 3 loges, pendant 84 jours, soumis aux régimes que voici :

groupe $\mathbf{A}-2 \mathrm{r}$ sujets :

Ensilage de pommes de terre à volonté + I $\mathrm{kg}$ d'aliment complémentaire.

groupe $\mathrm{B}-20$ sujets :

Ensilage de pommes de terre à volonté + I kg d'aliment complémentaire + farine d'orge en quantité variable.

groupe $\mathrm{C}-2 \mathrm{I}$ sujets :

Aliment standard. 


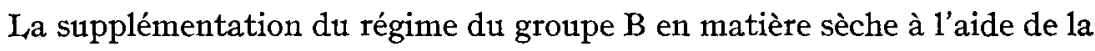
farine d'orge était conduite de manière à maintenir dans celui-ci, la consommation de pommes de terre à un niveau aussi rapproché que possible de celui du groupe $A$. Dès que l'adjonction de farine entraînait un abaissement de ce niveau, ces doses subissaient une réduction en conséquence. En fait, les quantités d'orge qu'il a été possible d'ajouter au régime du groupe $B$ sans enfreindre ce principe expérimental ont été très faibles, comme on le verra d'après les résultats

\section{Résultats}

\section{TABLEAU VIII}

Mesures efjectuées

Groupes

Effectifs :

a) Pré-expérience (durée 21 jours) :

Régime

Consommation moyenne journalière $(\mathrm{kg}) \ldots$.

Consommation totale $(\mathrm{kg}) \ldots \ldots \ldots \ldots \ldots$.

Indice de consommation $(\mathrm{kg}) \ldots \ldots \ldots \ldots \ldots$

Poids vif moyen initial $(\mathrm{kg}) \ldots \ldots \ldots \ldots \ldots$

Poids vif moyen final $(\mathrm{kg}) \ldots \ldots \ldots \ldots \ldots$

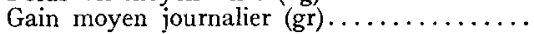

b) Expérience (durée 84 jours) :

Régimes comparés

Consommalion moyenne journalière $(\mathrm{kg})$ :

Aliment standard ...................

Pommes de terre....................

Aliment complémentaire ...............

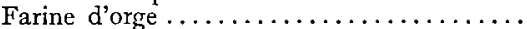

M. S. totales ingérées $\ldots \ldots \ldots \ldots \ldots \ldots$

M. S. de la pomme de terre, \% de la M. S. totale $\ldots \ldots \ldots \ldots \ldots \ldots \ldots \ldots \ldots$

Consommation totale $(\mathrm{kg})$ :

Aliment standard ...................

Pommes de terre...................

Aliment complémentaire ..............

Orge

Indices de consommation:

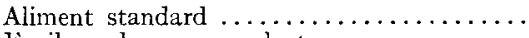

Ensilage de pommes de terre ............

Aliment complémentaire ................

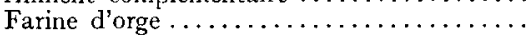

Accroissement de poids vif :

Poids vif moyen initial $(\mathrm{kg})$.

Poids vif moyen final $(\mathrm{kg})$

Gain moyen journalier (g)

(g) $\ldots \ldots \ldots \ldots \ldots$

Écarts \% dans la consommation de M. S. par rapport

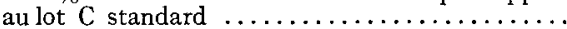
Écart \% dans la croissance par rapport au même

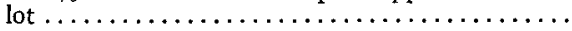

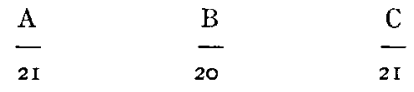

al. standard croissance

$\mathbf{I}, 23$
$54 \mathbf{1}, 3$
2,80
25,87
35,09
$440+39$

al. standard croissance

al. standard croissance

I,I 7
$49 \mathrm{I}, 6$
2,59
25,97
35,45
$45 \mathrm{I} 35$

$\mathrm{I}, \mathrm{I} 3$
499,4
2,62
26,33
35,39
$32=39$

ensilage pommes de terre -

al. complém.

ensilage pommes de terre + al. complém. + aliment standard farine d'orge

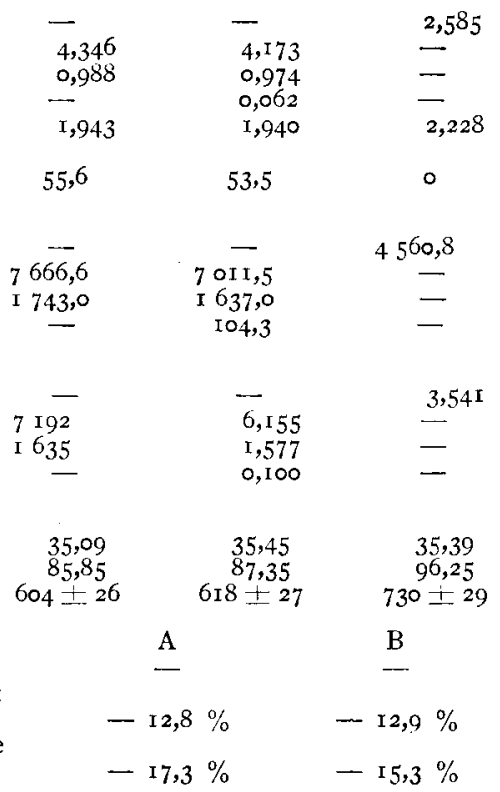




\section{Interprétation}

Il apparaît donc pratiquement impossible d'ajouter à un régime comportant des proportions élevées de pommes de terre un supplément de matière sèche sans abaisser les quantités de pommes de terre absorbées. Ein effet, la distribution de $100 \mathrm{~g}$ d'orge a entraîné une diminution de $45^{\circ} \mathrm{g}$ de l'ingestion de pommes de terre et n'a pas amélioré la croissance des porcs.

Kgs.

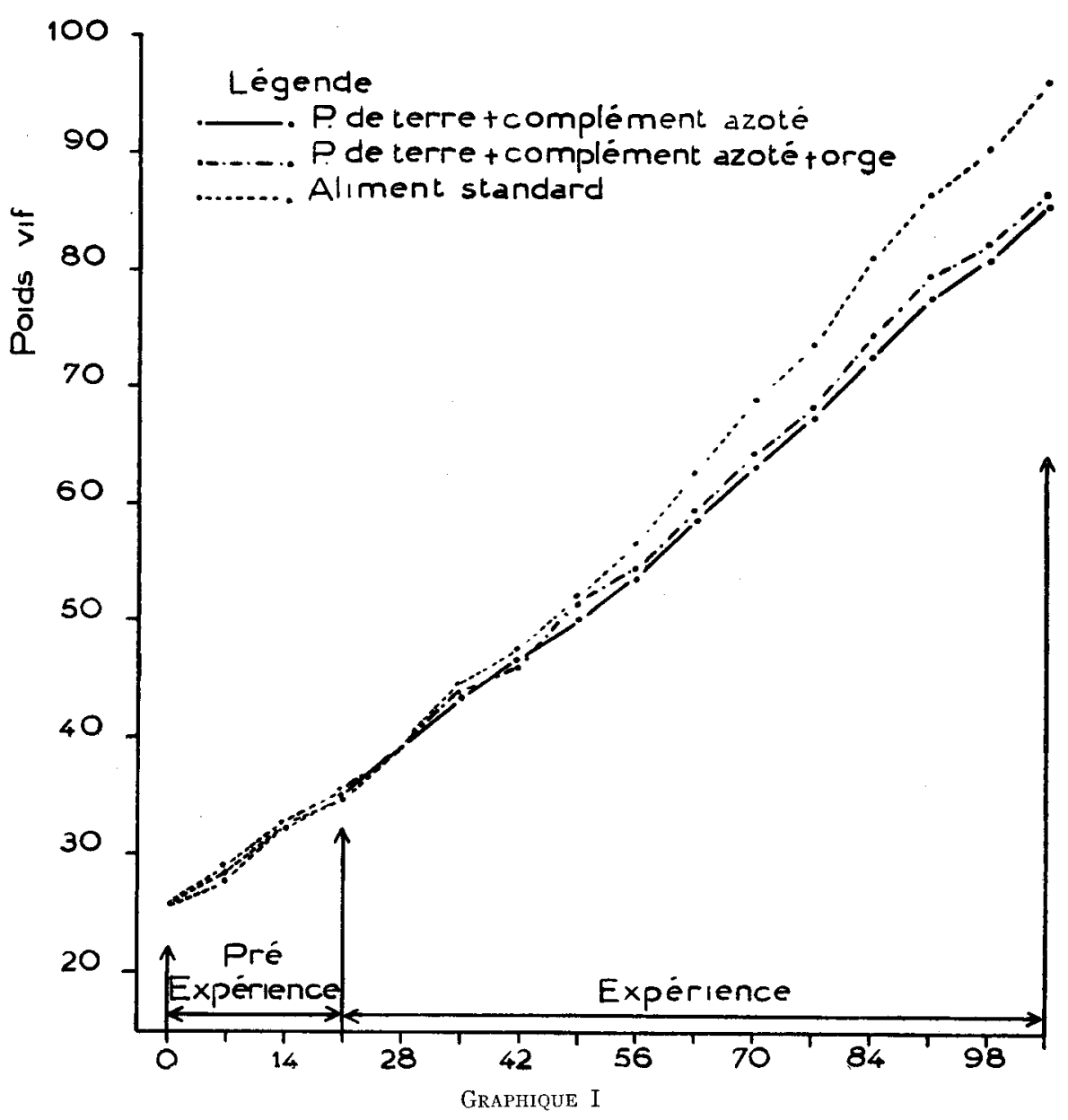

Nos observations confirment également que la croissance moindre des sujets nourris avec des pommes de terre, résulte uniquement de la réduction de la teneur de ce régime en matière sèche. Ni la qualité différente des protéines, ni l'absence de vitamines du groupe $B$ qui caractérisaient la première formule de 
l'aliment complémentaire, ne semblent avoir exercé une influence sur l'accroissement du poids vif des animaux, puisque nous retrouvons le même phénomène dans cette expérience où cet élément de variation a été éliminé.

\section{Expérience $n^{\circ} 5$ de Bois-corbon}

Nous avons constitué 4 groupes de porcs issus d'un croisement Danois $\times$ Large White. Ils furent soumis aux régimes suivants :

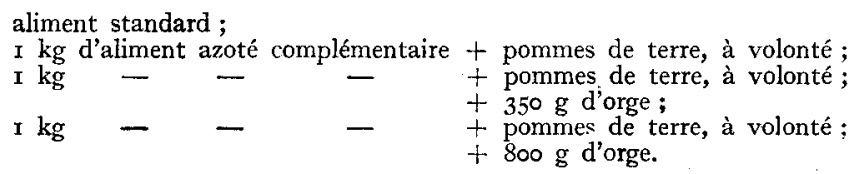

Chacun de ces lots comportait I 8 animaux, dont I 2 en 3 loges de 4 et 6 en loges individuelles.

Une épidémie de rouget a provoqué des pertes dans deux de ces lots et les seules observations valables ont pu être enregistrées sur les deux lots dont les sujets recevaient :

\section{TABLEAU IX}

Mesures effeciuées

Groupes :

A $\quad$ C

a) Pré-expérience (28 jours) :

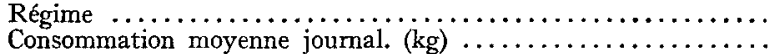

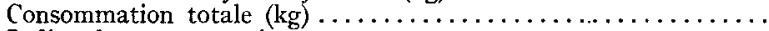

Indice de consommation.

Accroissement de poids vif :

Poids vif moyen initial $(\mathrm{kg})$

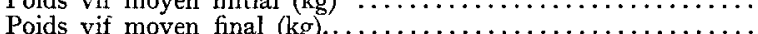

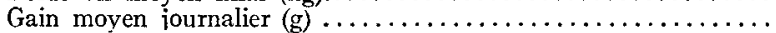
b) Expérience ( 65 jours) :

Régime

Consommation movenne pournalière $(\mathrm{kg})$ :

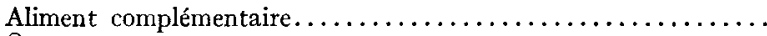

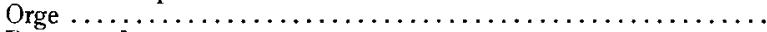

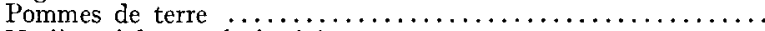

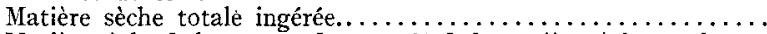

Matière sèche de la pomme de terre, $\%$ de la matière sèche totale...

Consommation totale $(\mathrm{kg})$ :

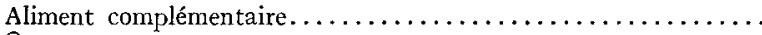

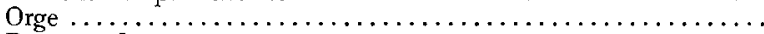

Pommes de terre

Indices de consommation $(\mathrm{kg})$ :

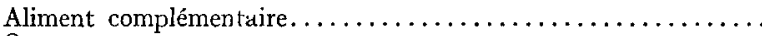

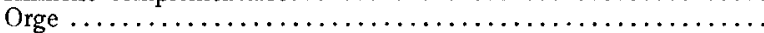

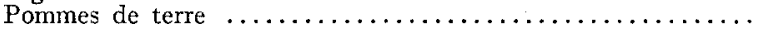

Accroissement de poids vit :

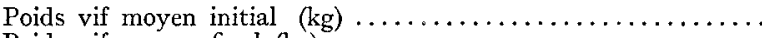

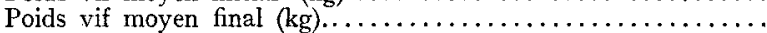

Gain moyen journalier $(g)$

al. standard

$\mathrm{I}, 73$

48,5

3,62

33,2

$480+8$

pommes de

terre +

complément

+ orge

0,92
0,74
2,18
2,058
28,1

0,92
0,74

2,18

$28, \mathrm{I}$

I, 844

2,473

I,79

I,43

4,24

46,6

79,0

$5 \mathrm{I} 4 \pm 5^{8}$ al. standard

I, 68

$47, \mathrm{I} 2$

3,80

33,3

45,5

$444 \pm 76$

pommes de terre + complément

\section{0,92 \\ $3, \overline{86}$ \\ 1,844 \\ 55 , r}

I, 044

4,375

1,90

7,97

45,5

76,2

$484 \pm 5^{\mathrm{I}}$ 
lot A :

I $\mathrm{kg}$ d'aliment azoté complémentaire + ensilage de pommes de terre étuvées, à volonté + $800 \mathrm{~g}$ d'orge. lot $\mathrm{C}$ :

I kg d'aliment azoté complémentaire + ensilage de pommes de terre étuvées, à volonté.

Les groupes ont été constitués après une période d'observation de 28 jours effectuée avec l'aliment standard " coureur ", et soumis ensuite aux régimes cités plus haut pendant 63 jours.

L'expérience a été conduite d'après le dispositif général décrit au début de ce chapitre.

\section{Résultats}

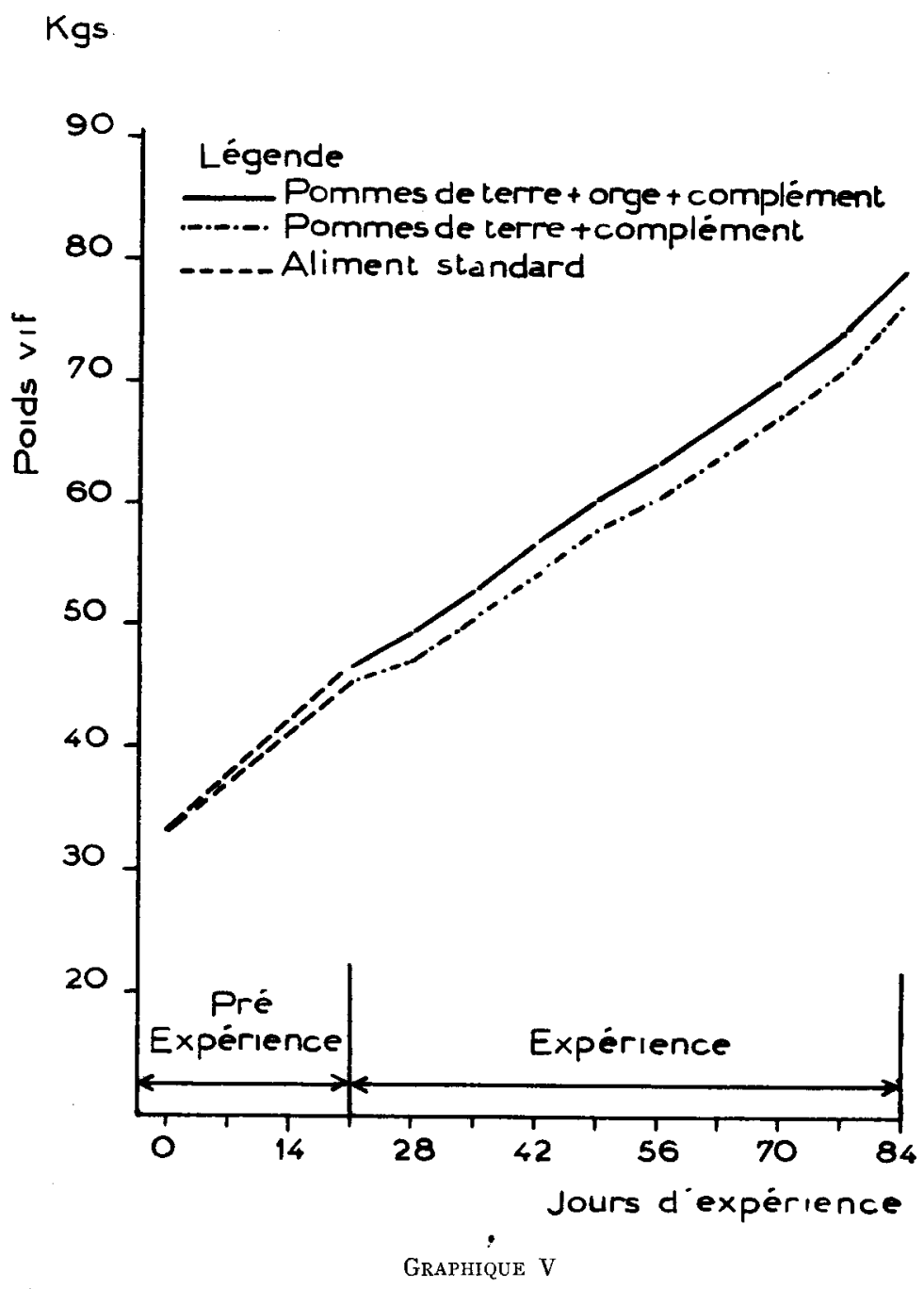




\section{Interprétation}

La vitesse de croissance des deux groupes est à peu près la même, et leurs indices de consommation peuvent être valablement comparés.

Cette expérience confirme nettement les observations précédentes : la tentative d'améliorer la croissance en augmentant la quantité d'aliment concentré dans la ration, aboutit à un échec, puisqu'en donnant $0,74 \mathrm{~kg}$ d'orge, on diminue la consommation de pommes de terre de $\mathbf{I}, 68 \mathrm{~kg}$ sans activer le croît.

Dans ces conditions, l'on peut se demander si l'utilisation d'un concentré à une dose plus faible (pour un apport de mêmes quantités de matières azotées), ne permettrait pas d'accroitre la consommation de pommes de terre, ce qui économiquement - paraît souhaitable, sans présenter d'inconvénient pour la croissance de l'animal.

\section{COMPARAISON DES QUALITES DE CARCASSES OBTENUES AVEC LE REGIME «STANDARD» ET LE REGIME « POMMES DE TERRE»}

Les mensurations habituelles ont été effectuées. Elles n'ont révélé aucune différence de qualité entre les carcasses, qui étaient toutes excellentes. Par contre, une légère différence de $-2,8 \%$ dans le rendement de viande nette a pu cependant être observée en défaveur du régime " pommes de terre ". Elle est hautement significative $(t=6,36$ et $\mathrm{P}<0, \mathrm{or})$.

\begin{tabular}{|c|c|c|c|c|c|c|c|c|c|}
\hline & $\begin{array}{c}\text { Nombre } \\
\text { de }\end{array}$ & $\begin{array}{c}\text { Poids } \\
\text { vif }\end{array}$ & $\begin{array}{l}\text { Poids } \\
\text { moyen } \\
\text { de la } \\
\text { carcasse }\end{array}$ & Rendement & $\begin{array}{l}\text { Longueur } \\
\text { moyenne }\end{array}$ & Épais & & & $\mathrm{nm}$ \\
\hline Régime & $\begin{array}{l}\text { sujets } \\
\text { abattus } \\
\text { - }\end{array}$ & $\begin{array}{l}\text { moyen } \\
\text { à jeun. } \\
\overrightarrow{(\mathrm{kg})}\end{array}$ & $\begin{array}{l}\text { sans } \\
\text { tête } \\
\overline{(\mathrm{kg})}\end{array}$ & $\begin{array}{c}\text { viande } \\
\text { nette } \\
\frac{\overline{\%}}{\%}\end{array}$ & $\begin{array}{c}\text { de la } \\
\text { carcasse } \\
\text { (cm) }\end{array}$ & $\underline{\text { Rein }}$ & Dos & $\stackrel{\mathrm{Cou}}{-}$ & $\begin{array}{c}\text { Poi- } \\
\text { trine } \\
-\end{array}$ \\
\hline $\begin{array}{l}\text { ard........ } \\
\text { ges de terre. }\end{array}$ & $\begin{array}{l}50 \\
49\end{array}$ & $\begin{array}{r}\text { ror }, 8 \\
99,3\end{array}$ & $\begin{array}{l}75,3 \\
70,7\end{array}$ & $\begin{array}{l:l}73,90 & 0,33 \\
7 \mathrm{I}, \mathrm{I0} \pm & \mathbf{1}\end{array}$ & $\begin{array}{l}96,6 \\
96,8\end{array}$ & $\begin{array}{l}34 \\
29\end{array}$ & $\begin{array}{l}32 \\
28\end{array}$ & $\begin{array}{l}47 \\
44\end{array}$ & $\begin{array}{l}28 \\
26\end{array}$ \\
\hline
\end{tabular}

Durée comparée (en jours) qu'exigent le régime standard et le régime pommes de terre pour amener un porc de 40 à $100 \mathrm{~kg}$ de poids vif.

A l'aide des données figurant au tableau VII, on peut calculer le temps exigé par chacun des types d'alimentation pour réaliser un gain de poids vif de $60 \mathrm{~kg}$.

\begin{tabular}{|c|c|c|c|c|c|c|}
\hline Centres : & $\begin{array}{l}\text { Cour- } \\
\text { celles- } \\
\text { Chaussy }\end{array}$ & $\begin{array}{l}\text { Rouf- } \\
\text { fach }\end{array}$ & $\begin{array}{c}\text { Erme- } \\
\text { non } \\
\text { ville }\end{array}$ & $\begin{array}{l}\text { Bois } \\
\text { Corbon }\end{array}$ & $\begin{array}{l}\text { Grand } \\
\text { Morin }\end{array}$ & $\begin{array}{c}\text { Durée } \\
\text { moyenne }\end{array}$ \\
\hline - & - & - & - & - & 一 & - \\
\hline$\ldots \ldots \ldots \ldots \ldots \ldots \ldots$ & 9 I & 86 & 90 & go & 82 & 88 \\
\hline de terre,$\ldots \ldots \ldots \ldots \ldots$ & 93 & 100 & 99 & I 20 & 100 & 102 \\
\hline
\end{tabular}

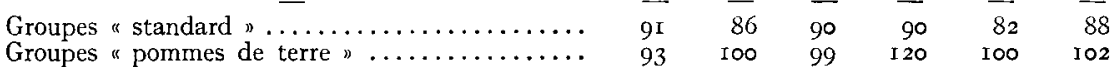

L'engraissement avec le régime « pommes de terre » nécessite donc environ deux semaines de plus que celui avec le régime "Standard ». 


\section{ASPECT ECONOMIQUE DE L'EMPLOI DE L'ENSILAGE DE POMMES DE TERRE POUR L'ENGRAISSEMENT DU PORC}

D'après le tableau $\mathrm{V}$, la production de $60 \mathrm{~kg}$ de gain de poids vif par des porcs pesant au départ 4o $\mathrm{kg}$, occasionne une dépense de $259 \mathrm{~kg}$ d'aliment standard, qui revient à environ 30 francs le $\mathrm{kg}$. Les frais de l'alimentation au cours de l'engraissement s'élèvent, par conséquent, à $259 \times 30=7770$ francs.

Le même gain de poids par des porcs soumis à un régime de pommes de terre exige 102,3 kg d'aliment complémentaire à 35 francs le $\mathrm{kg}$, soit I02,3 $\times$ $35=3580$ francs, complétés par $495 \mathrm{~kg}$ d'ensilage de pommes de terre étuvées, dont la valeur peut donc être estimée à : $7770-3580=4$ Igo francs, soit 8,50 le $\mathrm{kg}$ d'ensilage.

En réalité, les déchets de triages de pommes de terre sont, dans les meilleures conditions, commercialisés à raison de 4 francs le $\mathrm{kg}$ au départ de l'exploitation. Leur utilisation directe à la ferme pour l'alimentation du porc entraîne des frais de cuisson et d'ensilage (compte tenu des pertes dues à la conservation, chiffrée au maximum à $30 \%$ ), qui sont d'environ 2 francs par kg. Le prix de revient de l'ensilage de pommes de terre consommé par le porc peut donc être évalué à 6 franes le $\mathrm{kg}$. Entre ce dernier prix et celui de la valorisation théorique calculée plus haut, il existe donc une marge de $2 \mathrm{fr} 50$ par $\mathrm{kg}$, qui permet de réduire le coût total de l'engraissement de $495 \times 2,5^{\circ}=\mathrm{I} 237$ francs par sujet.

Cette économie compense largement et au-delà même, la plus longue durée de l'engraissement et les frais supplémentaires de main-d'œuvre occasionnés par l'utilisation de la pomme de terre, qui exclut l'utilisation des nourrisseurs automatiques.

\section{DETERMINATION DE LA VALEUR FOURRAGERE DE L'ENSILAGE DE POMMES DE TERRE ETUVEES}

\section{a) A partir de l'analyse chimique}

Les analyses effectuées au laboratoire permettent, en utilisant les coefficients de digestibilité de BoLLMAN (25), de calculer la valeur fourragère des différents lots de pommes de terre utilisés au cours de ces essais.

\begin{tabular}{|c|c|c|c|c|c|}
\hline \multirow{3}{*}{ Centres } & \multicolumn{3}{|c|}{$\begin{array}{c}\text { Equivalence tourragère } \\
\text { par kg de : }\end{array}$} & \multicolumn{2}{|c|}{$\begin{array}{l}\text { Valeur fourragère } \\
\text { par lig de: }\end{array}$} \\
\hline & $\begin{array}{l}\text { Matière } \\
\text { brute }\end{array}$ & $\begin{array}{l}\text { Matière } \\
\text { sèche }\end{array}$ & $\begin{array}{l}\text { Matières } \\
\text { organique }\end{array}$ & $\begin{array}{l}\text { Matière } \\
\text { brute }\end{array}$ & $\begin{array}{l}\text { Matière } \\
\text { sèche }\end{array}$ \\
\hline & - & - & - & - & - \\
\hline ircelles-Chaussy. & 3,50 & 0,085 & $0,73^{8}$ & 0,268 & $\mathrm{I}, 24$ \\
\hline ffach $\ldots$ & 3,60 & 0,883 & 0,793 & 0,278 & $\mathrm{I}, \mathrm{I} 3$ \\
\hline ienonville & 3,65 & $0,93^{6}$ & 0,808 & 0,274 & $x, 07$ \\
\hline Corbon. & 3,13 & 0,820 & 0,778 & 0,320 & 1,22 \\
\hline $\operatorname{rard} A$ & $3,5^{2}$ & 0,876 & 0,792 & 0,284 & $I, 14$ \\
\hline & $3,5^{2}$ & 0,876 & 0,792 & 0,284 & $\mathrm{I}, \mathrm{I} 4$ \\
\hline nérales & 3,49 & 0,866 & 0,784 & 0,285 & 1,16 \\
\hline
\end{tabular}




\section{b) A partir des résultats expérimentaux}

I $^{\circ}$ L'expérience $\mathrm{n}^{\circ} 5$ est intéressante à considérer, parce que les croissances des deux lots sont voisines et que, comme nous l'avons déjà montré, 1a comparaison des indices de consommation nous permet de comparer 1'aptitude des diverses rations à couvrir les besoins des animaux.

Nous pouvons, dans ce cas, estimer que les quantités d'aliments nécessaires pour produire $\mathrm{I} \mathrm{kg}$ de poids vif sont isodynames.

Autrement dit : I,79 $\mathrm{kg}$ d'aliment complémentaire : I,43 $\mathrm{kg}$ d'orge : $4,24 \mathrm{~kg}$ de pommes de terre sont équivalents à : $1,90 \mathrm{~kg}$ d'aliment complémentaire : 7,97 kg de pommes de terre ce qui revient à dire que, énergétiquement : $I, 43 \mathrm{~kg}$ d'orge est équivalent à 0, I I kg d'aliment complémentaire $+3,53 \mathrm{~kg}$ de pommes de terre.

Nous connaissons, par l'analyse chimique, la valeur fourragère de l'orge $(0,95)$ et de 1'aliment complémentaire $(\mathrm{I}, 06)$.

En appelant $x$ la valeur fourragère de la pomme de terre, nous pouvons écrire :

$$
3,53 x-0, \mathrm{II} \times \mathrm{I}, 06=\mathrm{I}, 43 \times 0,95
$$

d'où :

$$
x=\frac{\mathrm{I}, 24}{3,53}=0,35 \text {. }
$$

Quant à l'équivalent fourrager $\left(\frac{\mathrm{I}}{x}\right)$, il est :

$$
\begin{aligned}
& \text { matière brute } \quad \frac{\mathrm{I}}{x}=2,35(\mathrm{~kg} \text { pour I U. F) } \\
& \text { matière sèche " }=0,76 " \text { " " } \\
& \text { matières organiques " }=0,66 \text { " " }
\end{aligned}
$$

Dans le cas de cette expérience, les valeurs correspondantes obtenues à partir de l'analyse chimique étaient :

$$
\begin{array}{ll} 
& x=0,29 \\
\text { matière brute } & \frac{I}{x}=3,42 \\
\text { matière sèche } & "=0,910 \\
\text { matières organiques } & "=0,80 \mathrm{II}
\end{array}
$$

Ces valeurs diffèrent donc sensiblement.

Pour les autres expériences, la vitesse de croissance étant sensiblement différente dans les deux lots, nous avons été amenés à employer la méthode suggérée par l'un de nous.

Nous imaginons, à cet effet, un lot témoin $\left(t^{\prime}\right)$ dont les sujets auraient eu même vitesse de croissance que ceux du lot expérimental $(e)$. Dans ces conditins, les besoins des animaux de $t^{\prime}$ et de $e$ sont les mêmes.

I1 est possible de calculer les besoins et l'indice de consommation hypo- 
thétique de ce lot $t^{\prime}$ à partir des mesures effectuées pour le lot témoin $t$, en utilisant la formule :

$$
\mathbf{I}=\frac{\mathrm{E}}{\mathrm{G}}+\mathbf{P}
$$

où $\mathrm{I}=$ indice de consommation,

$\mathrm{E}=$ besoin d'entretien,

$\mathrm{G}=$ gain moyen quotidien de poids vif,

$\mathrm{P}=$ besoin de production par $\mathrm{kg}$ de gain de poids vif.

Pour le lot $t$, nous avons :

d'où :

$$
\begin{aligned}
& \mathrm{I} t=\frac{\mathrm{E} t}{\mathrm{G} t}+\mathrm{P} \\
& \mathrm{P}=\mathrm{I} t-\frac{\mathrm{E} t}{\mathrm{G} t}
\end{aligned}
$$

Pour le lot $t^{\prime}$, nous avons :

$$
\mathrm{I} t^{\prime}=\frac{\mathrm{E} t^{\prime}}{\mathrm{G} t^{\prime}}+\mathrm{P}
$$

$P$ étant sensiblement le même pour les différents lots.

Or, par hypothèse, le gain de poids étant le même pour le lot témoin fictif et pour le lot expérimental, nous avons :

$$
\begin{aligned}
\mathrm{G} t^{\prime} & =\mathrm{G} e \\
\mathrm{G} t^{\prime} & =\mathrm{E} e
\end{aligned}
$$

car les animaux ont le même poids au départ.

\begin{tabular}{|c|c|c|c|c|c|}
\hline & & & & $\mathrm{Et}$ & \\
\hline & It & Et & Gt & $\overline{\mathrm{Gt}}$ & $\mathbf{P}$ \\
\hline Courcelles-Chaussy $\ldots \ldots \ldots \ldots \ldots \ldots \ldots$ & 4,54 & 0,90 & $0,66 \mathrm{I}$ & I, 36 & 3,18 \\
\hline Rouffach $: \ldots . .$. . & 3,94 & 0,90 & 0,698 & 1,29 & 2,65 \\
\hline & 4,04 & 0,88 & 0,667 & $\mathrm{I}, 33$ & $2,7 \mathrm{I}$ \\
\hline Bois-Corbon. & 3,87 & 0,86 & 0,663 & $\mathrm{I}, 3^{\circ}$ & 2,57 \\
\hline 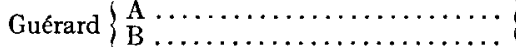 & 3,40 & 0,86 & $0,73^{\circ}$ & $\mathrm{I}, \mathrm{I} 8$ & 2,22 \\
\hline
\end{tabular}

d'où :

$$
\mathrm{I} t=\frac{\mathrm{E} e}{\mathrm{G} e}+\mathrm{P} .
$$

\begin{tabular}{|c|c|c|c|c|}
\hline & $\mathrm{Ee}$ & $\mathrm{Ge}$ & $\mathrm{Ge}$ & $1 t^{\prime}$ \\
\hline Courcelles-Chaussy $\ldots \ldots \ldots \ldots \ldots$ & 0,90 & 0,647 & $\overline{1,39}$ & 4,57 \\
\hline & 0,8 & 0,597 & $\mathrm{I}, 46$ & \\
\hline Ermenonville & 0,86 & 0,605 & $\mathrm{I}, 42$ & $4, I_{3}$ \\
\hline Bois-Corbon. & 0,78 & 0,498 & $\mathrm{I}, 57$ & $4, \mathrm{I}$ \\
\hline Guérard $\left\{\begin{array}{l}\mathrm{A} \\
\mathrm{B}\end{array} \ldots \ldots \ldots \ldots \ldots \ldots \ldots \ldots \ldots \ldots\right.$ & 0,82 & 0,618 & I,33 & \\
\hline
\end{tabular}

Nous aurons ainsi la valeur fourragère de l'indice de consommation du lot expérimental.

Calcul de $P=I t-\frac{E t}{G t}$

Calcul de $I t^{\prime}=P+\frac{E e}{G e}$ 
Dans chacune des expériences, nous pouvons dire que :

Dans les mêmes conditions de croissance, une quantité $a$ de pommes de terre + une quantité $b$ d'aliment complémentaire ont donné le même résultat (gain de $\mathrm{I} \mathrm{kg}$ de poids vif) qu'une quantité $c$ d'aliment témoin ayant une valeur fourragère de $I t^{\prime}$. Les deux rations étant équilibrées dans les deux cas, leur valeur fourragère est la même.

Nous avons :

d'où :

$$
\begin{aligned}
& a x+b y=\mathrm{I} t^{\prime} \\
& x=\frac{\mathrm{I} t^{\prime}-b y}{a} .
\end{aligned}
$$

L'analyse chimique nous permet de connaître $y$. Nous connaissons d'autre part $a$ et $b$ d'après le tableau VII. Il nous est ainsi facile de calculer $x$, valeur fourragère de la pomme de terre.

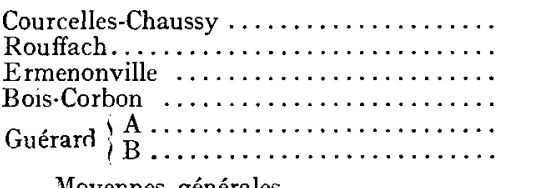

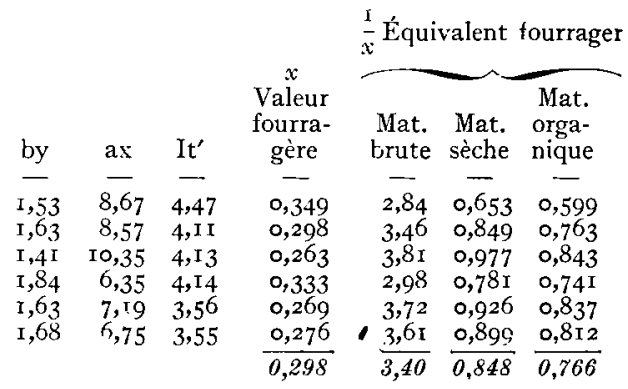

La moyenne de ces résultats concorde d'une façon satisfaisante avec ceux qui avaient été obtenus à partir de l'analyse chimique.

\section{CONCLUSIONS}

Notre étude d'ensemble de l'emploi de la pomme de terre pour la production de viande de porc, fait constater que :

I $^{0}$ L'utilisation nutritive de la pomme de terre crue, broyée et ensilée malgré une bonne conservation, est défectueuse chez le porc. La vitesse de croissance est de $30 \%$ inférieure à celle observée dans un régime de pommes de terre cuites et ensilées. L'indice de consommation est très élevé.

$2^{\circ}$ Les animaux nourris à l'ensilage de pommes de terre étuvées subissent un léger retard dans leur croissance (- I5 \%) par rapport à ceux consommant des aliments à base d'orge.

$3^{\circ}$ Cet écart de croissance est dû à une plus faible ingestion de matière sèche, dans le cas du régime à base de pommes de terre.

$4^{\circ}$ Toutes nos tentatives d'augmenter cette ingestion de matière sèche ont abouti à un insuccès, et se sont soldées par une diminution sensible de la consommation de pommes de terre.

$5^{\circ}$ L'utilisation de l'ensilage de pommes de terre pour l'alimentation des porcs est très économique dans les conditions actuelles. 


\section{EXPÉRIENCES SUR OVINS : ENGRAISSEMENT D'AGNEAUX}

Par A. M. LEROY et S. ZELTER

La littérature renseigne très peu sur l'utilisation de la pomme de terre pour l'alimentation du mouton. Cependant, GIRARD et CORNEvIN (32) signalent que ces tubercules donnent un rendement et une qualité de viande meilleurs que les betteraves.

Lors de nos recherches, nous nous sommes préoccupés uniquement du problème de la production de viande d'agneau gris à partir d'un ensilage de pommes de terre étuvées. Les agneaux étaient mis en expérience, soit après sevrage, soit pendant la période d'allaitement ; dans ce dernier cas, les mères nourrices étaient soumises au même régime que leurs petits.

\section{Expérience $n^{\circ} 6$ avec agneaux sevrés}

L'expérience effectuée en r 949 à Ermenonville a porté sur 36 sujets mâles castrés, de race Ile-de-France. Ils venaient d'être sevrés et étaient âgés de 3 mois au début de l'expérience.

\section{Dispositif expérimental}

Pendant une période de pré-expérience de 2 I jours, les 36 sujets ont été alimentés avec un régime composé de pulpes de betteraves sucrières ensilées, de foin de luzerne et d'aliments concentrés. Deux groupes homogènes et comparables ont pu être constitués pendant la période expérimentale, qui a duré 42 jours. Le groupe $\mathrm{A}$ a été nourri au régime témoin, tandis que le groupe $\mathrm{B}$ a reçu le régime expérimental, dans lequel les pulpes ont été remplacées par un ensilage de pommes de terre étuvées. Les quantités d'aliments distribuées ont été adaptées à l'appétit des sujets de chaque groupe, de manière à éviter les refus. Les doses moyennes journalières de pommes de terre ingérées étaient de I $\mathrm{kg}$, au début de la période, pour atteindre, à la fin de celle-ci, r, $8 \mathrm{~kg}$ environ. Cet aliment se présentant sous une forme pâteuse qui répugnait aux animaux, $8 \%$ de balles de céréales y ont été incorporés, afin d'en faciliter l'ingestion. Les quantités de nourriture consommées ont été pesées journellement. Des prélèvements périodiques d'aliments ont été analysés au laboratoire (voir tableau à l'annexe du mémoire). Le croît a été suivi par des pesées hebdomadaires de chaque sujet.

Pour l'interprétation des résultats, nous nous sommes servis des méthodes statistiques décrites précédemment pour les porcins, et avons, en outre, e1 recours à la méthode d'ajustement des droites par les moindres carrés pour la présentation graphique des résultats. 


\section{Résultats}

\section{TABLEAU X}

Mesures effectuées

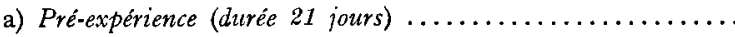

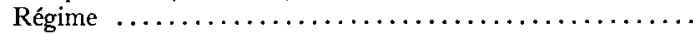

Io Consommation journalière moyenne $(\mathrm{kg})$ :

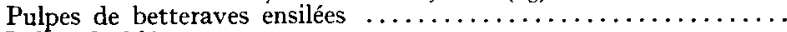

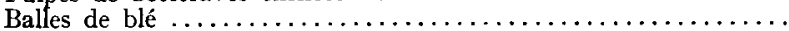

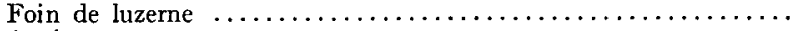

Avoine

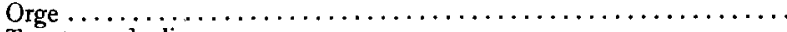

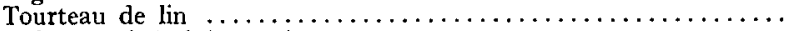

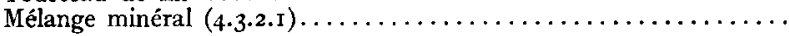

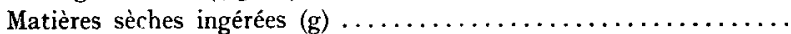

Matières protéiques digestibles $(\mathrm{g}) \ldots \ldots \ldots \ldots \ldots \ldots \ldots \ldots \ldots \ldots$

$2^{\circ}$ Accroissement de poids rif :

Poids vif moyen initial (kg)

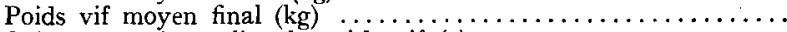

Gain moyen journalier de poids vif $(\mathrm{g}) \ldots \ldots \ldots \ldots \ldots \ldots \ldots \ldots$

\begin{tabular}{|c|c|}
\hline$\underset{\text { témoin }}{\text { Groupe } A}$ & $\begin{array}{l}\text { Groupe } B \\
\text { témoin }\end{array}$ \\
\hline 0,996 & I, \\
\hline 0,122 & 0,12 I \\
\hline $0,6 \mathbf{I}_{2}$ & $0,6 \mathrm{I} 2$ \\
\hline $0,{ }^{1} 5^{I}$ & $0,1_{5} \mathrm{r}$ \\
\hline 0,225 & 0,225 \\
\hline 0,043 & 0,043 \\
\hline 0,012 & 0,012 \\
\hline I I $5^{8}$ & I I $5^{8}$ \\
\hline 72,5 & 72,5 \\
\hline $\begin{array}{r}24,16 \\
27,94 \\
\mathrm{I} 80 \pm \text { I I }\end{array}$ & $\begin{array}{r}25,12 \\
29,00 \\
\mathrm{I} 82 \pm 15 \\
\end{array}$ \\
\hline Groupe $A$ & Groupe $B$ \\
\hline $\begin{array}{l}26,05 \\
180 \\
0,696 \\
0,434\end{array}$ & $\begin{array}{c}27,06 \\
\mathrm{r} 85 \\
0,696 \\
0,443\end{array}$ \\
\hline $\begin{array}{l}0,262 \\
0,146\end{array}$ & $\begin{array}{l}0,253 \\
0,137\end{array}$ \\
\hline
\end{tabular}

$3^{\circ}$ Besoins énergétuques nets par $100 \mathrm{~g}$ de croît (en unités fourragères) :

Poids vif moyen à la $1 / 2$ période $(\mathrm{kg})$

Gain moyen journalier de poids vif $(\mathrm{g}) \ldots \ldots \ldots \ldots \ldots \ldots \ldots \ldots$

Valeur énergétique de la ration (U. F.) $\ldots \ldots \ldots \ldots \ldots \ldots \ldots \ldots$

Besoins énergétiques d'entretien (U. F.) $\ldots \ldots \ldots \ldots \ldots \ldots \ldots \ldots$

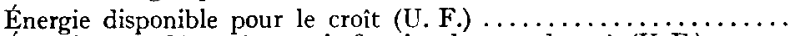

Énergie nette dépensée pour la fixation de $100 \mathrm{~g}$ de croît (U. F.) .....

La similitude du croît et de la dépense énergétique qu'il a entraîné pendant la pré-expérience démontrent la parfaite identité des groupes.

b) Expérience (durée 42 jours) :

Régime

Io Consommations movennes journalières $(\mathrm{kg})$ :

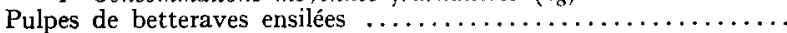

Ensilage de pommes de terre étuvées $\ldots \ldots \ldots \ldots \ldots \ldots \ldots \ldots \ldots$

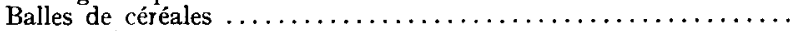

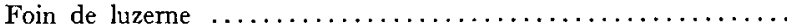

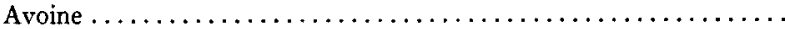

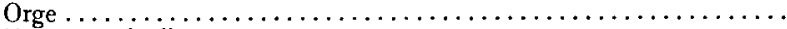

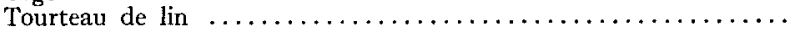

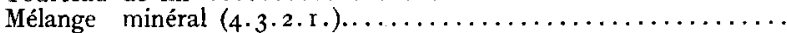

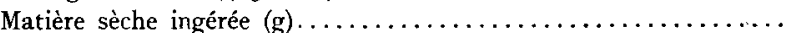

Matière sèche de la pomme de terre, $\%$ de la matière sèche ingérée ....

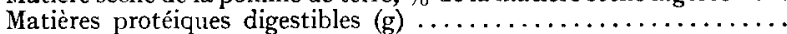

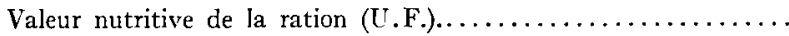
$2^{\circ}$ Accroissement de poids vif :

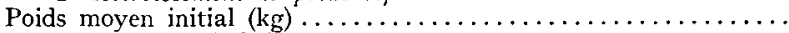

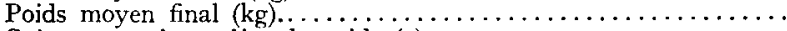

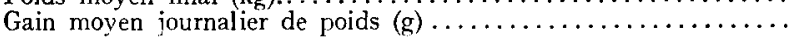

$3^{\circ}$ Jiesoins énergéliques nets par $100 \mathrm{~g}$ de croît (en U. F.) :

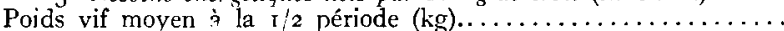

Gain noven joumalier de poids vif $(g) \ldots \ldots \ldots \ldots \ldots \ldots \ldots \ldots$

Valeur énergétique de la ration totale (U.F.) $\ldots \ldots \ldots \ldots \ldots \ldots$

Besoins énergétiques d'entretien (U. F.) $\ldots \ldots \ldots \ldots \ldots \ldots \ldots \ldots$

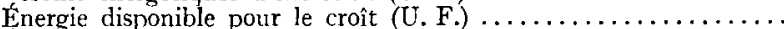

Énergie dépensée par roog de crôit (U. F.) $\ldots \ldots \ldots \ldots \ldots \ldots \ldots \ldots$

$\begin{array}{cc}\text { Groupe } A & \text { Groupe } B \\ \text { témoin } & \begin{array}{c}\text { expérimental } \\ \text { (pommes de terre) }\end{array}\end{array}$

\begin{tabular}{|c|c|}
\hline $\mathrm{I}, 855$ & - \\
\hline- & I, 476 \\
\hline 0,206 & 0,117 \\
\hline 0,665 & 0,597 \\
\hline o, I 75 & 0,176 \\
\hline 0,260 & 0,262 \\
\hline 0,050 & 0,050 \\
\hline 0.015 & o,oI 5 \\
\hline $\begin{array}{l}30 \\
\circ \\
85\end{array}$ & $\begin{array}{c}\text { I } 473 \\
26,0 \% \\
80\end{array}$ \\
\hline
\end{tabular}

Rat. compl. sans pommes de terre

\begin{tabular}{cc} 
& de terre \\
0,85 & 0,69 \\
& \\
27,94 & 29,00 \\
33,70 & 35,25 \\
$139 \pm 7$ & $149 \pm 9$ \\
\hline
\end{tabular}

$\begin{array}{cc}30,82 & 32, \mathrm{I} 2 \\ \mathrm{I} 39 & \mathrm{I} 49 \\ 0,85 & - \\ 0,48 & 0,48 \\ 0,375 & - \\ 0,270 & -\end{array}$




\section{Interprétation}

Lors de la période expérimentale, les besoins de production du groupe A témoin sont normaux et conformes aux indications des tables pour ovins. Par contre, ceux du groupe B, nourri avec de l'ensilage de pommes de terre étuvées, apparaissent particulièrement aberrants si on prend en considération la valeur nutritive de cet aliment, telle qu'elle ressort de l'analyse chimique. Ceci fait supposer que pour l'agneau cette valeur est fortement surestimée.
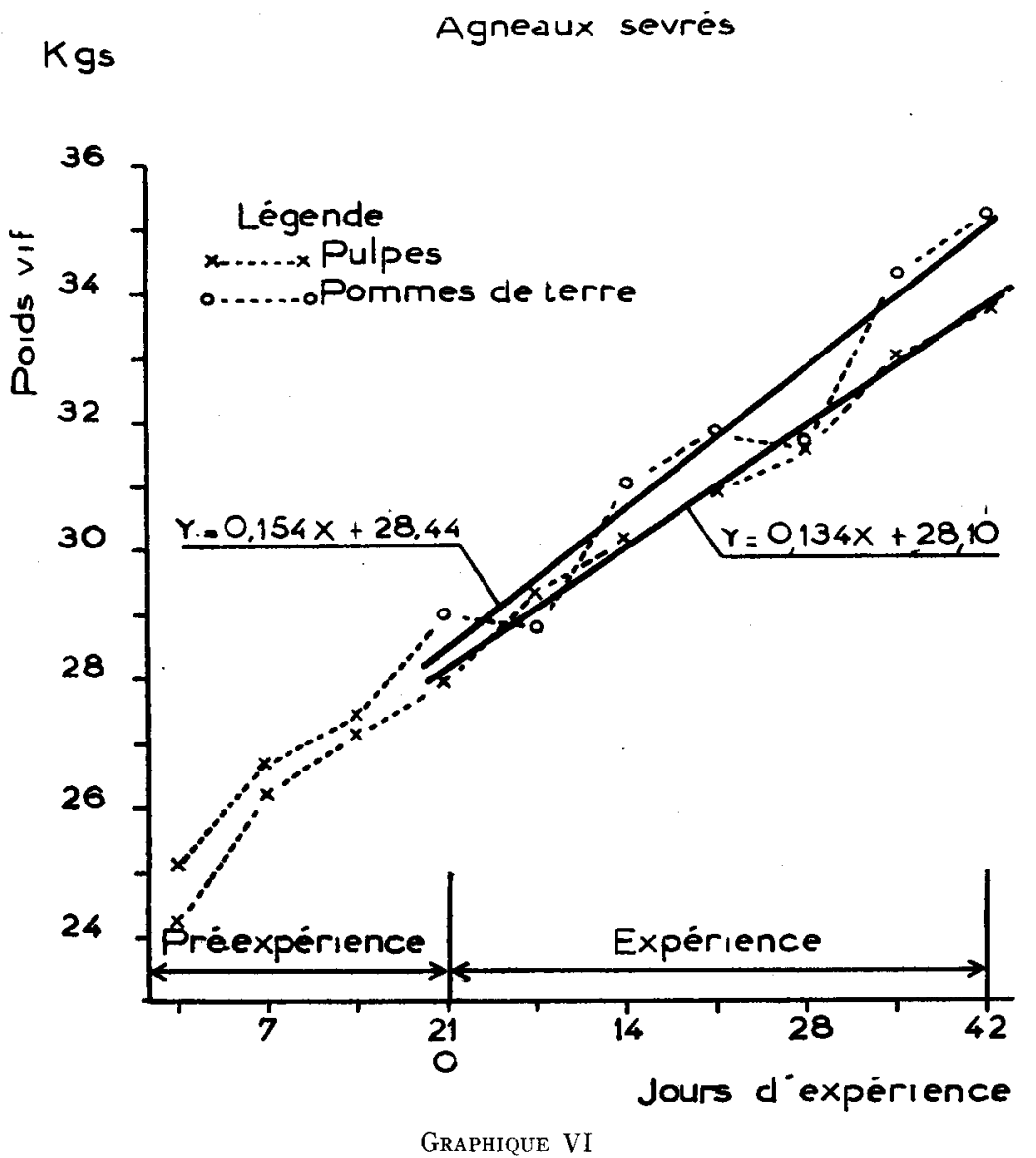

Les données zootechniques de cette expérience doivent cependant permettre de calculer la valeur nutritive effective de l'aliment en question. En effet, les 2 groupes soumis à l'expérience ont accusé, pendant la pré-expérience, une dépense énergétique de croît sensiblement identique. Lors de la période expérimentale, celle du groupe A témoin concorde nettement avec les normes établies. On peut, par conséquent, prendre cette dernière comme base de calcul pour les besoins du groupe B. Leur évaluation (entretien + croît), permettra 
de déterminer la valeur nutritive réelle de l'ensilage de pommes de terre, que nous posons égale à $\mathrm{X}$.

Soit :

$e=$ besoins énergétiques d'entretien (U. F.) ;

$p=$ besoins énergétiques de croît (U. F.) calculés d'après ceux du groupe A (soit 0,270 U. F. par Ioo g).

$t=$ besoins énergétiques totaux (U. F.).

Les besoins totaux $(t)$ du groupe $B$ dont le poids vif moyen était à la I/2 période de $32, \mathrm{I} 2 \mathrm{~kg}$ et le croît journalier de $\mathrm{I} 49 \mathrm{~g}$, seront donc :

$$
t=e+p=0,482+0,402=0,884 \text {. }
$$

Cet apport énergétique de $0,884 \mathrm{U}$. F. a été fourni par la ration complémentaire de valeur nutritive $0,689 \mathrm{U}$. F. additionnée de $I, 476 \mathrm{~kg}$ de pommes de terre ensilées (voir tableau $\mathrm{X} b$ ), dont la valeur nutritive réelle est :

$$
\underset{\text { (U. F. } / \mathrm{kg})}{\mathrm{X}}=\frac{0.88-0.69}{\mathrm{I} .476}=0, \mathrm{I} 4 \mathrm{U.F} \text {. }
$$
U. F.).

soit 6 I $\%$ seulement de la valeur théorique résultant de l'analyse $(0,23$

Ces deux valeurs permettent de calculer la quantité de M. S. correspondant à I U. F., soit, respectivement, I $850 \mathrm{~g}$ et I I $38 \mathrm{~g}$.

\section{Examen des carcasses}

Dans chacun des groupes, Io sujets jugés fin gras à la fin de l'expérience ont été sacrifiés et leur carcasse examinée. Les observations n'ont fait ressortir aucune différence dans le rendement en viande nette.

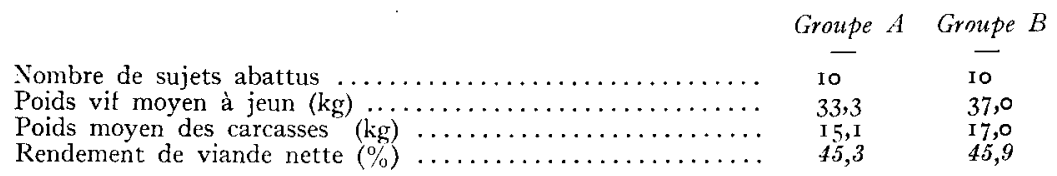

Cependant, de l'avis des spécialistes, la qualité de la viande provenant du groupe $\mathrm{B}$ était très supérieure à celle du groupe $\mathrm{A}$.

\section{Expérience no 7 avec agneaux allaités}

\section{Dispositif d'expérience}

Les essais entrepris à Rouvillers, au cours de 1'hiver I949-I950, ont porté à la fois sur les brebis nourrices et sur les agneaux allaités. Deux groupes de sujets, de race Ile-de-France, ont été formés, comprenant chacun un nombre égal de mères et d'agneaux de même âge, à raison de 26 agneaux et de 25 mères par lot (une naissance jumelée a été enregistrée dans chacun des lots au moment de leur constitution). Les groupes ont d'abord été soumis à une période de préexpérience d'une durée de $I_{5}$ jours, pendant laquelle le régime témoin à base 
de pulpes a été donné aux mères, pendant que les agneaux se nourrissaient exclusivement de lait maternel. L'âge des agneaux était de I5 jours au début de la pré-expérience, et d'un mois exactement à la fin de celle-ci.

TABLEAU XI

\section{Consommations d'aliments}

\section{A. - Alimentation DES BREBIS NOURRICES}

a) Pré-expérience (durée 15 jours) :

\section{Régime :}

Consommations journalières moyennes $(\mathrm{kg})$ :

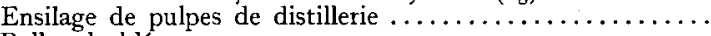

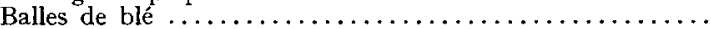

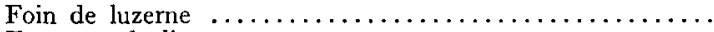

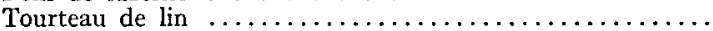

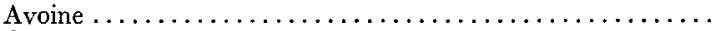

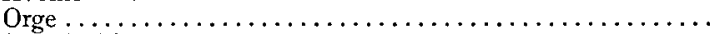

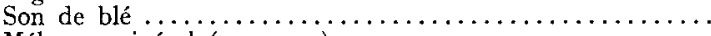

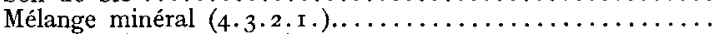

Matières sèches totales ingérées $(g) \ldots \ldots \ldots \ldots \ldots \ldots \ldots$

Matières protéiques digestibles $(\mathrm{g}) \ldots \ldots \ldots \ldots \ldots \ldots \ldots \ldots$

Valeur fourragère de la ration (U.F)

\section{b) Expérience (durée 70 jours) :}

\section{Régime :}

Consommations journalières moyennes $(k g)$ :

Ensilage de pulpes de distillerie $\ldots \ldots \ldots \ldots \ldots \ldots \ldots \ldots$

Ensilage mixte de pommes de terre et luzerne $\ldots \ldots \ldots \ldots$

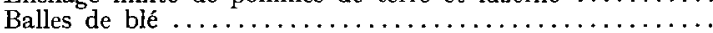

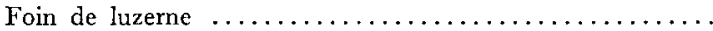

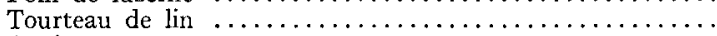

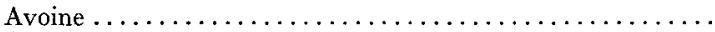

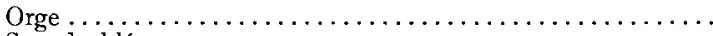

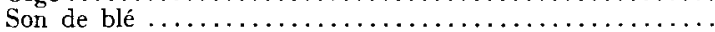

Mélange minéral.

Matières sèches totales ingérées $(\mathrm{g}) \ldots \ldots \ldots \ldots \ldots \ldots \ldots$

Matières sèches de l'ensilage mixte, \% de la matière sèche totale

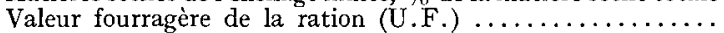

Valeur fourragère de la ration complémentaire $\ldots \ldots \ldots \ldots$

Mat. protéiques digestibles ingérées $(\mathrm{g}) \ldots \ldots \ldots \ldots \ldots \ldots \ldots$

\section{Groupe $A$ \\ pulpes}

4,050
0,430
0,750
0,460
0,140
0,162
0,030
0,035
293
I97
1,51
pulpes

pulpes

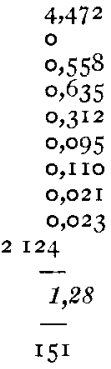

Groupe $B$

pulpes

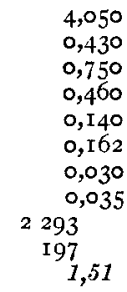

ensilage mixte de pommes de terre et luzerne

\section{B. - Alimentation des agneauX}

\section{Groupe A}

lait maternel exclusivement

Betteraves fourragères

\section{b) Expérience Régime :}

Consommations moyennes iournalières $(\mathrm{kg})$ Lait maternel pour les $2 \mathrm{~g}$ roupes + ration complémentaire comportant:

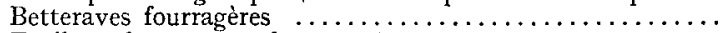

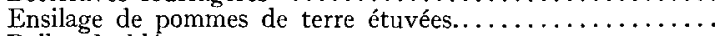

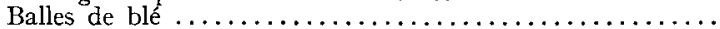

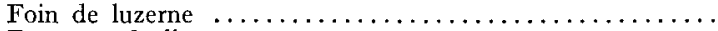

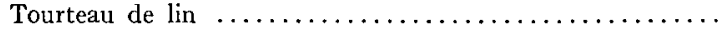

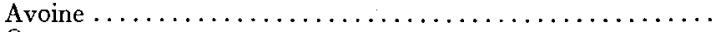

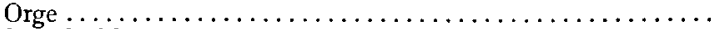

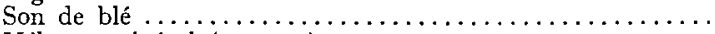

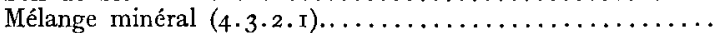
M.S.totale ingérée (g), lait excepté $\ldots \ldots \ldots \ldots \ldots \ldots \ldots$ M. S. de l'ensilage de pommes de terre, $\%$ de la M. S. totale... M. protéiques digestibles totales $(g) \ldots \ldots \ldots \ldots \ldots \ldots \ldots$ (celles du lait excepté).

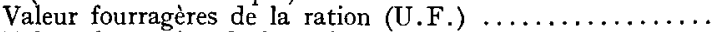
Valeur fourragère de la ration complémentaire...........

0
3,763
0
0,668
0,260
0
0
0
0,012
I 820
$53,1 \%$
$\frac{0,56}{1}$
2 23

\section{Groupe B}

lait maternel exclusivement

Ensilage de pommes de terre étuvée 
Pendant la période expérimentale, d'une durée de 70 jours, le groupe A des mères servant de témoin continuait à être soumis au régime témoin comportant des pulpes de betteraves, du foin de luzerne et des aliments concentrés. Les mères du groupe $B$ recevaient le même régime mais dans lequel les pulpes de betteraves avaient été remplacées par de l'ensilage mixte de pommes de terre étuvées et de luzerne verte, préparé deux mois auparavant. Pendant cette période, les agneaux du groupe $\mathrm{A}$ commençaient à recevoir, en plus du lait maternel, une alimentation complémentaire croissant avec l'âge et l'appétit des sujets, comportant des betteraves fourragères, du foin de luzerne et des aliments concentrés. Les agneaux du groupe B - expérimental - étaient soumis au même régime alimentaire, à l'exception des betteraves qui avaient été remplacées par de 1'ensilage de pommes de terre étuvées (la luzerne avait été écartée, parce que souillée de particules terreuses qui risquaient d'entraîner des accidents d'obstruction du tube digestif des jeunes).

Les quantités des divers aliments ingérés ont été contrôlées par les pesées journalières. Les échantillons prélevés ont été examinés au laboratoire (voir résultats à l'annexe de ce mémoire).

L'évolution du croît a été suivie par des pesées hebdomadaires en groupe pour les mères, et individuelles pour les agneaux.

\section{TABLEAU XII}

\section{Croissances}

\section{A. - ACCRoISSEMENT DE POIDS DES MÈres}

a) Pré-expérience :

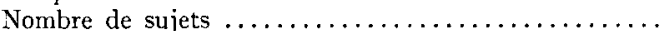

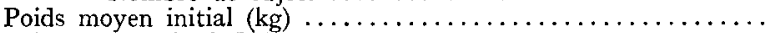

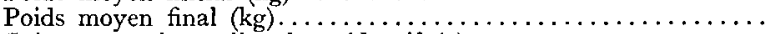

Gain moyen journalier de poids vif $(g) \ldots \ldots \ldots \ldots \ldots \ldots$

b) Expérience :

Poids moyen initial $(\mathrm{kg})$

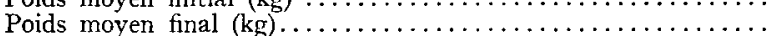

Poids moyen à la $\mathrm{J} / 2$ période $(\mathrm{kg})$

(méthode des moindres carrés)

Gain moyen journalier de poids vif $(\mathrm{kg}) \ldots \ldots \ldots \ldots \ldots \ldots$

\begin{tabular}{|c|c|}
\hline Groupe $A$ & Groupe \\
\hline $\begin{array}{l}25 \\
65,45 \\
65,50\end{array}$ & $\begin{array}{l}25 \\
67,30 \\
67,20\end{array}$ \\
\hline- & - \\
\hline 65,45 & 67,20 \\
\hline 68,60 & 69,70 \\
\hline 68,20 & $68,5^{\circ}$ \\
\hline 0,025 & 0,043 \\
\hline
\end{tabular}

\section{B. - ACCROISSEMENT DE POIDS DES AGNEAUX}

\begin{tabular}{|c|c|c|}
\hline Nombre de sujets $\ldots \ldots \ldots \ldots \ldots \ldots \ldots \ldots \ldots \ldots$ & ${ }_{26}^{\text {Groupe }} A$ & $\frac{\text { Groupe }}{26}$ \\
\hline 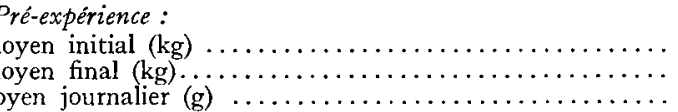 & $\begin{array}{r}9,2 \\
13,9 \\
309+\text { I } 5\end{array}$ & $\begin{array}{r}8,5 \\
13,0 \\
305 \text { I I3 }\end{array}$ \\
\hline 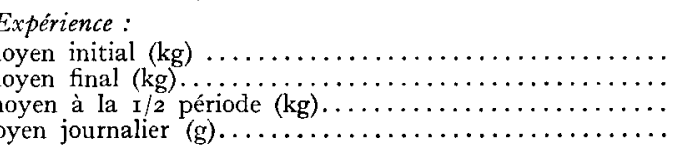 & $\begin{array}{r}13,9 \\
33,6 \\
23,8 \\
280 \pm 9\end{array}$ & $\begin{array}{r}13,0 \\
33,2 \\
23,1 \\
288 \pm \text { I0 }\end{array}$ \\
\hline
\end{tabular}



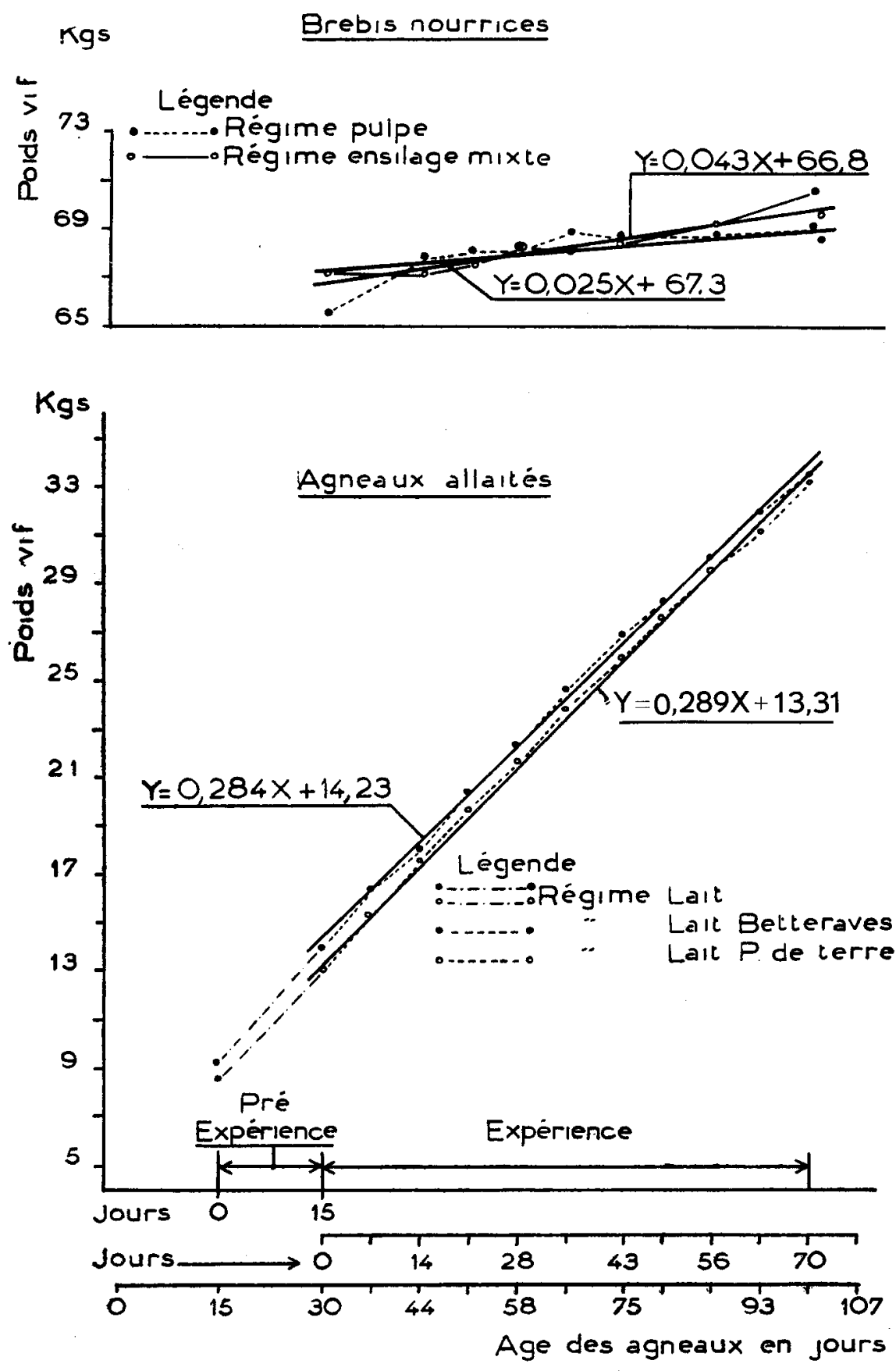


\section{Résultats}

A titre d'information, signalons que les quantités de betteraves, de balles et de pommes de terre consommées par les agneaux vers 1'âge de 5 semaines, n'étaient respectivement que de I5o g et $240 \mathrm{~g}$. Un peu avant le sevrage, vers l'âge de IOO jours, ces quantités ont atteint I,40 $\mathrm{kg}$ et I,I2 $\mathrm{kg}$ par agneau et par jout.

\section{Interprétations}

On observe une parfaite similitude de croissance dans les deux groupes d'agneaux, pendant la pré-expérience.

Le lait maternel ayant constitué l'aliment exclusif des agneaux pendant cette période, on peut en conclure que la quantité de lait dont disposaient les jeunes était sensiblement la même pour les sujets de chaque groupe.

On peut donc supposer que cette similitude s'est conservée pendant la suite de l'expérience, ce qui permet de calculer la valeur réelle des ensilages consommés par les mères et les agneaux pendant la période expérimentale.

$\mathrm{I}^{\mathrm{O}}$ Valeur nutritive de l'ensilage mixte de pommes de terre et de luzerne consommé par les mères :

D'après les tableaux XI $b$ et XII $b$, nous pouvons calculer à l'aide des tables d'alimentation, les besoins d'énergie de chaque groupe :

\begin{tabular}{|c|c|c|}
\hline & Groupe $A$ & Groupe B \\
\hline coins d'entretien $(\mathrm{IT} \mathbf{F})$, & $\overline{0,69}$ & 0,69 \\
\hline 265 par 100 g).. & 0,07 & $0, \mathrm{II}$ \\
\hline$\ldots \ldots \ldots, \ldots, \ldots, \ldots$ & $0,7^{6}$ & $\overline{0,80}$ \\
\hline $\begin{array}{l}\text { Énergie disponible pour la secrétion lactée du groupe } \mathrm{A} \ldots \ldots \ldots \ldots \ldots \ldots \\
\text { Energie réservée par hypothèse à la secrétion lactée du groupe } \mathrm{B} \ldots \ldots \ldots \ldots \\
\text { Valeur fourragère de la ration } \ldots \ldots \ldots \ldots \ldots \ldots \ldots \ldots \ldots \ldots\end{array}$ & 0,52 & $\begin{array}{r}\overline{0,52} \\
\mathrm{I} \mathrm{u}, 32\end{array}$ \\
\hline
\end{tabular}

La valeur fourragère $(x)$ de la ration complétant l'ensilage étant de $0,56 \mathrm{U}$ la différence entre ces deux valeurs correspond à l'énergie fournie par les $3,76 \mathrm{~kg}$ d'ensilage mixte de pommes de terre et de luzerne consommé par le groupe $B$ des mères :

$$
x=\frac{\mathrm{I} .32-0.56}{3.7^{6}}=\mathrm{Ou} .20
$$

supérieure de Io \% à la valeur de $\mathrm{X}$ calculée à partir de données chimiques (o,I8 U).

Ces deux valeurs permettent de calculer la quantité de M. S. correspondant à I U. F., soit respectivement I 266 et I $389 \mathrm{~g}$.

$2^{\circ}$ Valeur nutritive de l'ensilage de pommes de terre étuvées consommé par les agneaux pendant la période expérimentale

Les données des tableaux XI $b$ et XII $b$ permettent de calculer d'après les normes, les beoins énergétiques des deux groupes, évalués en U. F. 
Groupe A Groupe B

$0,39 \mathrm{I}$

0,320

Valeur fourragère de la ration ingérée (lait excepté) en U. F......

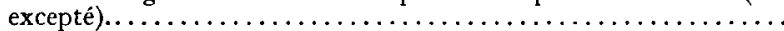

Les besoins d'énergie sont :

Besoins d'entretien (U.F.)

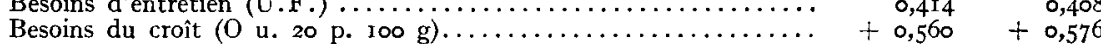

Total théorique des besoins énergétiques.

Les besoins diffèrent donc de o,or $\mathrm{U}$. en faveur du groupe $\mathrm{B}$.

En posant :

$l=$ valeur fourragère du lait maternel,

$e=$ valeur fourragère des pommes de terre ensilées consommées nous pouvons écrire que les rations apportées aux deux groupes ont couvert les besoins :

$$
\begin{aligned}
& \text { A : } 0,974=\mathrm{I}+0,39 \mathrm{I} \\
& \mathrm{B}: 0,984=\mathrm{I}+0,320+e
\end{aligned}
$$

ce qui donne :

$$
e=0,08 \mathrm{I}
$$

la valeur fourragère $\mathrm{X} \mathrm{d} \mathrm{du} \mathrm{kg}$ de pommes de terre est donc :

$$
\frac{0,08 \mathrm{I}}{0,392}=0,207
$$

soit inférieure de $28 \%$ à la valeur théorique calculée à partir de l'analyse chimique $(0,289$.)

Ces deux valeurs permettent de calculer la quantité de M. S. correspondant à I U. F, soit respectivement : I $396 \mathrm{~g}$ et I ooo g.

Conclusions. - Les résultats des expériences no 6 et 7 révèlent une différence sensible entre les estimations de la valeur fourragère de la pomme de terre que l'on peut faire à partir des mesures chimiques et des mesures biologiques.

Deux raisons peuvent, à notre avis, expliquer ce phénomène :

a) une mauvaise utilisation digestive de cet aliment riche en glucides, chez le jeune ruminant dont la panse est en pleine évolution ;

b) la présence d'acides organiques dans l'ensilage, qui pourrait être préjudiciable au métabolisme général du jeune.

Nos expériences démontrent que l'ensilage de pommes de terre étuvées est à écarter de l'alimentation de l'agneau. Par contre, l'ensilage mixte de pommes de terre et de luzerne convient parfaitement à la brebis nourrice à raison de $3-4 \mathrm{~kg}$ par jour. Son emploi permet de réduire de $50 \%$ la consommation d'aliments concentrés, et d'abaisser le prix de revient de la viande d'agneau. 
EXPÉRIENCES SUR BOVINS : UTILISATION DE LA POMME DE TERRE POUR LA PRODUCTION LAITIEERE

Par A. M. LEROY et S. ZELTER

CORNEvIN (33) signale que les pommes de terre cuites favorisent la sécrétion de matières grasses chez la vache laitière. Les expériences effectuées en I895 en Suisse à l'Ecole Laitière de Rutti (34) ont permis d'observer que la distribution de grosses quantités de pommes de terre crues (plus de Io $\mathrm{kg}$ ) aux vaches communique au fromage un goût amer très désagréable. Cette observation est confirmée en I937 par LANDIS et BURCKHARDT (35) qui ne recommandent l'emploi de la pomme de terre pour la vache en lactation qu'après cuisson et considèrent que des doses journalières de 8 à Io $\mathrm{kg}$ de cet aliment ne sont pas défavorables à l'activité mammaire. La littérature consultée ne mentionne aucune recherche concernant 1'utilisation de l'ensilage de pommes de terre étuvées pour la production laitière. Notre étude sur ce sujet comble donc une lacune.

\section{Expérience $n^{\circ} 8$}

Influence d'un ensilage mixte de pommes de terre étuvées et de luzerne sur la sécrétion lactée de la vache.

L'étude a été menée à bien entre le I5-I2-49 et le 2-5-50 à Moufflaines (Eure), où nous avons pu disposer d'un certain nombre de vaches en lactation répondant aux nécessités de notre protocole expérimental.

\section{Dispositif général de l'expérience}

a) Les animaux. - Le matériel animal était constitué par ro vaches que nous avons partagées en deux lots, en tenant compte de la race, de l'âge, du nombre de lactations antérieures, de la date de vélage, ainsi que des aptitudes de chacun des sujets.

b) Les régimes alimentaires. - Six semaines environ ont été nécessaires à la préparation des sujets, durant lesquelles le régime alimentaire équilibré destiné à servir par la suite de régime témoins a permis de régulariser la production et d'uniformiser l'état général des sujets. Une période de pré-expérience et trois périodes expérimentales, ayant duré chacune $2 \mathrm{I}$ jours, ont suivi cette phase préparatoire. Des intervalles de 4 jours séparaient deux périodes successives, pour faciliter 1'adaptation aux changements de régime.

Pendant la pré-expérience, les deux groupes $\mathrm{A}$ et $\mathrm{B}$ ont été soumis au régime type témoin comportant, comme aliment de base, des betteraves demisucrières en mélange avec des balles de céréales et du foin de luzerne, distribué en quantités égales à tous les sujets.

Des mélanges complémentaires à teneur variable en protéines comprenant 


\section{TABLEAU XIII}

\section{Mesures concernant la consommation d'aliments}

a) Pré-expérience (régime) :

Consommation movenne fournalière $(\mathrm{kg})$ :

Betteraves

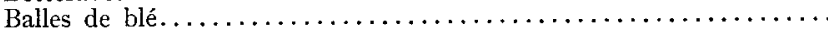

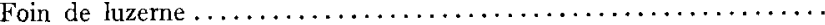

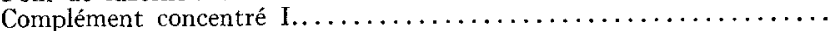

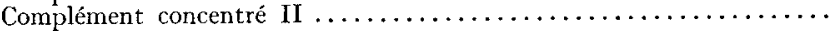

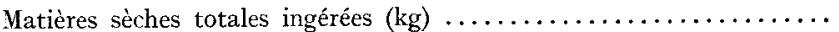

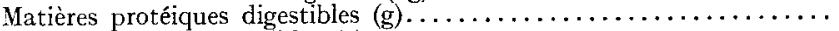

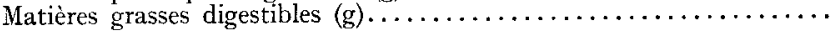

Valeur nutritive de la ration (U.F.)

\section{b) Expérience :}

Période I. - Régime alimentaire :

Consommation moyenne journalière $(\mathrm{kg})$ :

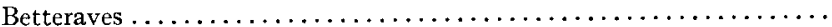

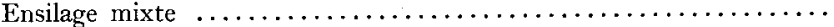

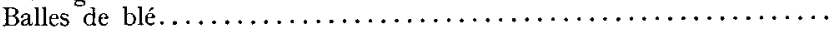

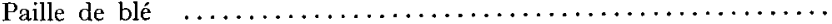

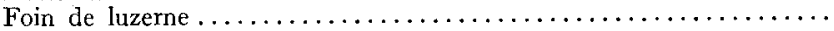

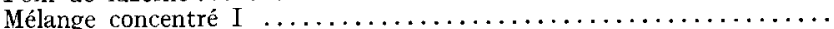

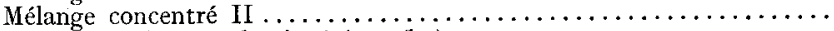

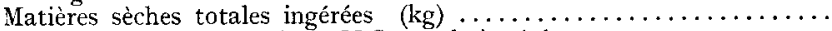

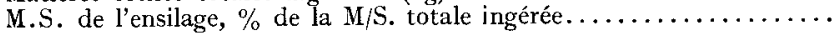

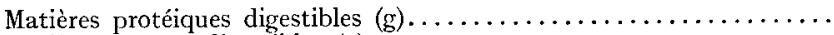

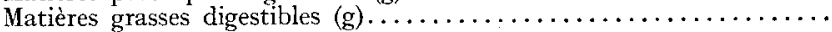

Valeur nutrivive de la ration $(\mathrm{U}, \mathrm{F}.) \ldots \ldots \ldots \ldots \ldots \ldots \ldots \ldots \ldots$

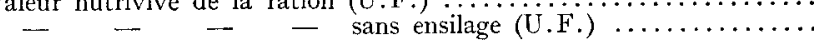

\section{Période 11. - Régime :}

Consommation moyenne yournatière $(\mathrm{kg})$.

Betteraves

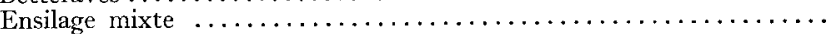

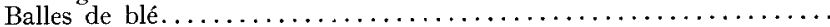

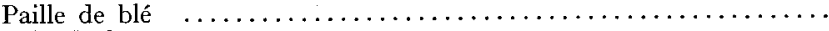

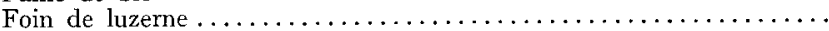

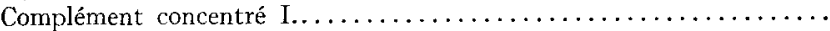

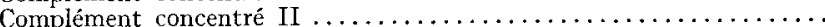

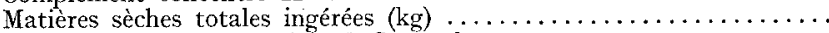

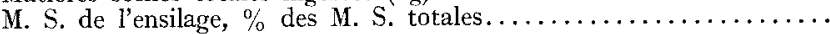

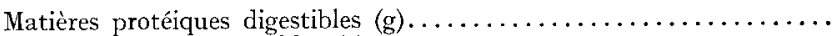

Matières grasses digestibles $(\mathrm{g})$..

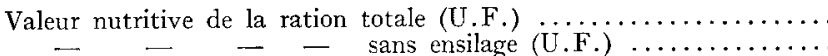

Période III. - Régime :

Consommation moyenne journaliève $(\mathrm{kg})$ :

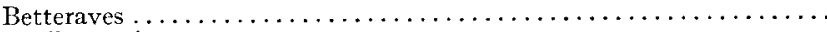

Ensilage mixte $\ldots \ldots \ldots \ldots \ldots \ldots \ldots \ldots \ldots \ldots \ldots \ldots \ldots \ldots \ldots \ldots \ldots \ldots \ldots$

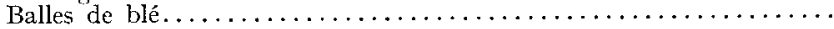

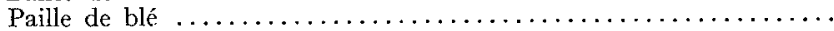

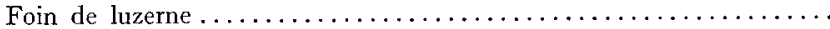

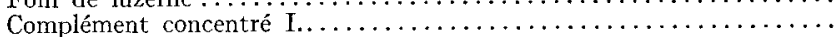

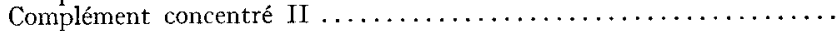

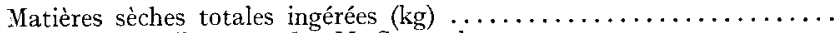

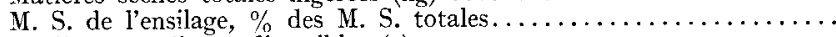

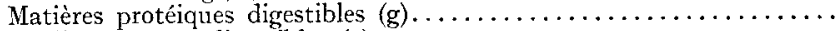

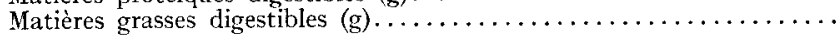

Valeur nutritive de la ration totale (U.F.) $\ldots \ldots \ldots \ldots \ldots \ldots \ldots \ldots$
Groupe $A$ Groupe $B$

betteraves betteraves

fourragères fourragères

$\begin{array}{cc}4 \mathrm{r}, 50 & 4 \mathrm{r}, 50 \\ 4,73 & 4,73 \\ 4,56 & 4,5^{6} \\ 0,635 & 0,783 \\ 3,636 & 3,346 \\ \mathrm{I} 6,584 & \mathrm{I} 6,45^{\circ} 8 \\ \mathrm{I}, \mathrm{I} 82 & \mathrm{I}, \mathrm{I} 88 \\ 0,366 & 0,35^{8} \\ 10,44 & 10,33\end{array}$

ensilage mixte betteraves

(20 kg)

$\begin{array}{cc}0 & 4 \mathrm{I}, 70 \\ 20,80 & 0 \\ 0 & 5,20 \\ 4,50 & 0 \\ 4, \mathrm{II} & 4, \mathrm{II} \\ 0,403 & \mathrm{I}, 323 \\ 2,943 & 2,0 \mathrm{I} 6 \\ \mathrm{I} 6, \mathrm{I} 90 & \mathrm{I} 5,782 \\ 32,7 \% & - \\ 886 & \mathrm{I}, 067 \\ 263 & 296 \\ 9,60 & 9,54 \\ 6,03 & -\end{array}$

ensilage mixte betteraves $(3 \circ \mathrm{kg})$

$\begin{array}{cc}0 & 39,50 \\ 29,80 & 0 \\ 0 & 4,90 \\ 4,50 & 0 \\ 4,10 & 4,10 \\ 0,896 & \mathrm{I}, \mathrm{I} 9 \\ 0,486 & \mathrm{I}, 58 \\ \mathrm{I} 6,72 \mathrm{I} & \mathrm{I} 5,759 \\ 45,3 \% & - \\ 78 \mathrm{r} & 950 \\ 209 & 262 \\ 9,46 & 8,21 \\ 4,33 & -\end{array}$

betteraves ensilage mixte

$\begin{array}{cc} & (30 \mathrm{~kg}) \\ 39,80 & 0 \\ 0 & 30,40 \\ 4,76 & 0 \\ 0 & 4,5 \circ \\ 3,73 & 3,73 \\ 0,973 & 0,596 \\ 2,139 & 0,523 \\ 14,634 & 16,298 \\ 47,4 \% & - \\ 929 & 657 \\ 269 & 187 \\ 8,87 & 9,14 \\ - & 3,90\end{array}$


des tourteaux de lin et d'arachide, des céréales secondaires, du son deblé et des sels minéraux étaient ajoutés à la ration de base, de façon à couvrir les besoins énergétiques et protéiniques des vaches, calculés d'après les tables d'alimentation.

Pendant toute la durée de l'expérience, le groupe expérimental recevait le régime témoin, dans lequel les betteraves avaient été remplacées par de l'ensilage mixte de pommes de terre étuvées et de luzerne. Une certaine quantité de paille de céréales a été substituée aux balles de céréales, afin d'assurer un lest suffisant et comparable à celui du régime témoin, en prenant la précaution de ne pas modifier par cette substitution l'équilibre énergétique pré-établi.

Le schéma ci-après résume la succession des régimes alimentaires appliqués à chacun des groupes :

Expérience

\begin{tabular}{|c|c|c|c|c|}
\hline Groupe & Pré-expérience & Période I & Période II & Période III \\
\hline A $\ldots$. & $\begin{array}{l}\text { Régime témoin } \\
\text { (betteraves) }\end{array}$ & $\begin{array}{l}\text { Régime expérimen- } \\
\text { tal (2o kg ensilage } \\
\text { mixte) }\end{array}$ & $\begin{array}{l}\text { Régime expérimen- } \\
\text { tal (3o kg ensilage } \\
\text { mixte) }\end{array}$ & $\begin{array}{l}\text { Régime témoin } \\
\text { (betteraves) }\end{array}$ \\
\hline B.... & $-\mathrm{id}^{\circ}-$ & $\begin{array}{l}\text { Régime témoin } \\
\text { (betteraves) }\end{array}$ & $\begin{array}{l}\text { Régime témoin } \\
\text { (betteraves) }\end{array}$ & $\begin{array}{l}\text { Régime expérimen- } \\
\text { tal ( } 30 \mathrm{~kg} \text { ensilage } \\
\text { mixte). }\end{array}$ \\
\hline
\end{tabular}

Les quantités d'aliments consommés par chacun des sujets ont été relevées journellement. Des prélèvements fréquents ont été examinés au laboratoire (voir tableau no 8 en annexe du mémoire).

c) Les mesures concernant la production laitière. - Les effets du régime ont été suivis grâce à des pesées portant sur le lait et le poids vif des sujets.

La sécrétion lactée individuelle a été mesurée à l'aide des pesées effectuées à chaque traite. La teneur du lait en matières grasses a été déterminée journellement pour chacun des sujets, par la méthode Gerber, sur un échantillon proportionnel des traites. Les quantités totales de matières grasses produites ont été obtenues en multipliant la quantité de lait produite par sa richesse en matières grasses.

Pour faciliter les comparaisons, la production totale de lait a été exprimée en lait à $4 \%$ de matières grasses d'après la formule de GArNEs :

Des pesées régulières, effectuées au début et à la fin de chaque période, ont permis de suivre l'état général des animaux. Deux à trois pesées intermédiaires complétaient ces observations.

\section{Les résultats}

L'interférence d'un certain nombre de facteurs peut masquer l'influence du régime sur la production laitière et rend très délicate l'interprétation des résultats expérimentaux.

La courbe de lactation, pour un intervalle restreint, peut se confondre avec une droite, et, par conséquent, se définit : 


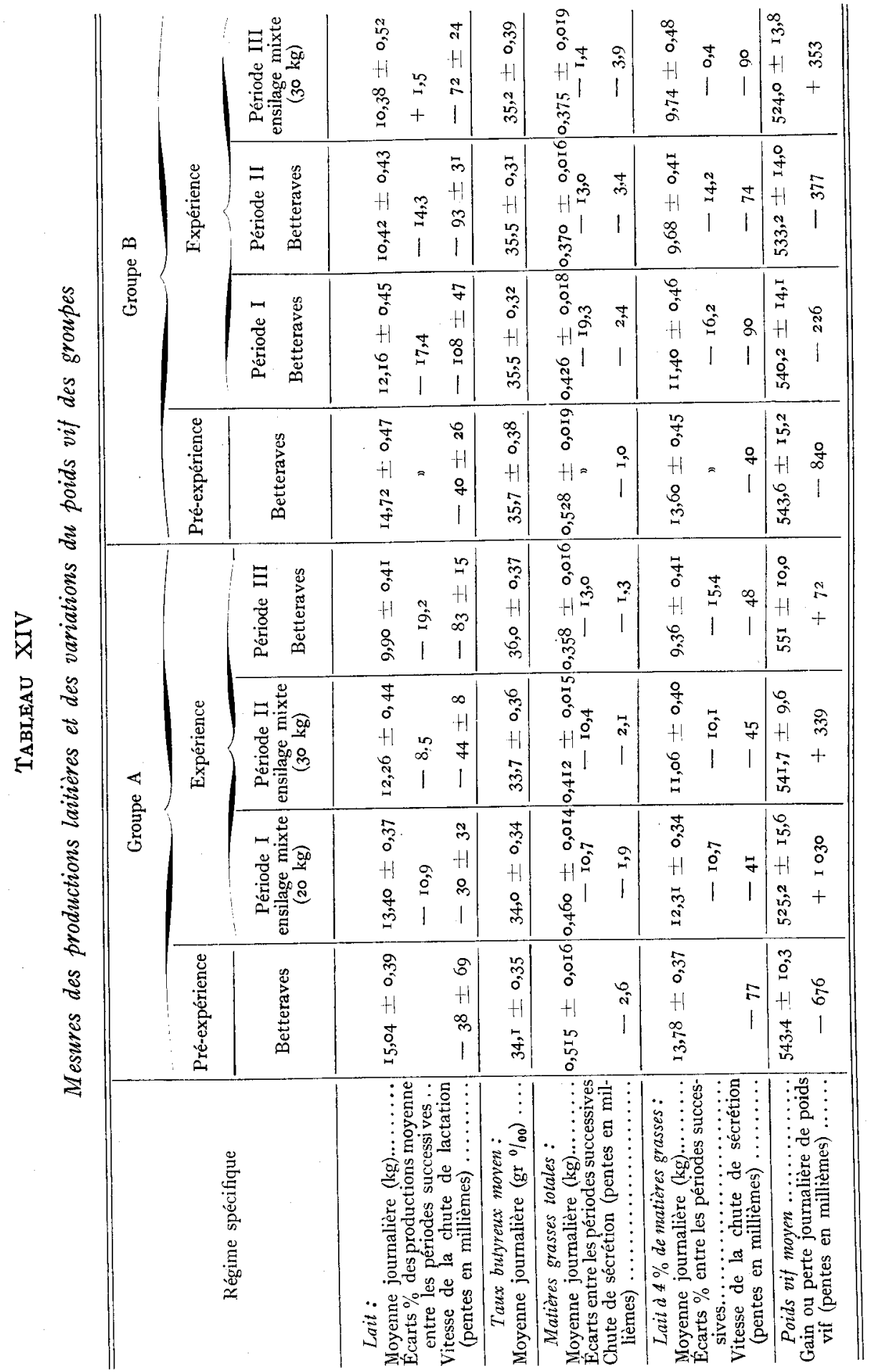



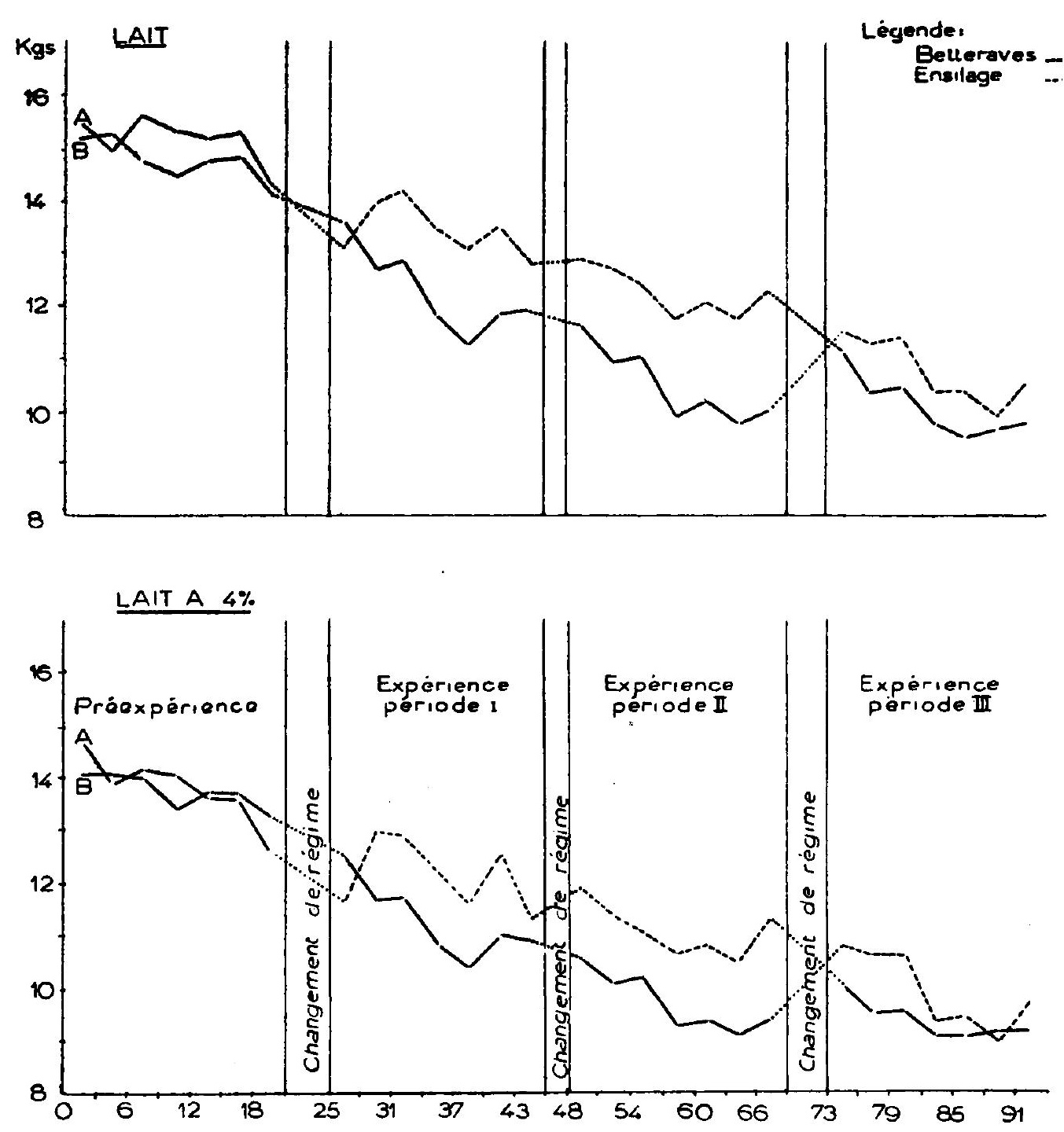

GRAPHIQUe VIII 
Grs Malières grasses lolales

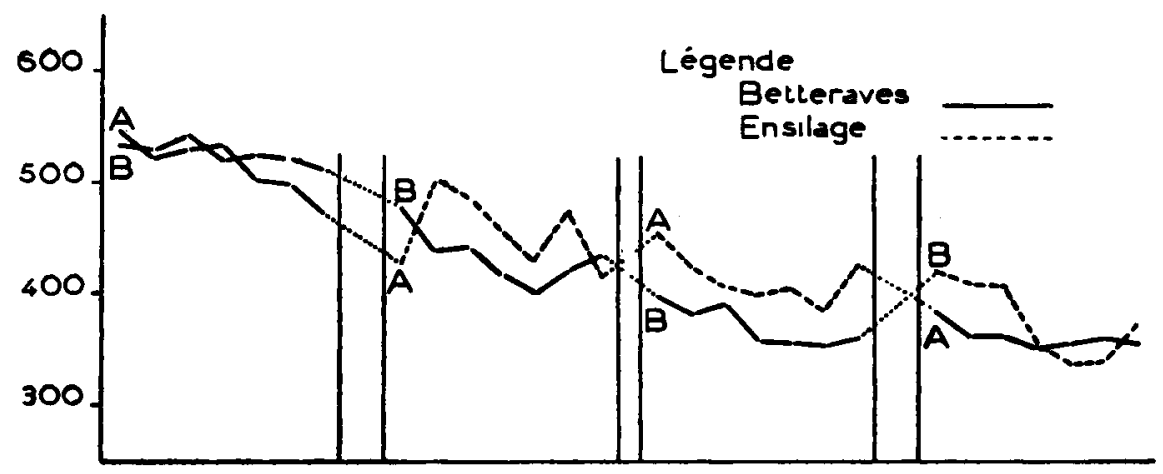

$\%$ Taux butyreux

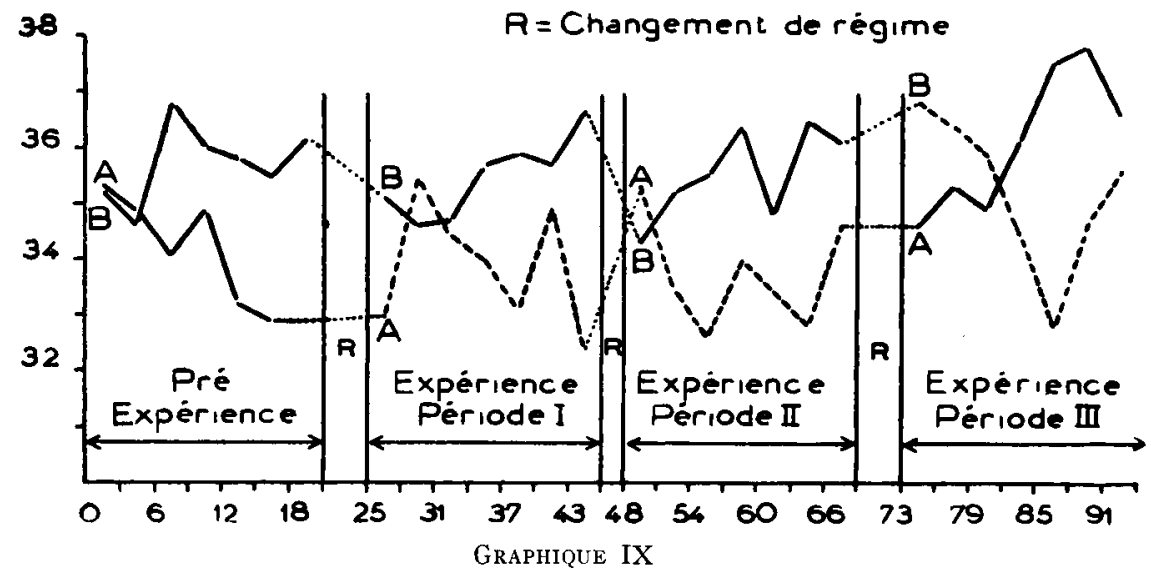

\section{Légende}

Betteraves

Ensilage

$\hat{R}=$ Changement de régıme

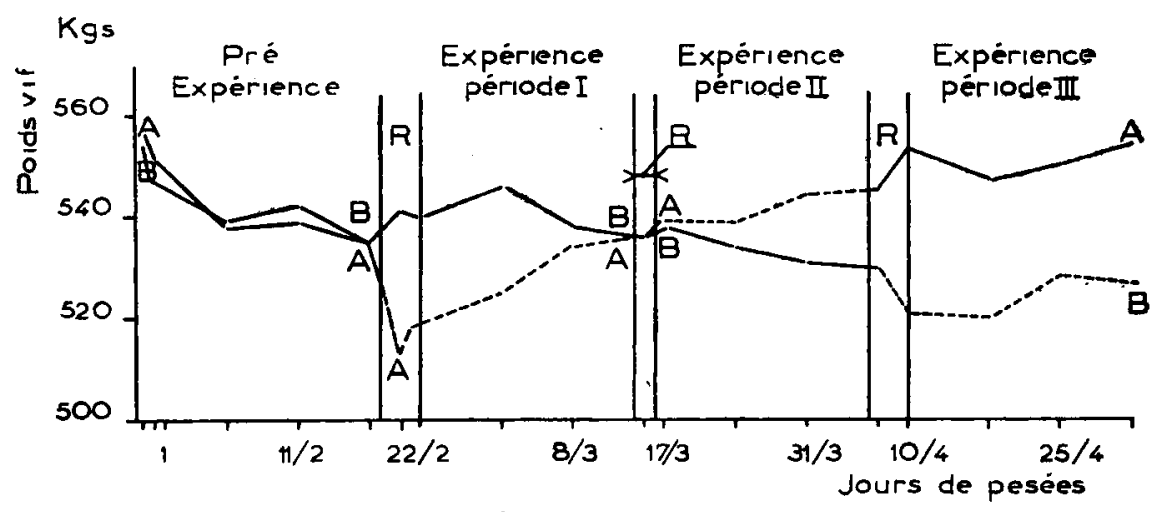

Graphique X 
Io par un point (ex. la moyenne de production, dans l'intervalle considéré) ; $2^{\circ}$ par une pente.

Celle-ci traduit la rapidité avec laquelle la production laitière diminue. Elle peut être plus ou moins grande, selon l'intervention d'un facteur d'origine alimentaire.

Les calculs que nous avons effectués à partir de nos mesures sont ceux de la moyenne pondérée par période, de l'erreur standard de cette moyenne, et de la pente de la droite d'ajustement obtenue par la méthode des moindres carrés. Cette dernière, exprimée en millièmes, représente les variations absolues des mesures effectuées.

La comparaison des résultats obtenus pendant la même période permet une interprétation plus correcte des phénomènes.

Chaque point des graphiques no 8 et 8 bis représente la moyenne des mesures effectuées pendant 3 jours successifs.

\section{Discussion des résultats}

Io Moyennes de production par période. - La comparaison entre les moyennes respectives des deux groupes de vaches en expérience et l'étude de leur variance commune font ressortir que :

a) Le très léger écart observé pour la sécrétion lactée pendant la préexpérience entre les deux groupes soumis au régime témoin est dépourvu de toute signification $(t=0,490$ et $0,6<\mathrm{P}<0,7)$. Ce test d'homogénété prouve donc que nos groupes sont comparables.

b) Pendant les périodes I et II, la substitution de l'ensilage mixte aux betteraves a permis de maintenir la production laitière du groupe $A$ à un niveau plus élevé que celle du groupe $B$ soumis au régime témoin.

La différence en faveur du groupe nourri à l'ensilage atteint $+6,5 \%$ environ. L'étude statistique des moyennes démontre que, pour la période $I$ : $t=2, \mathrm{IO} 2$ et $0,02<\mathrm{P}<0,03$, et pour la période II : $t=2,99$ et $\mathrm{P}<0,0$ I. Elle prouve que cette différence est très significative.

c) Lors de la période expérimentale III, le retour du groupe $\mathrm{A}$ au régime témoin, et le passage du groupe $B$ au régime expérimental, provoquent une inversion du phénomène : la chute de la sécrétion du lait dans le premier groupe est très forte et atteint - I9,2\%. Dans le groupe B, par contre, la chute continuelle enregistrée lors des précédentes périodes avec le régime témoin est, non seulement enrayée, mais encore la sécrétion a tendance à remonter légèrement. Elle s'accroît, en effet, de + I,5\% par rapport à celle enregistrée lors de la période II.

Les variations de régimes ont eu peu d'effet sur le taux butyreux. Les différences entre les données respectives des groupes concernant la sécrétion de matières grasses totales et de lait à $4 \%$ apparaissent, par conséquent, directement en rapport avec celles observées pour la production laitière et reflètent surtout ce dernier phénomène. 
Les variations de poids vif des animaux font apparaître un accroissement sensible de celui-ci toutes les fois que 1'ensilage mixte remplace les betteraves dans le régime, tandis que ce dernier aliment produit une variation inverse.

$2^{\circ}$ Chute des lactations. - L'examen des pentes reflète, plus clairement encore que celui des moyennes, l'effet des régimes sur la chute de lactation.

Pendant la pré-expérience, la chute de lactation est sensiblement la même dans les deux groupes. La baisse journalière de la production lactée est de 38 à $40 \mathrm{~g}$, ce qui est normal. L'homogénéité des deux groupes est très satisfaisante.

Durant les périodes expérimentales I et II, la chute de lactation du groupe A soumis au régime expérimental est du même ordre que la précédente. Celle du groupe $B$, nourri avec le régime témoin (betteraves) s'accentue, par contre, très significativement. Elle atteint - I $08 \mathrm{~g}$, soit le triple d'une chute normale.

A la suite de l'inversion des régimes, opérée pendant la période expérimentale III, la chute de lactation du groupe $\mathrm{A}$, remis au régime témoin, s'amplifie fortement ; tandis que celle du groupe $B$, passé au régime expérimental, s'atténue par contre très sensiblement.

La tendance du taux butyreux à remonter légèrement dans le groupe $\mathrm{A}$ sous l'effet de l'inversion des régimes pendant la période III, peut être attribuée à l'abaissement brutal du volume de lait produit pendant cette période.

L'évolution du poids vif des animaux est également extrêmement suggestive.

Les phénomènes observés montrent que, pour la vache laitière, l'ensilage mixte de pommes de terre étuvées et de luzerne verte constitue un aliment plus favorable à la production laitière que les betteraves.

L'explication de ce fait doit être recherchée dans l'étude approfondie des différences existant entre ces deux régimes, dont les aspects énergétique, protéique et lipidique méritent une attention particulière.

\section{L'APPORT D' ENERGIE}

Les apports énergétiques du régime témoin, calculés à partir de la composition chimique des aliments, étaient plus élevés que les besoins théoriques calculés d'après les normes classiques (voir tableau XV). Déduction faite des besoins de l'entretien et de l'accroissement dı poids, l'énergie disponible pour la production laitière variait entre $0,43 \mathrm{U}$ et $0,49 \mathrm{U}$ par $\mathrm{kg}$ de lait à $4 \%$. Or, d'après les normes, celles-ci n'aurait dû être que de 0,38 U. Cet excédent théorique d'énergie disponible n'a pas empêché cependant une décroissance anormale de la production laitière.

Le régime comportant des betteraves paraît donc exiger une dépense énergétique de production relativement élevée. 


\section{TABLEAU XV}

Tableau comparatif des besoins journaliers théoriques et des apports réels d'énergie (en Unités Fourragères)

Normes théoriques de besoins énergétiques:

Entretien selon le poids vif:

$400 \mathrm{~kg}: 3$ u. 25

$500 \mathrm{~kg}: 3$ u. 85

$600 \mathrm{~kg}: 4$ u. 40

Production laitière : 0 u. $3^{8}$ par $\mathrm{kg}$ de lait à $4 \%$ de $\mathrm{M} . \mathrm{G}$

Croît : 2 u. 65 par $\mathrm{kg}$ de gain de poids vif.

\section{Expérience}

Groupe A :

Besoins théoriques (UF..) ..................
Apports réels (U.F.) (y compris l'ensilage d'après

Apports réels (U.F.) (y compris l'ensilage d'après
sa valeur nutritive résultant de l'analyse)...

U.F. disponibles par $\mathrm{kg}$ de lait à $4 \%$ de M.G. produit $\ldots \ldots \ldots \ldots \ldots \ldots \ldots \ldots \ldots \ldots$.

\section{Groupe B :}

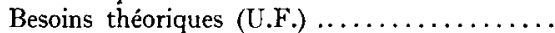

Apports réels (U.F.) (y compris l'ensilage d'après

sa valeur nutritive théorique résultant de

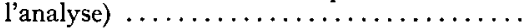

U.F. disponibles par $\mathrm{kg}$ de lait à $4 \%$ de M.G.

\begin{tabular}{|c|c|c|c|}
\hline \multicolumn{4}{|c|}{ Expérience } \\
\hline $\begin{array}{c}\text { Pré- } \\
\text { expérience } \\
\text { Betteraves } \\
-\end{array}$ & $\begin{array}{c}\text { Période } 1 \\
\text { Ensilage } \\
\text { mixte } \\
(20 \mathrm{~kg}) \\
-\end{array}$ & $\begin{array}{c}\text { Période II } \\
\text { Ensilage } \\
\text { mixte } \\
(30 \mathrm{~kg}) \\
\end{array}$ & $\begin{array}{c}\text { Période } \\
\text { III } \\
\text { Betteraves } \\
-\end{array}$ \\
\hline 9,33 & I I , 40 & $9, \mathrm{I} 8$ & 7,88 \\
\hline IO,44 & 9,59 & 9,45 & 8,87 \\
\hline o u. 46 & o u. 23 & o 11. 40 & $\begin{array}{c}\text { o u. } 49 \\
\text { Ensilage } \\
\text { mixte }\end{array}$ \\
\hline Betteraves & Betteraves & Betteraves & $(30 \mathrm{~kg})$ \\
\hline - & - & - & - \\
\hline 9,26 & 8,40 & 7,75 & 8,62 \\
\hline 10,33 & 9,54 & $8,2 \mathrm{I}$ & $9, \mathrm{I} 3$ \\
\hline o u. $4^{6}$ & ○ u. 48 & o u. 43 & o u. 43 \\
\hline
\end{tabular}

Pendant les périodes avec régime expérimental à base d'ensilage, l'énergie théoriquement disponible par $\mathrm{kg}$ de lait à $4 \%$ est de $0,23 \mathrm{U}$ avec une ration de $20 \mathrm{~kg}$ d'ensilage, et de $0,40 \mathrm{U}$ à $0,43 \mathrm{U}$ avec une ration de $30 \mathrm{~kg}$. Dans le premier cas, le chiffre est anormalement bas et indiquerait que la valeur nutritive réelle de 1'ensilage est supérieure à celle qui résulte de l'analyse chimique. Dans le second cas, l'énergie disponible apparaît très proche de celle recommandée par les normes.

L'influence heureuse de l'ensilage sur la production laitière ne peut donc être due à un facteur d'origine énergétique. La valeur nutritive effective de l'ensilage mixte semblerait en outre varier avec les quantités ingérées et être tantôt supérieure, tantôt inférieure à la valeur théorique. Le calcul de celles-ci figure dans les tableaux XVI $a$ et XVI $b$ et indique que la valeur effective de l'ensilage étudié ressort à $0,26 \mathrm{U}$ par $\mathrm{kg}$ avec une ration journalière de $20 \mathrm{~kg}$, tandis que la valeur théorique d'après l'analyse chimique est de $0, \mathrm{I}_{7} \mathrm{U}$ seulement. L'utilisation réelle lui est supérieure de $35 \%$. Par contre, lorsque la quantité journalière ingérée atteint $30 \mathrm{~kg}$, la valeur nutritive effective n'est plus que de $0, I 6 \mathrm{U}$, soit sensiblement la même que celle escomptée théoriquement. 
Les valeurs moyennes résultant des calculs effectués, soit à partir des données moyennes des groupes (XVI $a$ ), soit à partir des données individuelles des sujets (XVI $b$ ) concordent parfaitement ; les calculs individuels font cependant ressortir des différences d'utilisation très marquées d'un sujet à l'autre. Les valeurs extrêmes diffèrent de $35 \%$ et les écarts maxima à la moyenne sont de $-22 \%$ et de $+\mathrm{I}_{4} \%$.

\section{TABLEAU XVI}

Tableau comparatif des valeurs nutritives effectives et théoriques de l'ensilage mixte de pommes de terre et de luzerne consommé par les vaches en expérience.

XVI a. - a Calcul effectué à partir des données moyennes des groupes.

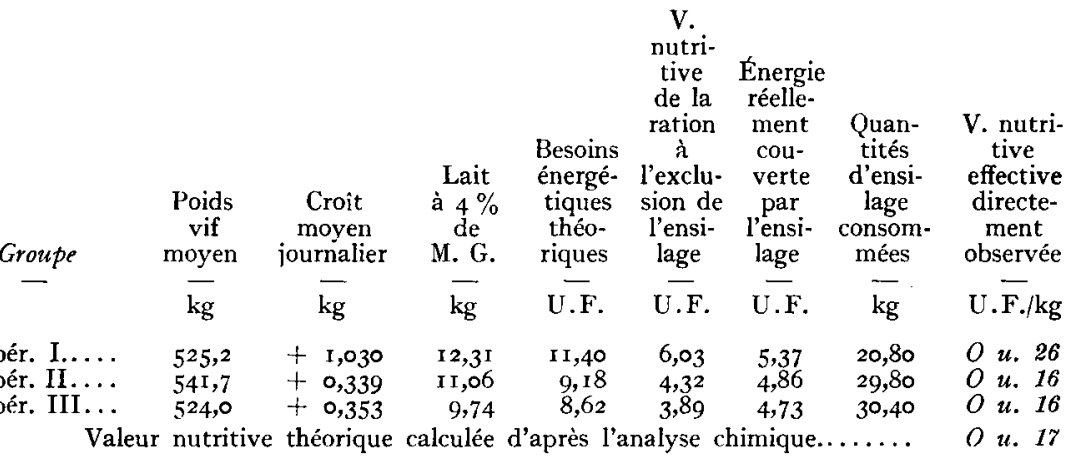

XVI b. - Calcul effectué à partir des données individuelles des sujets composant les groupes. Nom de la Vache:

Période I

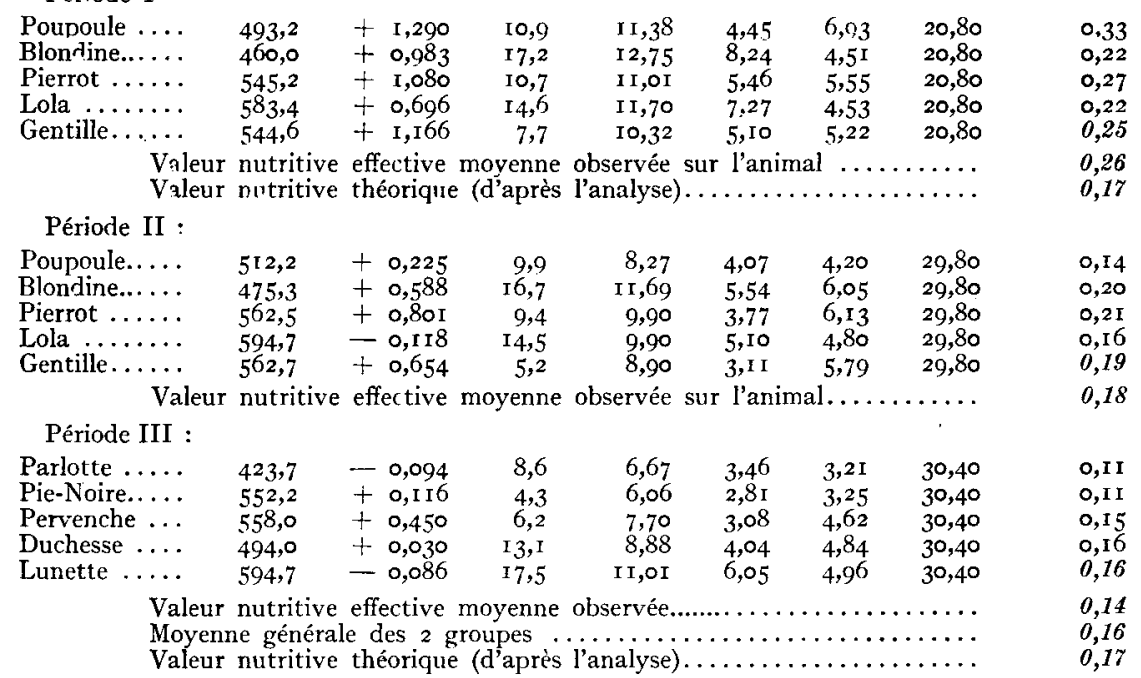

Les différences constatées dans la valeur nutritive effective avec des rations de 20 à $30 \mathrm{~kg}$ d'ensilage mixte, dont les $2 / 3$ sont constitués par des pommes de 
terre, pourraient être mises sur le compte du phénomène - bien connu et particulier aux ruminants — de la dépression de digestibilité : les microorganismes de la panse se trouvant en présence d'un aliment d'attaque facile tel que l'amidon, négligent la cellulose et les autres principes nutritifs, il en résulte un amoindrissement sensible de 1'utilisation digestive de la ration ingérée.

Dans notre expérience, ce phénomène semble particulièrement intense lorsque les doses de pommes de terre présentes dans l'ensilage mixte s'élèvent à $20 \mathrm{~kg}$, tandis qu'avec celles de $\mathrm{I} 2$ à $\mathrm{I} 3 \mathrm{~kg}$, il ne paraît guère avoir lieu. On peut, par conséquent, admettre qu'une dose journalière de $20 \mathrm{~kg}$ d'ensilage mixte constitue une ration qu'il ne convient pas de dépasser, lorsqu'il s'agit d'alimenter des vaches laitières d'un poids d'environ $500 \mathrm{~kg}$.

\section{L'APPORT DE MATIERES PROTEIQUES DIGESTIBLES}

Une comparaison entre les exigences théoriques des groupes en matières protéiques digestibles et les quantités qu'ils ont réellement ingérées (voir tableau XVII), fait constater que le régime témoin apportait les doses requises. Celui renfermant de l'ensilage montre en revanche, un déficit très marqué. Si cependant, l'activité mammaire ne semble pas avoir souffert pendant les périodes où cette carence s'est produite, il faut supposer que, dans le régime expérimenta1, la qualité biologique très élevée des protéines de la pomme de terre et de la luzerne (voir chapitre des Généralités) a dû suppléer à l'insuffisance des quantités de matières azotées distribuées.

\section{TABLEAU XVII}

Comparaison entre les besoins théoriques et les quantités réelles de matières protéiques digestibles assurées journellement par les régimes.

Normes théoriques Entretien $0,5 \mathrm{~g}$ par $\mathrm{kg}$ de poids vif des besoins Production de lait $60 \mathrm{~g}$ par $\mathrm{kg}$ de lait sécrété Croît ${ }_{5}$ o g par $\mathrm{kg}$ de gain de poids vif.

\begin{tabular}{cccc}
\multicolumn{5}{c}{ Expérience } \\
Groupe $A:$ \\
Pré-expérience Période I I Période II Période III \\
Betteraves
\end{tabular}

Il apparaît donc très douteux que l'augmentation de la sécrétion lactée, consécutive à une consommation d'ensilage mixte, puisse avoir pour origine un facteur de nature protéique. 


\section{L'APPORT DE LIPIDES}

Les quantités de matières grasses digestibles ingérées quotidiennement avec le régime témoin pendant la pré-expérience, étaient de 1'ordre de $360 \mathrm{~g}$. Elles correspondent aux doses minima qu'exige un fonctionnement normal de la glande mammaire, comme l'a démontré l'un de nous dans une recherche antérieure $(36)$.

Pendant toute cette étude, les quantités de lipides apportées par les deux régimes étaient nettement inférieures à ce seuil de $350 \mathrm{~g}$ (voir tableau XVIII). A elle seule, cette insuffisance lipidique pourrait expliquer une baisse anormale de la production laitière.

Ce phénomène est effectivement enregistré dans les groupes soumis au régime comportant des betteraves, mais la chute de production est atténuée lorsque l'on substitue de l'ensilage mixte de pommes de terre et de luzerne. Et pourtant, la teneur en lipides de ce dernier régime était encore plus faible que précédemment. De récentes recherches concernant la lipogénèse chez le ruminant permettent d'expliquer cette apparente contradiction.

Leurs auteurs, FOLIEY et FRENCH (37) attribuent à certains acides gras de poids moléculaire peu élevé (en particulier à l'acide acétique) un rôle de méta-

\section{TABLEAU XVIII}

\section{Apports journaliers des régimes en matières grasses}

Groupe $A$ :

Régime :

Lipides digestibles ingérés (g)... .

Acides gras volatils ingérés (g)

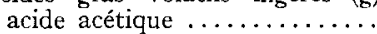

acide butyrique............

Lipides digestibles \% de la matière sèche ingérée ............

Lipides digestibles + ac. gras volatils $\%$ de M.S. ingérée ......

Variation de la production en $\%$ :

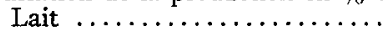

Matières grasses totales........

Groupe $B$ :

Régime :

Lipides digestibles ingérés $(g) \ldots$ Acides gras volatils ingérés (g) acide acétique $\ldots \ldots \ldots \ldots \ldots$

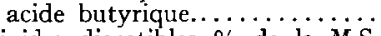
Lipides digestibles $\%$ de la M.S. ingérée .................. Lipides digestibles + ac. gras volatils $\%$ de la M.S. ingérée ... Variations de la production en $\%$ :

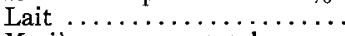
Matières grasses totales .....
Expérience

\begin{tabular}{|c|c|c|c|}
\hline $\begin{array}{c}\text { Pré-expérience } \\
\text { Betteraves } \\
-\end{array}$ & $\begin{array}{c}\overline{\text { Période I }} \\
\text { Ensil. mixte } \\
\quad \overline{(20 \mathrm{~kg})}\end{array}$ & $\begin{array}{c}\text { Période II } \\
\text { Ensil. mixte } \\
(30 \mathrm{~kg})\end{array}$ & $\begin{array}{c}\text { Période III } \\
\text { Betteraves } \\
-\end{array}$ \\
\hline 366 & 263 & 209 & 269 \\
\hline $\begin{array}{l}\text { traces } \\
\text { traces }\end{array}$ & $\begin{array}{l}83 \\
48\end{array}$ & $\begin{array}{r}\text { rig } \\
68\end{array}$ & $\begin{array}{l}\text { traces } \\
\text { traces }\end{array}$ \\
\hline 2,21 & 1,62 & 1,25 & 1,84 \\
\hline- & 2,43 & 2,36 & - \\
\hline - & 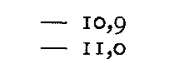 & $\begin{array}{r}8,5 \\
-\quad 10,4\end{array}$ & $\begin{array}{l}-19,2 \\
-\quad{ }^{1} 3, \mathrm{r}\end{array}$ \\
\hline Betteraves & Betteraves & Betteraves & $\begin{array}{c}\text { Ens. mixte } \\
(-\overline{\mathrm{kg}})\end{array}$ \\
\hline $35^{8}$ & 296 & 262 & 187 \\
\hline $\begin{array}{l}\text { traces } \\
\text { traces }\end{array}$ & $\begin{array}{l}\text { traces } \\
\text { traces }\end{array}$ & $\begin{array}{l}\text { traces } \\
\text { traces }\end{array}$ & $\begin{array}{r}122 \\
70\end{array}$ \\
\hline 2,18 & 1,88 & 1,66 & 1,15 \\
\hline- & - & - & 2,45 \\
\hline - & $\begin{array}{l}-17,4 \\
-\quad 19,3\end{array}$ & $\begin{array}{r}14,3 \\
-13,2\end{array}$ & $\begin{array}{l}+\quad 1,5 \\
+\quad r, 4\end{array}$ \\
\hline
\end{tabular}


bolite intermédiaire dans la synthèse lipidique de la glande mammaire du ruminant. Une vérification expérimentale de cette hypothèse a été effectuée dernièrement sur des vaches en lactation, par l'un de nous (38). Ses résultats apportent la preuve que les acides gras volatils (acides acétique et butyrique) présents en doses appréciables dans les ensilages, sont capables de stimuler les sécrétions mammaires, et de suppléer éventuellement à une carence du régime de la vache en matières grasses.

Le tableau ci-dessus fait apparaître que les quantités journalières d'acides gras volatils absorbées avec l'ensilage mixte variaient entre 130 et $200 \mathrm{~g}$, selon que les rations étaient de 20 ou de $30 \mathrm{~kg}$, ce qui correspond à des quantités presque égales à celles des autres lipides digestibles du régime.

L'effet stimulant de l'ensilage pourrait donc s'expliquer par les quantités d'acides gras volatils qu'il renferme.

\section{ASPECT ECONOMIQUE DE L'INTRODUCTION DE L'ENSILAGE MIXTE DANS LE REGIME ALIMENTAIRE DE LA VACHE LAITIERE}

L'introduction des doses élevées d'ensilage mixte dans le régime de la vache laitière permet de réduire la consommation d'aliments concentrés. Cette importante observation pratique est à signaler. Les calculs faits à partir de nos données expérimentales mettent ce fait en évidence et sont très suggestifs (voir tableau ci-dessous).

\section{TABLEAU XIX}

Comparaison entre les consommations d'aliments concentrés qu'entraînent un régime à base de betteraves et un autre à base d'ensilage

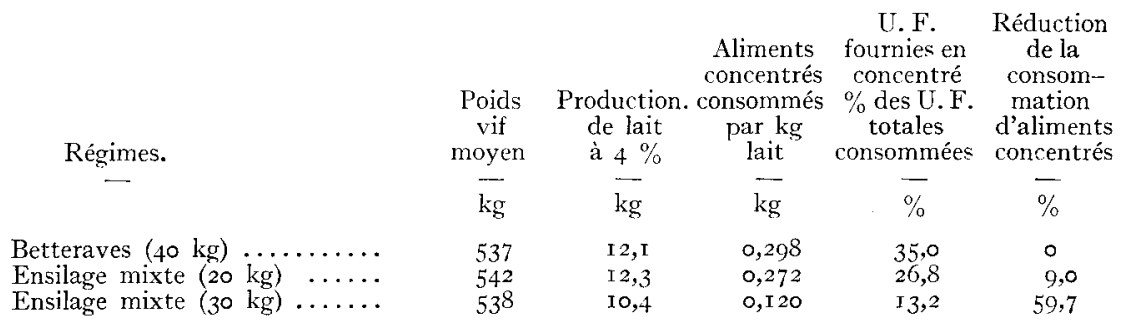

Pour des productions sensiblement équivalentes, les besoins en compléments concentrés sont faiblement réduits lorsqu'à la ration de betteraves est substituée une quantité de $20 \mathrm{~kg}$ d'ensilage. Par contre, lorsque le remplacement s'effectue à raison de $30 \mathrm{~kg}$, l'économie de concentré qui en résulte atteint $60 \%$.

La moins bonne utilisation des fortes rations d'ensilage mixte est donc compensée par la possibilité d'abaisser substantiellement le coût de la production laitière, en raison de la réduction de l'alimentation à base de concentrés qu'elle autorise. 


\section{CONCLUSIONS}

On peut, à la suite de cette recherche, affirmer que, contrairement à l'opinion fréquemment admise, l'efficacité de la betterave fourragère pour la production du lait apparaît comme très discutable. Cette racine semble incapable de fournir à la glande mammaire toutes les substances qu'exige son activité physiologique. Sa présence à doses élevées dans le régime alimentaire de la vache en lactation contribue à abaisser le rendement énergétique de la ration consommée.

Les carences manifestées par cet aliment pourraient provenir des profonds changements biochimiques qu'il subirait dans les derniers mois de sa conservation, changements qu'il reste à mettre en évidence.

L'ensilage mixte de pommes de terre et de luzerne convient à la vache laitière bien mieux que la betterave. Il semble exercer sur la sécrétion lactée un effet stimulant qui peut être attribué à ses acides gras volatils.

Malgré une moins bonne utilisation, les rations de $30 \mathrm{~kg}$ d'ensilage mixte présentent plus d'intérêt que celles de $20 \mathrm{~kg}$ parce qu'elles permettent de restreindre la consommation d'aliments concentrés de plus de $50 \%$ et contribuent à la diminution du prix de revient de la production laitière.

\section{RÉSUMÉ ET CONCLUSIONS GÉNÉRALES}

Une série de recherches sur l'utilisation de la pomme de terre pour l'alimentation du bétail a été.effectuée sur des porcins, des ovins, et des vaches en lactation. Les résultats obtenus nous autorisent à présenter les conclusions suivantes :

Io L'utilisation des tubercules de pommes de terre par le bétail est étroitement liée au problème de leur conservation. La cuisson suivie d'ensilage apporte une solution satisfaisante et peut même faciliter la conservation en nature de certains fourrages verts, incorporés aux tubercules.

$2^{\circ}$ L'introduction de fortes quantités de pommes de terre dans le régime de nos animaux de ferme est parfaitement compatible avec une production animale intensive, à la condition de respecter les règles fondamentales des équilibres alimentaires.

$3^{0}$ L'engraissement intensif du porc n'est à conseiller qu'avec des pommes de terre cuites.

Cet aliment procure, chez le porc, le maximum de son effet nutritif s'il est associé à un complément renfermant environ $24 \%$ de protéine digestible et une proportion suffisante de matières minérales. L'adjonction des vitamines $A$ et D à ce régime est indispensable.

A ces conditions, l'utilisation de la pomme de terre ou de ses déchets de triage est rentable pour l'agriculteur.

La qualité de la carcasse ainsi obtenue est excellente et soutient la comparaison avec celle que donne l'emploi de l'orge. 
$4^{0}$ L'ensilage mixte de pommes de terre et de luzerne convient aux brebis nourrices et aux vaches en lactation, chez lesquelles il semble stimuler l'activité mammaire.

Il permet de réduire de plus de moitié la consommation d'aliments concentrés complémentaires.

$5^{\circ}$ Les pommes de terre étuvées et ensilées ne conviennent pas aux jeunes agneaux. Cet aliment ne freine pas leur croissance mais est très mal utilisé par eux.

\section{EXPÉRIENCE N $N^{\circ} \mathrm{I}$}

Composition et valeur énergétique des aliments utilisés

p. mille d'aliment

EXPÉRIENCE $\mathrm{N}^{\circ} 2$ ET 3

Composition et valeur énergétique des aliments utilisés

Centres expérimentaux:

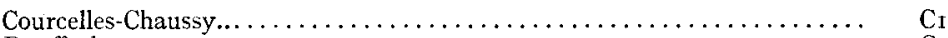

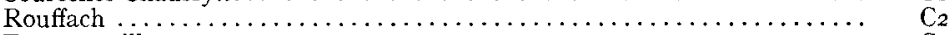

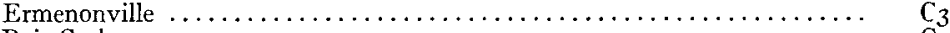

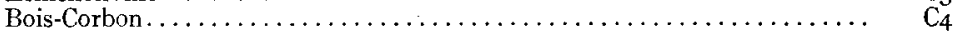

\begin{tabular}{|c|c|c|c|c|c|c|c|c|c|c|}
\hline & & Aliments & $\begin{array}{l}\text { Mat. } \\
\text { sèche } \\
-\overline{g r}\end{array}$ & $\begin{array}{l}\text { Mat. } \\
\text { miné- } \\
\text { rales } \\
\overline{\mathrm{gr}}\end{array}$ & $\begin{array}{l}\text { Mat. } \\
\text { cellul. } \\
\text { gr }\end{array}$ & $\begin{array}{l}\text { Mat. } \\
\text { azo- } \\
\text { tées } \\
\overline{g r}\end{array}$ & $\begin{array}{c}\text { Mat. } \\
\text { grasses } \\
\text { gr }\end{array}$ & $\begin{array}{l}\text { Ext. } \\
\text { non } \\
\text { azotés } \\
\frac{\mathrm{gr}}{\mathrm{gr}}\end{array}$ & $\begin{array}{l}\text { Matière } \\
\text { azotées } \\
\text { digest. } \\
\frac{\mathrm{gr}}{}\end{array}$ & $\begin{array}{l}\text { Valeur } \\
\text { nutritive } \\
\overline{\mathrm{U} . \mathrm{F}}\end{array}$ \\
\hline Stand & $\begin{array}{l}\text { coureur } \\
- \\
-\end{array}$ & 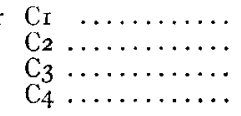 & $\begin{array}{l}908 \\
911 \\
85 I \\
912\end{array}$ & $\begin{array}{l}55 \\
55 \\
52 \\
86\end{array}$ & $\begin{array}{l}74 \\
55 \\
64 \\
52\end{array}$ & $\begin{array}{l}183 \\
209 \\
207 \\
I 36\end{array}$ & $\begin{array}{l}37 \\
40 \\
35 \\
39\end{array}$ & $\begin{array}{l}559 \\
550 \\
493 \\
599\end{array}$ & $\begin{array}{l}\text { I } 46 \\
\text { I76 } \\
\text { I } 67 \\
\text { I } 5\end{array}$ & $\begin{array}{l}0,92 \\
1,02 \\
0,89 \\
0,99\end{array}$ \\
\hline Stand & $\begin{array}{l}\text { "gras } \\
- \\
-\end{array}$ & $\begin{array}{l}\mathrm{C}_{1} \ldots \ldots \ldots \ldots \ldots \\
\mathrm{C}_{2} \ldots \ldots \ldots \ldots \ldots \\
\mathrm{C}_{3} \ldots \ldots \ldots \ldots \ldots \\
\mathrm{C}_{4} \ldots \ldots \ldots \ldots \ldots\end{array}$ & $\begin{array}{l}904 \\
905 \\
858 \\
899\end{array}$ & $\begin{array}{r}46 \\
47 \\
4 \\
59\end{array}$ & $\begin{array}{l}56 \\
58 \\
5^{2} \\
71\end{array}$ & $\begin{array}{l}I 20 \\
\text { I } 28 \\
\text { II I } \\
\text { I } 4 \mathrm{I}\end{array}$ & $\begin{array}{l}40 \\
30 \\
30 \\
37\end{array}$ & $\begin{array}{l}652 \\
642 \\
621 \\
591\end{array}$ & $\begin{array}{r}\text { IOI } \\
\text { IO7 } \\
94 \\
\text { Ir } 4\end{array}$ & $\begin{array}{l}1,01 \\
0,99 \\
0,96 \\
0,92\end{array}$ \\
\hline Compl & $\begin{array}{l}\text { ément a } \\
- \\
- \\
-\end{array}$ & 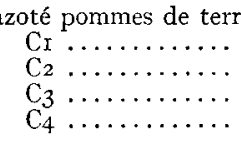 & $\begin{array}{l}922 \\
917 \\
846 \\
895\end{array}$ & $\begin{array}{r}71 \\
64 \\
7 \\
7\end{array}$ & $\begin{array}{l}59 \\
62 \\
55 \\
60\end{array}$ & $\begin{array}{l}330 \\
309 \\
303 \\
33^{2}\end{array}$ & $\begin{array}{l}43 \\
42 \\
27 \\
37\end{array}$ & $\begin{array}{l}419 \\
440 \\
384 \\
389\end{array}$ & $\begin{array}{l}276 \\
255 \\
253 \\
225\end{array}$ & $\begin{array}{l}\mathrm{r}, 0 \mathrm{I} \\
0,99 \\
0,89 \\
0,95\end{array}$ \\
\hline Ensila & $\begin{array}{l}\text { ge de } p o \\
- \\
-\end{array}$ & $\begin{array}{l}\text { ommes de terre étuvé } \\
\mathrm{C}_{\mathbf{1}} \ldots \ldots \ldots \ldots \ldots \\
\mathrm{C}_{2} \ldots \ldots \ldots \ldots \ldots \\
\mathrm{C}_{3} \ldots \ldots \ldots \ldots \ldots \\
\mathrm{C}_{4} \ldots \ldots \ldots \ldots \ldots\end{array}$ & $\begin{array}{l}230 \\
245 \\
256 \\
262\end{array}$ & $\begin{array}{l}\text { I9 } \\
25 \\
35 \\
\text { I3 }\end{array}$ & $\begin{array}{r}9 \\
10 \\
14 \\
10\end{array}$ & $\begin{array}{l}17 \\
23 \\
28 \\
24\end{array}$ & $\begin{array}{l}3 \\
3 \\
3 \\
2\end{array}$ & $\begin{array}{l}\mathrm{I} 82 \\
\mathrm{I} 84 \\
\mathrm{I} 76 \\
2 \mathrm{II}\end{array}$ & $\begin{array}{l}\text { I I } \\
\text { I } 5 \\
\text { I } 9 \\
\text { I6 }\end{array}$ & $\begin{array}{l}0,268 \\
0,278 \\
0,274 \\
0,320\end{array}$ \\
\hline & ge de 1 & $\begin{array}{c}\text { mmes de terre crues. } \\
\mathrm{CI}\end{array}$ & $3^{67}$ & 28 & I 2 & I8 & 4 & 305 & I 7 & $0,4 \mathrm{I} 7$ \\
\hline
\end{tabular}


$6^{\circ}$ La valeur énergétique des ensilages de pommes de terre étuvées, mesurée expérimentalement avec des animaux adultes, est au moins égale à celle que l'on peut calculer d'après leur composition chimique. Elle lui est parfois même supérieure dans le cas des ruminants lorsque les doses consommées sont faibles. Cependant, la distribution de fortes rations présente malgré cela de l'intérêt pour des raisons économiques.

$7^{\circ}$ Certains phénomènes, notamment ceux que nous avons observés sur les jeunes ruminants mériteraient de faire 1'objet de recherches ultérieures.

\section{EXPÉRIENCE No 4}

\begin{tabular}{|c|c|c|c|c|c|c|c|c|}
\hline Stand. coureur $\ldots \ldots \ldots \ldots \ldots \ldots$ & 869 & 99 & 50 & 226 & 42 & $45^{2}$ & I9I & 0,94 \\
\hline Stand. gras. . . . . . . . . . . & $85^{8}$ & 59 & 47 & $13^{6}$ & $3^{2}$ & 584 & I 6 & 0,97 \\
\hline $\begin{array}{l}\text { Complément azoté pommes de } \\
\text { terre } \ldots \ldots \ldots \ldots \ldots \ldots \ldots \ldots \ldots \ldots\end{array}$ & 872 & 99 & $4^{2}$ & $27^{6}$ & 62 & 393 & 238 & $1, \infty$ \\
\hline Orge....................... & 953 & 27 & 39 & 99 & $3 \sqrt{I}$ & 657 & 69 & 1,00 \\
\hline 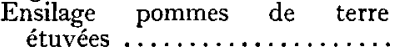 & 249 & 24 & 6 & 25 & 4 & I90 & I7 & 0,284 \\
\hline
\end{tabular}

\section{EXPÉRIENCE N ${ }^{\circ} 5$}

\section{Aliments}

Stand. coureur..............

Stand. gras................

Complément azoté pommes de

terre...................

Ensilage pommes de terre étuvées $\ldots \ldots \ldots \ldots \ldots \ldots \ldots$.
Mat. Mat. Extr. Mat. Valeur Mat. miné- Mat. azo- Mat. non azotées foursèche rales cellul. tées grasses azotés digest. ragère

\begin{tabular}{|c|c|c|c|c|c|c|c|}
\hline - & 二 & 一 & 一 & - & - & - & - \\
\hline 896 & 85 & 59 & IgI & 35 & $5^{26}$ & I 59 & 0,94 \\
\hline 892 & 62 & 63 & I39 & 30 & 598 & I 14 & 0,93 \\
\hline 892 & $8 I$ & $3^{6}$ & 245 & $5^{I}$ & 479 & 215 & ז, 06 \\
\hline 6 & 32 & 7 & 32 & IO & I 84 & $2 I$ & 0,292 \\
\hline & 52 & 68 & 96 & 25 & 837 & 77 & 0,90 \\
\hline
\end{tabular}

\section{EXPÉRIENCE No 6}

\begin{tabular}{|c|c|c|c|c|c|c|}
\hline $\begin{array}{l}\text { Pulpes } \\
\text { de } \\
\text { sucrerie } \\
\text { ensilées }\end{array}$ & $\begin{array}{c}\text { Ensilage } \\
\text { pommes } \\
\text { de terre } \\
\text { étuvées }\end{array}$ & $\begin{array}{l}\text { Balles } \\
\text { de blé }\end{array}$ & $\begin{array}{c}\text { Foin } \\
\text { de } \\
\text { luzerne }\end{array}$ & $\begin{array}{l}\text { Tourt. } \\
\text { de } \\
\text { lin }\end{array}$ & Orge & Avoine \\
\hline - & - & - & - & - & & \\
\hline I I 4 & 259 & 876 & 909 & 904 & 874 & 896 \\
\hline I9 & 38 & I I I & $5 \mathrm{I}$ & 55 & 29 & $3^{6}$ \\
\hline 34 & I I & $30 r$ & 392 & Io9 & 68 & 137 \\
\hline I 5 & 25 & 72 & 122 & 296 & 86 & 86 \\
\hline 5 & 5 & $3 I$ & 30 & 67 & 28 & 50 \\
\hline $4^{1}$ & 180 & 361 & $3 \mathrm{I} 4$ & 377 & 663 & $5^{87}$ \\
\hline $58, \mathrm{I}$ & I 89,4 & 337,3 & 410,8 & 595 & 717,9 & 672,3 \\
\hline 3,8 & 4,6 & I 3,4 & 57,7 & 240 & 56,4 & 60,0 \\
\hline 0,06 & 0,232 & 0,24 & 0,37 & 0,97 & 0,99 & 0,79 \\
\hline
\end{tabular}




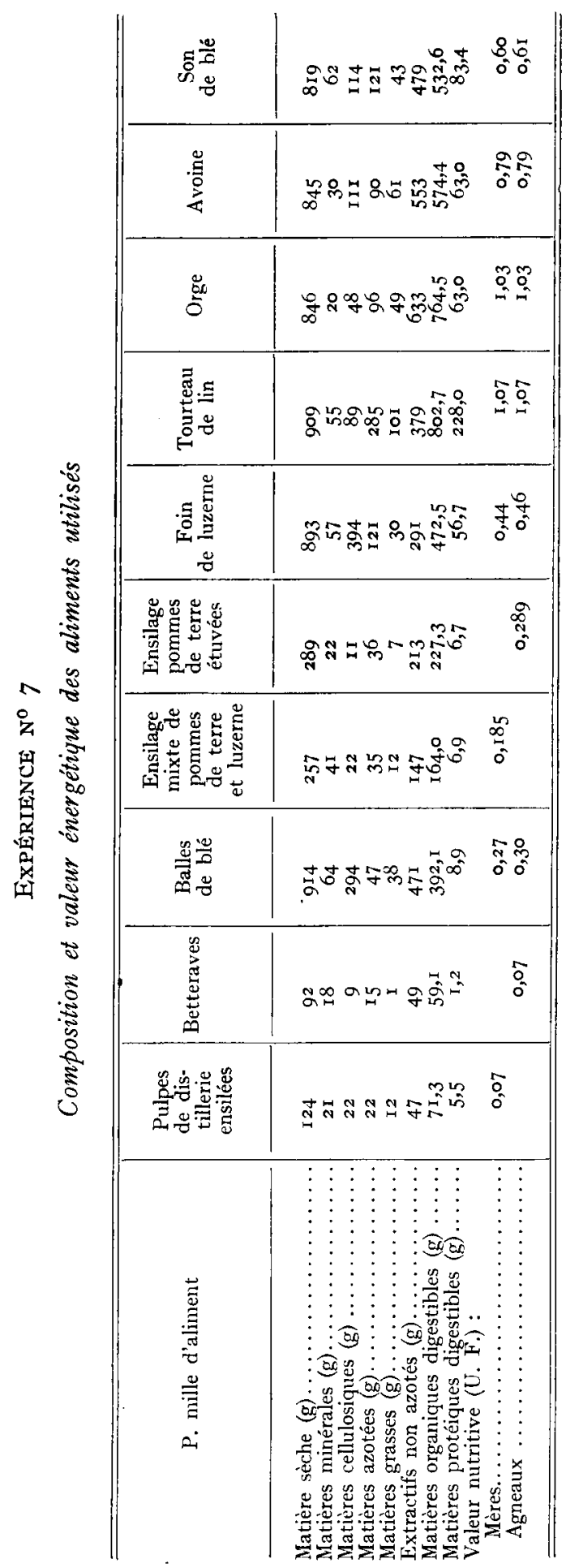




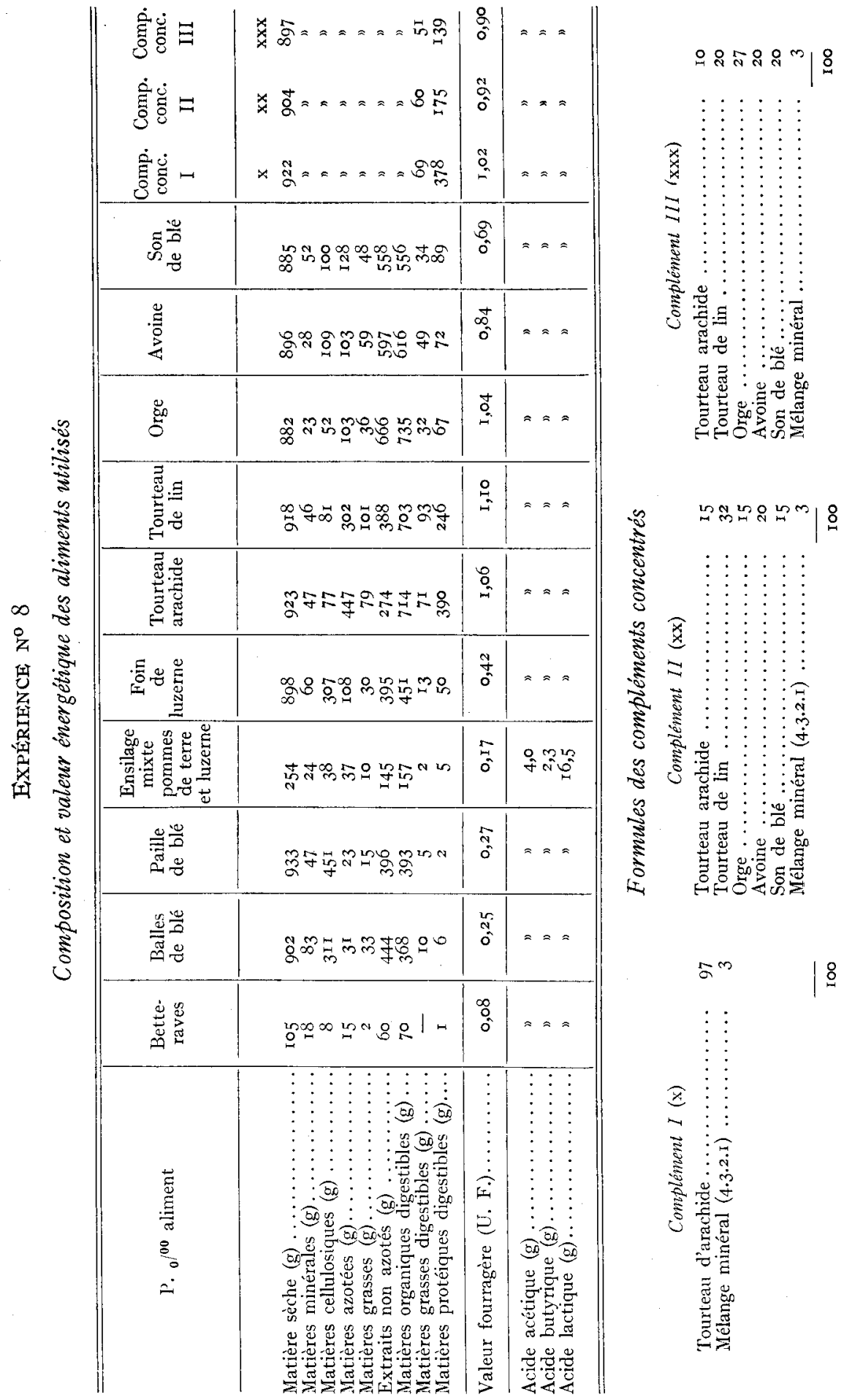




\title{
BIBLIOGRAPHIE
}

\author{
(Mémoire Pommes de Terre)
}

(I) Ротт (E.). - Tierernährung: u. Landwirtschaftliche Futtermitteln, 2, p. 349-375, 1907.

(2) Shermann (H. C.). - Food Products, p. 319, ig2o.

(3) RandoIn (L.). - Tables de composition des aliments, p. 87, 1947.

(4) Gouin (R.). - Les aliments du bétail, p. 92, I922.

(5) Rithausen (H.) et Osborne (T. B.). - Cités par Pott (i).

(6) SCHUlzE (F.). - Uber das Vorkommen von Hexonbasen in den Kartoffel (Solanum tuberosum) und der Dahlie (Dahlia variabilis). Landwirt. Versuchst., 59, p. 33I-344, rgo4.

(7) Kellner (O.). - Cité par Pott (I).

(8) Morgen (A.). - Cité par Pott (I).

(9) JACQuOT (R.). - Aspect physiologique et alimentaire de l'emploi de succédanés en panification. Ann. de la nutrition, 2, p. $647,1948$.

(ro) Jacquot (R.) et ARMand (Y.). - Etude Biochimique et Physiologique des protides de pommes de terre, leur intérêt alimentaire. C. R. Académie de l'Agricult., 28, p. 595, I 942.

(iI) Jones et Nelson. - Cités par JacQuot (io).

(12) Terroine (E.). - Le métabolisme de l'azote, 1, p. 229, I933.

(I3) Thomas (K.). - - Uber die biologische Wertigkeit der Stickstoffsubstanzen in verschiedenen Nahrungsmitteln. Arch. Anat. u. Physiol., 219, p. 302, I9o9.

(14) SteelwaAg (A.). - Die Zusammensetzung der Futtermittelfette. Landwirt. Versuchst., 37, p. 148, I 890 .

(i5) Stone (W. E.). - Die Einwirkungen von Enzymen auf Stärken Verschiedenen Ursprungs. Chem. Zentralbl., 1, p. 853, I897.

(16) Grimme (C.). - Uber Maniokmehl. Zeitschr. f. untersuch. u. Nahr., 41, p. 172, I921,

(I 7$)$ Forfang (E.). - Cité par Pott (I).

(I8) Muntz (A.). - Cité par Pott (I).

(19) Hant (0.). - Cité par Huzemann. Die Pflanzenstof, p. 421, 1871.

(2o) Mayer (G.). - Ueber Vergiftungen durch Kartoffeln. Arch. f. Exper. Pathol. u. Pharmakol., 36, p. 360 , I 895 .

(21) WOLF (E.). - Versuche mit Pferden über die Verdaulichkeit von Kartoffeln und Mohren neben Heu und Hafer. Landwirt. Jahrb., 13, p. 245, I 884.

(22) VOLTZ (W.) et DiETRICH (W.). - Die Verwertung roher, gedämpfter und durch Reinzuchtsäuerung Konserwierter roher und gedämpfter Kartoffeln für die Milchleistung. Landwirt. Jahrb., 48, p. 535, I915.

(23) WATSON (S. J.) et HoRToN (E. A.). - Composition. Digestibility and Nutritive value of Graasland Products. J. Agricult. Sci., 26, p. I42, I936.

(24) BollmanN (W.). - Untersuchungen über die Verdaulichkeit der Nährstoffe von rohen, gedämpften und gedämpft eingesäuerten Kartoffeln, am Schwein am Hammel, and der Milchkuh und Mastochsen. Zeits. f. Zücht. u. Tierernähr., 24, 3, p. 329-358, 1932.

(25) Voltz (W.) et collab. - Die Verwertung der Kartoffeln in ihren Verschiedenen Verwendungsformen durch das Schwein und der Wiederkäuer. Landwirt Jahrb., 1, p. 3, I9I 7 .

(26) Heidens (F.). - Beitrag Z. Ernährung des Schweines, I877.

(27) LehmanN (F.) cité par Marce (J.) et Lahaye (J.). - Le Porc, p. i8o, ig4r.

(28) KirSCH (W.), Jantzon (H.) et REISCH (E.). - - Der Einfluss von Milch und Essigsäuren Kartoffeln auf die Entwiklung und die Schlachtqualität von Marstschweinen in Vergleich zur Magermilch Gerstenfütterung. Zeits. f. Zücht u. Tierernähr, 21, 3, p. 504, I93r.

(29) LERoY (A. M.) et FÉvrier (R.). - Étude des aptitudes économiques et de leur transmission chez les différentes souches et races porcines. Ann. Agronom., 19, 6, p. 925, 1949.

(30) CLAusen (H.). - $39^{\mathrm{e}}$ Beretning fra Sammenliguende Forsog med Swin fra Statsanerkendte Avlscentre. Beretning fra Forsoglaboratoriet, 256, I95.

(3i) Jespersen (J. O.) et Plesner (U. A.). - Forsog med Ensilage of Kogte Kartofler samt Forsog med Raa ofg Kogte Kartofler Beretning fra Forsoglaboratoriet, 166, p. roII, I936.

(32) Girard (A.). - Application de la pomme de terre à l'alimentation du bétail. J. d'Agricult. Prat., 1, p. 709, I895. 
(33) Cornevin (Ch.). - La Pomme de terre dans l'alimentation de la vache laitière. $J$. d'Agriculture Prat., 2, p. 46, 1894.

(34) École laitikire de RuTti citée par Landis (J.) et Burkhardt (H.) (35).

(35) Landis (J.) et BuRkhardT (H.). - Utilisation de la pomme de terre dans l'alimentation de la vache laitière. Annuaire Agric. Suisse, 10, p. IIIO-I I23, 1937.

(36) LEROY (A.-M.) et BONNET (J.). - Sur la production de matières grasses des vaches laitières. Ann. Agron., 17, 3, p. 455, 1947.

(37) Folley (S. J.) et French (T. M.). - Utilisation of acetate by Ruminant Tissues. Bioch. J., 43, p. LV, 1948.

(38) Zelter (Z.). - Participation des acides acétique et butyrique à la lipogénèse chez la vache laitière. $C$. $R$. Acad. des Sci. Paris, 231, p. 1574, 1950. 